Illinois State University

ISU ReD: Research and eData

Theses and Dissertations

10-13-2014

\title{
Contradicting Conventional Wisdom: Women Presidents' Abilities to Forge Purposeful and Instrumental Relationships for Institutional Outcomes
}

Susan Amy Woollen

Illinois State University, sawooll@ilstu.edu

Follow this and additional works at: https://ir.library.illinoisstate.edu/etd

Part of the Feminist, Gender, and Sexuality Studies Commons, Higher Education Administration Commons, and the Higher Education and Teaching Commons

\section{Recommended Citation}

Woollen, Susan Amy, "Contradicting Conventional Wisdom: Women Presidents' Abilities to Forge Purposeful and Instrumental Relationships for Institutional Outcomes" (2014). Theses and Dissertations. 288.

https://ir.library.illinoisstate.edu/etd/288

This Dissertation is brought to you for free and open access by ISU ReD: Research and eData. It has been accepted for inclusion in Theses and Dissertations by an authorized administrator of ISU ReD: Research and eData. For more information, please contact ISUReD@ilstu.edu. 


\title{
CONTRADICTING CONVENTIONAL WISDOM: WOMEN PRESIDENTS' ABILITIES TO FORGE PURPOSEFUL AND INSTRUMENTAL RELATIONSHIPS FOR INSTITUTIONAL OUTCOMES
}

\author{
Susan A. Woollen
}

268 Pages

May 2015

There is a perception in the literature that women presidents are weak in the function of instrumental relationship building. The purpose of this qualitative study was to explore the practices developed and utilized by women presidents of 4-year institutions to identify and build relationships with key constituents whom they recognized as having resources that could lead to institution building and to learn how the presidents secured those resources.

Through an interview format, 12 presidents elaborated on the internal and external constituents on whom they were dependent to achieve their goals as president and how the stakeholders came to hold value for their institutions. Using social capital as a theoretical lens, presidents' social connections and networks were examined to determine how presidents created or enhanced resources for their institutions. The key findings captured the deliberate actions and behaviors undertaken by presidents to identify key stakeholders and the multiple dimensions associated with fostering relationships to move them closer to the acquisition of resources. Finally, presidents shared how they made the case to their constituents to release resources to their institutions. The dissertation 
concludes with recommendations for future research on the leadership practices of women presidents of colleges and universities. 
CONTRADICTING CONVENTIONAL WISDOM: WOMEN PRESIDENTS'

ABILITIES TO FORGE PURPOSEFUL AND INSTRUMENTAL

RELATIONSHIPS FOR INSTITUTIONAL OUTCOMES

SUSAN A. WOOLLEN

A Dissertation Submitted in Partial

Fulfillment of the Requirements for the Degree of

DOCTOR OF PHILOSOPHY

Department of Educational Administration and Foundations

ILLINOIS STATE UNIVERSITY

2015 


\section{Copyright 2015 Susan Woollen}




\section{CONTRADICTING CONVENTIONAL WISDOM: WOMEN PRESIDENTS' ABILITIES TO FORGE PURPOSEFUL AND INSTRUMENTAL RELATIONSHIPS FOR INSTITUTIONAL OUTCOMES}

SUSAN A. WOOLLEN

COMMITTEE MEMBERS:

James C. Palmer, Chair

Amee Adkins

Linda Lyman

Phyllis McCluskey-Titus

Richard Wilson 


\section{ACKNOWLEDGMENTS}

Stories have always played an incredible part of my life. My father is an oral historian whose stories of his childhood on the Southside of Chicago in the late 1920s and 1930s are incredible history. My mother shared her stories about growing up in Nagasaki during World War II and the devastating effects of war on her family. Their narratives give me reasons to be proud of who I am and where I am from. Other stories were collected from high school students I met as an admissions counselor in San Antonio. I saw how "opportunity" played out differently for individuals, and their stories wove themselves into the fabric of my life, giving me a central purpose for my vocation. More stories came from the 12 presidents in this study. They shared stories that were rich in insights about women's leadership, and their commitment to their students, institutions, and higher education will remain with me always. Oh, the power of stories and the power of the lives which inspire them.

To my dear, dear friends who supported my research on a "messy" subject and to my committee members who allowed me to embrace and rejoice in this study's complications, I say thank you. They asked "Why only women presidents?" to which I replied "Why not?" Maybe to truly understand the strengths of women in leadership positions, we should examine the strategies and mechanisms they use once they are in those positions. By not including male presidents, I wanted to avoid distorting these women's unique experiences. That is what I hope I accomplished with this study. 
Life has given me two special gifts—my husband, Tim, and my daughter, Katharine - both of whom simply love me for who I am, making my life feel complete, fulfilled, and valued. They are truly remarkable individuals.

To the memory of my mother, Chiyono Shoji Hamer, 1935-2001

To the memory of my brother, William Hamer, 1957-2010

For my father Herbert Hans Hamer, Jr.

And my husband, Tim, and daughter, Katharine Chiyono

S. A. W. 


\section{CONTENTS}

Page

ACKNOWLEDGMENTS $\quad$ i

CONTENTS

$\begin{array}{ll}\text { TABLES } & \text { ix }\end{array}$

\section{CHAPTER}

I. INTRODUCTION 1

Purpose of the Study and Research Questions 7

Definitions $\quad 8$

Theoretical Framework $\quad 8$

$\begin{array}{ll}\text { Research Design } & 10\end{array}$

Limitations of the Study 11

$\begin{array}{ll}\text { Significance of the Study } & 11\end{array}$

II. REVIEW OF THE LITERATURE 13

Historical and Contemporary Functions of the Academic Presidency 14

Historical Functions of the Academic Presidency 14

Contemporary Functions of the Academic Presidency 18

Fundraising $\quad 18$

Planning $\quad 21$

Administrative leadership 23

Campus visionary $\quad 27$

External relations 28

$\begin{array}{ll}\text { Summary } & 29\end{array}$

$\begin{array}{ll}\text { Presidential Effectiveness } & 30\end{array}$

Personal Traits of Effective Presidents 33

Surveys of "effective" and "representative" presidents 34 
Constituent perceptions 38

$\begin{array}{ll}\text { Strategies } & 41\end{array}$

Summary 43

Presidential Testimonials and Recognition of the Role of Relationships 44

$\begin{array}{ll}\text { Summary } & 47\end{array}$

Women's Leadership and Strategic Relationship Building 48

Affiliations, Stakeholders, and Partnerships $\quad 49$

Affiliations $\quad 49$

Stakeholders $\quad 51$

Partnerships 53

The Relationship Building Paradox $\quad 54$

Facilitating relationship building $\quad 55$

Valuing relationship building $\quad 55$

Perceptions of Women and Relationship Building $\quad 56$

Summary $\quad 56$

Theoretical Framework $\quad 57$

$\begin{array}{ll}\text { Chapter Summary } & 62\end{array}$

III. RESEARCH METHODOLOGY, DESIGN, AND PROCEDURES 63

Purpose of the Study and Research Questions 63

Characteristics of Qualitative Research 64

Qualitative Research Strategy $\quad 67$

Participant Selection $\quad 69$

$\begin{array}{ll}\text { Data Collection } & 70\end{array}$

$\begin{array}{ll}\text { Data Collection Procedures } & 72\end{array}$

$\begin{array}{ll}\text { Data Analysis } & 73\end{array}$

$\begin{array}{ll}\text { Validity Strategies } & 74\end{array}$

Ethical Issues in the Study $\quad 75$

Limitations of the Study $\quad 75$

$\begin{array}{ll}\text { Chapter Summary } & 76\end{array}$ 


\section{BECOMING PRESIDENT: TWELVE DIFFERENT PATHS TO THE POSITION}

Chapter Overview

President Rebecca McKay

McKay's journey to the presidency

President Juliana Fletcher

Fletcher's journey to the presidency

President Sarah Drummond

Drummond's journey to the presidency

President Katharine Hamilton

Hamilton's journey to the presidency

President Gloria Kahn

Kahn's journey to the presidency

President Carolyn Callaghan

Callaghan's journey to the presidency

President Lauren Murphy

Murphy's journey to the presidency

President Hillary Sinclair

Sinclair's journey to the presidency

President Kathleen Childs

Childs' journey to the presidency 
$\begin{array}{ll}\text { President Ruth Graham } & 106\end{array}$

Graham's journey to the presidency 107

$\begin{array}{ll}\text { President Pat Hutchins } & 110\end{array}$

Hutchins' journey to the presidency 111

$\begin{array}{ll}\text { Chapter Summary } & 113\end{array}$

V. WITH WHOM DID THE PRESIDENTS DEVELOP INSTRUMENTAL RELATIONSHIPS? 116

$\begin{array}{ll}\text { Instrumental Internal Stakeholders } & 116\end{array}$

$\begin{array}{lr}\text { Administrators } & 118\end{array}$

Advancement Officers 120

Coaches 121

Faculty 122

Staff 124

Students 126

$\begin{array}{ll}\text { Instrumental External Stakeholders } & 126\end{array}$

$\begin{array}{lr}\text { Alumni } & 126\end{array}$

Board of Trustees 129

Board Chairs 133

Business Leaders and Economic Development Groups $\quad 134$

Church Leaders or Members 136

Community Leaders and Service Organizations 139

Donors and Friends 141

External Organizations 143

Higher Education Commission and System Administration $\quad 146$

$\begin{array}{ll}\text { Parents } & 147\end{array}$

Political Leaders $\quad 147$

Predecessors and Presidential Colleagues 148

$\begin{array}{ll}\text { Chapter Summary } & 151\end{array}$

VI. HOW DID PRESIDENTS IDENTIFY STAKEHOLDERS

WITH WHOM INSTRUMENTAL RELATIONSHIPS

NEEDED TO BE MADE?

Identifying Stakeholders with Embedded Resources 
Ascribing Meaning to Interactions

Fundraising Function

155

Strategic Planning and Administrative Leadership

Being a Campus Visionary

External Relations

Guided Attention and Interactions

Being Passionate and Mission-Oriented 160

Being Entrepreneurial 163

Being Strategic 166

Being Perceptive 169

Building Credibility 173

$\begin{array}{ll}\text { Creating a Presence } & 180\end{array}$

$\begin{array}{ll}\text { On-Campus Presence } & 181\end{array}$

Off-Campus Presence 183

$\begin{array}{ll}\text { Chapter Summary } & 188\end{array}$

VII. HOW DID PRESIDENTS BUILD AND FOSTER RELATIONSHIPS WITH INSTRUMENTAL STAKEHOLDERS?

Building and Fostering Relationships with Instrumental

Stakeholders

Staying Involved and Engaged

Using Surrogates

Minimizing Disruptions and Dysfunctions

199

Practicing Responsible Relationship Building

Chapter Summary

VIII. HOW DID PRESIDENTS SECURE RESOURCES FROM INSTRUMENTAL STAKEHOLDERS?

Securing Resources from Instrumental Stakeholders 205

Making the Case 206

Using Status of the Presidency 211

Recognizing and Seizing Opportunities 214

Appreciating Human Dynamics 218

$\begin{array}{ll}\text { Chapter Summary } & 228\end{array}$ 


\section{FORGING A NEW PERSPECTIVE FOR RESEARCH ON WOMEN PRESIDENTS AND INSTUMENTAL RELATIONSHIP BUILDING}

Key Findings

Research Question 1: How Do Women Presidents Identify Social Relations that have Embedded Resources?

Research Question 2: How Do Women Presidents Build and Foster Relationships with Individuals Who Possess Resources that Can Achieve Institutional Objectives?

Research Question 3: How Do Women Presidents Capture Embedded Resources in their Relationships to Generate a Return on that Investment?

Purposeful and Instrumental: Contradicting Conventional Wisdom

Attitude Towards Relationship Building 


\section{TABLES}

Table Page

1. Internal Relationships Considered Instrumental by Presidents 117

2. External Relationships Considered Instrumental by Presidents 128 


\section{CHAPTER I}

\section{INTRODUCTION}

How did a sitting university president with a total of 14 years of presidential experience at two institutions share and describe the challenges facing the position? On September 22, 2009, Dr. Jim Yong Kim was inaugurated as the $17^{\text {th }}$ president of Dartmouth College, and Dr. Ruth Simmons, president of Brown University and former president of Smith College, delivered greetings at his installation ceremony as a representative from his alma mater, as well as from the Council of Ivy League Presidents. She offered Kim, who was assuming a presidential helm for the first time, and the audience her insights into the complex web of relationships that presidents rely on and the trials those relations create for presidents working within a framework of shared governance:

Anyone beginning service as the president of a leading university, such as Dartmouth, invariably hears from skeptics that ours is an impossible task. They speak of the fractured nature of all academic communities today, where a president, in trying to forge a common agenda and strategic direction, must frequently balance opposing views, aims, intentions and, of course, identities. Critics of academic culture may speak of the challenge of working with tenured faculty, governing boards, alumni and donors, and activist students, who together, they observe create a cacophonous chorus of concerns. (Simmons, 2009)

While her comments reflected sensitivity to the needs and issues of institutional constituents and the oppositional forces they may exert on any president, Simmons was equally wise to the larger role of those groups and how an educational leader is dedicated to bringing diverse voices together to build their respective institutions: 
However, those who know the academy well also recognize that at its core, the university is a community in which the importance of intellectual rigor, freedom of speech and inquiry, dispassionate analysis, scholarly and creative innovation, and a passion for problem solving in the service of society override the disparate aims of its members. I am confident, President Kim, that in you this university has found another Dartmouth president who understands the centrality of these priorities to all members and supporters, and that you can demonstrate through personal example the ways in which many voices can become one in together building a bond and enhancing Dartmouth's stellar history. (Simmons, 2009)

Although her congratulatory remarks should be considered within the context of a ceremonial speech laced with higher education nostalgia and sentiments, Simmons spoke to the capacity of leadership that is anticipated and expected of college presidents.

Further, her use of the phrases "cacophonous chorus," "fractured nature," and "disparate aims" reflect the daunting and contentious task of being a college president, and a successful presidency may be measured by campus constituents and external stakeholders as to what the position was able to achieve in spite of that environment. Presidential achievements may come as a result of how successful a president can identify, listen to, and work with those "many voices" in order to develop an array of relationships that work towards institution building objectives.

The research on the academic presidency is filled with the complexity and equivocality of studying leadership in the academic environment (Bass \& Stogdill, 1990; Burns, 1978; Cohen \& March, 1986). Researchers have used a variety of frameworks to examine the presidency and the effectiveness of an individual in that position using a wide spectrum of leadership theories. Transactional, transformational, environmental, situational, trait and behavioral theories have been used extensively in the literature, as well as theories of power and influence. In their monograph on administrative leadership, Bensimon, Neumann, and Birnbaum (1989) argued that each theoretical perspective 
provides an understanding of "what ideal leaders should look like, what they should accomplish, or how they should carry out the role of leadership" (p. 70).

Scholars of the academic presidency have thus helped advance our knowledge base of the individuals who occupy the highest administrative position in American colleges and universities by examining the position's array of functions and responsibilities; the attributes, characteristics, and skills presidents may or may not possess; and the ways presidents may or may not effectively perform their duties (Bensimon et al., 1989; Birnbaum, 1992; Blau, 1994; Cohen, 1998; Cohen \& March, 1986; Fisher \& Koch, 1996; Fisher, Tack, \& Wheeler, 1988; Kezar, 2004; and Kezar, Carducci, \& Contreras-McGavin, 2006). Effectiveness of the academic presidency has been studied extensively by scholars (Bensimon et al., 1989; Birnbaum, 1988; Birnbaum, 1992; Cohen \& March, 1986; Fisher et al., 1988), as well as by presidents themselves (Bornstein, 2003; Fisher \& Koch, 1996). Presidents also shed light on their respective presidencies through their biographies and provide "how to" advice for a new president or the one who aspires to such a position (Flawn, 1990; Gardner, 2005; Hesberg, 1999).

The existing literature attempts to discern how presidents engender success in their positions. Nelson (2009) wrote that presidential effectiveness may be studied through the lens of the responsibilities, duties, and challenges presidents face and how they speak, behave, lead, react, and decide in confronting those demands. One strand of scholarship examines the key characteristics and attributes of "effective" or "good" presidents (Darden, 2006; Fisher et al., 1988; Fujita, 1994; McAdory, 2004; McGoey, 2007). Within this stream, studies have utilized surveys to distinguish effective presidents from those who are not identified as effective in their positions. The results 
suggest that successful presidents can be distinguished from others in terms of their attributes and leadership practices, including their reliance on and utilization of social relationships. Another approach has been to survey institutional constituents to learn what their perceptions are of presidents rather than relying on self-perceptions of presidents to evaluate effectiveness. A significant finding of these studies suggests that relationship building is critical in evaluating what constitutes an effective president.

Another strand of literature focuses on the strategies that presidents appear to deliberately construct in order to achieve both short-term and long-term institutional and positional objectives and goals (Fisher et al., 1988; Darden, 2006; Johnsen, 2006; Kezar \& Eckel, 2008; Mangels, 2008; Minor, 2001; Rosia, 2006). From this research, we learn more about presidential behaviors that describe their awareness and dependence on relationships external and internal to their institutions. From Blau (1994), we gather that presidents "worry about the concerns of trustees, community leaders, students, faculty members, and law enforcement officials" (p. 1), and that presidents respond to these demands by trying to "reconcile the conflicting pressures on the college" (p. 1). Shapiro noted that presidents have to "strike a fine balance between confronting external, as well as internal forces, making the pragmatic adjustments and accommodations necessary, while refusing to capitulate to the dictates of the demands without any chance of compromise" (Nelson, 2007, p. 34).

The literature also offers testimonials from presidents who recognized, upon assuming their positions, that they must also formulate multi-level relationships and networks to perform their administrative functions. Creating and sustaining relationships allow presidents to find allies, avoid future problems, educate stakeholders, identify 
benefactors, establish new relationships or continue bonds with key constituents, including boards, administrators, faculty, staff, students, alumni, donors, and partners of the institution. Advancing multiple institutional agendas within the context of the broader goals of higher education is a daunting task, and Kezar and Eckel (2008) have suggested that questions still remain about the suitable leadership approaches and styles that are undertaken by presidents to move forward agendas.

Finally, we also learn from the literature that gender differences exist in presidential leadership, and these differences may be based on how individuals perceive leadership (Tarule, Applegate, Earley, \& Blackwell, 2009). Turner (2007) argued that women may be hindered by how the dominant white, male culture views their abilities and qualifications. As a result, Dean, Bracken, and Allen (2009) posited that women may also be challenged by male norms that serve as the foundation for the structure of the academe. Thus, women leaders' credentials and abilities may not only be questioned but may often be compared and evaluated against male standards or patterns of behaviors. In one such study, Eddy (2009) considered if community college women presidents led in authentic or in gendered ways that differ from the leadership styles of their male counterparts. One theme that emerged about the leadership perspectives of the women presidents was relationship building; men tended to view relationship building as a means to affect their agendas, whereas women regarded relationship building as a means to build community within their campuses. Yet, other studies (Darden, 2006; Kuh \& Natalicio, 2004; Madsen, 2008; Mangels, 2008; Turner, 2007; Valdata, 2006; Woodlee, 1992) of women presidents suggest that women also seek and pursue relationships with internal and external stakeholders to achieve larger institutional goals. However, no studies 
specifically examine the phenomenon of women presidents who actively engage in relationship building. With more women present in higher-level leadership positions, studying the leadership practices of women in academic presidencies may unveil patterns of actions and behaviors that enhance our understanding of their ways of building relationships that may lead to institutional outcomes.

According to a 2011 survey of academic presidents of regionally accredited and degree-granting institutions in America conducted by the American Council on Education (ACE), women account for $26 \%$ of academic presidents (ACE, 2012). This represented a $3 \%$ increase in women presidents from ACE's previous survey of presidents conducted in 2006. The percentage of African-American and Hispanic women presidents increased slightly from 2006; however, the number of minority presidents making up all academic presidencies decreased from $14 \%$ to $13 \%$. Women presidents only represented $13.8 \%$ of presidents at doctorate-granting institutions (public and private) in 2006 but occupied $22.3 \%$ of those positions in 2011. A breakdown between public and private institutions indicates that the percentage of presidents at public doctorate-granting institutions who were women increased from $16.2 \%$ to $23.9 \%$ and from $7.6 \%$ to $20.7 \%$ at private institutions. The largest representation of women presidents during this time period was at associate's degree institutions (public and private), increasing from $28.8 \%$ to $33 \%$; public associate's degree institutions noticed an increase of women presidents from $29.1 \%$ to $32.3 \%$, and the percentage of presidents who were women increased from $32.6 \%$ to $40.7 \%$ at private institutions. The statistics on women presidents suggest that women are making inroads into the highest senior leadership position; however, they are 
still significantly underrepresented in the academic presidency, as well as in traditional career path positions leading to that position.

\section{Purpose of the Study and Research Questions}

Researchers suggest that one effective leadership practice of academic presidents is intentionally developing relationships with stakeholders who may possess valuable and needed resources to meet institutional objectives (Blau, 1994; Darden, 2006; Fisher et al., 1988; Johnsen, 2006; Kezar \& Eckel, 2008; Mangels, 2008; Minor, 2001; Rosia, 2006). A prevalent theme that emerges in the studies of women presidents (Darden, 2006; Kuh \& Natalicio, 2004; Madsen, 2008; Mangels, 2008; Turner, 2007; Valdata, 2006;

Woodlee, 1992) shows that they actively engage in instrumental relationship building; however, such studies offer few insights in how women presidents purposefully identify, build, and foster these relations. The purpose of this qualitative study was to explore the practices strategically developed and used by women presidents of 4-year public and private colleges and universities to identify, build, and foster relationships with institutional stakeholders whom they recognized as possessing resources that worked towards institutional outcomes.

This study was guided by the following research questions:

1. How do women presidents identify social relations that have embedded resources?

2. How do women presidents build and foster relationships with individuals who possess resources that can help achieve institutional objectives?

3. How do women presidents capture embedded resources in their relationships to generate a return on that investment? 


\section{Definitions}

Leverage: "To use (a quality or advantage) to obtain a desired effect or result" (Dictionary.com, 2014).

Relationship: "The state of being related or interrelated" (Merriam-Webster.com, 2014). Relationships and relations are interchangeably used throughout the study.

Returns: Acquired resources that can enhance institutional quality or reputation through the receipt of donations, grants, equipment, etc.

Social capital: This project defines social capital as an "investment in social relations with expected returns" (Lin, 2001a, p. 19).

Stakeholder: "A person or a group with a direct interest or investment in something. One who has a stake in an enterprise or one who is involved in or affected by a course of action" (Merriam-Webster, 2014).

\section{Theoretical Framework}

This research was framed by the proposition that there is an intentionality practiced by women academic presidents to foster social capital by identifying, developing, and cultivating relationships with stakeholders who possess resources to help advance institutional agendas. Often applied at the organizational level, Nahapiet and Ghoshal (1998) suggest that social capital is also appropriate to consider micro-level relationships, because it is the "sum of actual and potential resources embedded within and available through and derived from the network of relationships possessed by an individual or social unit” (p. 243). While not often cited as a leadership strategy, Coleman (1990) explained that social capital is productive, making possible the achievement of certain ends that would not be attainable in its absence. Research focusing on social 
capital suggests a relationship between people's social networks and efficacy of outcomes (Halpern, 2005), and these webs of connection provide shared understanding and behavioral expectations by the people involved with them. Using a capital lens, social capital contributes to the understanding of how capitalization can engage social structures, hierarchies, and individuals (Lin, 2001b). Zacharakis and Flora (2005) suggested that social capital facilitates coordination and cooperation; thus, it can be a powerful factor to explain individuals' relative success in a variety of areas (Adler \& Kwon, 2002).

An uncomplicated, working definition of social capital as it may apply to the college presidency can be borrowed from Lin (2001a), who defines social capital as an: “investment in social relations with expected returns" (p. 19). This definition works appropriately for the academic president who needs to engage and network with other individuals and does so with the expectation that those social interactions have embedded resources that will lead to profits or outcomes. Social networks and relationships can play an instrumental role for an academic president, particularly if they enhance the amount of resources for the institution. These returns for an institution could enhance institutional quality or reputation through the receipt of donations, grants, equipment, etc., and represent the resources embedded within and accessed through the networks and relationships of presidents. As such, a president searches for and attempts to obtain resources, but these actions take time and effort (Lin, 2001a). The position must also be mindful of maintaining and preserving the social capital she/he accumulates, since those resources can be depleted. Thus, it is an on-going process of identifying and tapping into resources embedded within the network, as well as the resources of contacts in the network. 


\section{Research Design}

This exploratory study used a qualitative, multi-case design to learn how a small number of women presidents positioned themselves to capitalize on their relationships with external and internal constituents. Qualitative research has been described as the gathering of data that is "rich in description of people, places and conversations, and not easily handled by statistical procedures" (Bogdan \& Biklen, 2003, p. 2). Denzin and Lincoln (2008) define qualitative research as a "situated activity that locates the observer in the world" (p. 4), allowing for a variety of different practices to "describe routine and problematic moments and meanings in individuals' lives" (p. 4). According to Patton (2002), the search to identify fundamental patterns of individuals is assumed to be both capable of being known and understood. For these reasons, this methodology was an appropriate means to study the sociological phenomenon of how women academic presidents forged relationships with key stakeholders and how they leveraged those relations in their leadership practices.

Through purposeful sampling, a total of 26 women presidents who met the criteria of the study were contacted by mail to determine if they would be interested in participating in the study. Of this pool, 12 presidents gave their consent to be interviewed by the researcher and were asked a series of semi-structured questions regarding their pathways to the positions, relationships they considered essential to their positions, and how they acquired resources from key stakeholders. 


\section{Limitations of the Study}

The following limitations were associated with this research:

1. The study was limited to a small number of presidents whose institutions were members of the National Association of Independent Colleges and Universities (NAICU) or the American Association of State Colleges and Universities (AASCU) or the American Association of Universities (AAU); therefore, their experiences and practices were not assumed to be the same as all presidents in the nation.

2. Interviews included only the perceptions and experiences of women presidents participating in the study. Perceptions of stakeholders who possessed insights regarding the effectiveness of participants to build and sustain instrumental relationships were not included.

3. There was a lack of follow-up interviews given the limited time available to the interviewees.

\section{Significance of the Study}

Even though prior research (Darden, 2006; Kuh \& Natalicio, 2004; Madsen, 2008; Mangels, 2008; Turner, 2007; Valdata, 2006; Woodlee, 1992) acknowledges the importance of relationships to women presidents, it does not fully explore how presidents identify, build, and foster relationships with embedded resources to leverage their leadership positions. The use of social capital brings a new theoretical lens to examine how presidents forged their relations and leveraged them in their leadership practices. Although there are significant studies of the American academic presidency, none focus on women presidents and relationship building for the purpose of generating social capital. 
From a practical perspective, the study may be of value to first-time women presidents. These leaders may be recipients of advice and counsel prior to assuming their offices by a wide array of those with good will and good intentions. Since most but not all presidents are from academe, they may be aware of the challenges that faced them in their previous positions as faculty members, deans, or provosts; however, being in a presidential position presents new challenges on a larger and broader scale that they have not been accustomed to. This research may help current presidents reflect and consider their present leadership practices or help develop new practices regarding relationship building. For presidents entering the position with no previous administrative experience in higher education, this research may provide insights on relationship building to achieve institutional results. 


\section{CHAPTER II}

\section{REVIEW OF THE LITERATURE}

Since the creation of Harvard College in 1636, American colleges and universities have reserved an administrative position for an institutional leader. In every 10-year period, over 5,000 individuals are selected to serve as presidents of academic institutions in higher education in the United States (Birnbaum \& Eckel, 2005). With more than 3,500 American colleges and universities, these presidents, regardless of institutional type, are expected to be visionaries, fundraisers, leaders, and managers of highly complex organizations. The research on presidential effectiveness supports Shapiro's (1998) claim that the academic presidency is "very much a human endeavor" (p. 65), and presidential tenures are evaluated by how successful they are or were in achieving certain outcomes. Considering the multitude of expectations they attempt to fulfill at their institutions and for higher education in general, it is important, if not essential, to know more about the diverse skills and actions these individuals rely upon to shape their institutions and to move institutional agendas forward. A prevalent theme that emerges in studies of women presidents suggests that they are actively engaged in instrumental relationship building (Darden, 2006; Kuh \& Natalicio, 2004; Madsen, 2008; Mangels, 2008; Turner, 2007; Valdata, 2006; Woodlee, 1992); however, this body of research offers few insights into how women presidents purposefully identify, build and foster these relations. This study explores how women in academic presidencies form these types of relationships and 
leverage them in their leadership practices.

This five-part chapter introduces the literature on presidential effectiveness and how scholars have examined the academic presidency. To provide a context of the presidency, the first section will outline the history of presidential functions and the contemporary responsibilities that are common to the position regardless of institution, all of which suggest a dependence on internal and external relationships. The second section focuses on the string of discourses undertaken to examine presidential effectiveness and presents the central themes that emerge from studies exploring how presidents attempt to engender success through their relationships. Section three explores presidential narratives in which presidents, themselves, suggest their reliance on relationships with diverse stakeholders. In section four, the literature examining women academic presidents who developed relationships with the intent of securing resources is considered. In the last section, a conceptual framework is introduced to help explain how women presidents may invest in social relations that appear to have resources necessary to move institutional agendas forward.

\section{Historical and Contemporary Functions of the Academic Presidency}

\section{Historical Functions of the Academic Presidency}

While the administrative positioning of the presidency has remained mostly unchanged, the functions of the position have altered over time. During the colonial and antebellum eras, presidential responsibilities included teaching classes, recruiting and disciplining students, raising money, and supervising all of the affairs of their campuses (Cohen, 1998). Francis Wayland, who was president of Brown University from 1827 to 1855, summed up presidential duties best with "I am a perfect dray horse. I am in harness 
from morning to night, and from one year to another. I am never turned out for recreation" (as cited in Cowley, 1980, p. 53). Since most presidents were clergy members, they also served as moral leaders in addition to their teacher, administrator, and fundraiser functions (Bornstein, 2003; Brubacher \& Rudy, 1976; Cowley, 1980). Brubacher and Rudy (1976) wrote that presidents of small institutions would even "watch over the books in the library" (p. 367). Shapiro (1998) noted that their array of responsibilities stemmed from the unique nature of American colleges being established for civic reasons rather than serving the purpose of "student-faculty communes" (p. 66) as in the European tradition. Duryea (2000a) added that the lack of qualified applicants and their reliance on tutoring for admission by local ministers contributed to this difference in systems. Based on the administrative position of the presidency, the tradition of the president being the board representative, campus representative, and community leader/liaison was born (Shapiro, 1998); however, the president who was both scholar and administrative specialist was about to appear in the institutional setting (Cowley, 1980).

Due to an increasing number of students, the role of the president was altered in the latter part of the $19^{\text {th }}$ century; the president became more responsible for coordinating and managing the complexities of larger institutions and less responsible for teaching (Brubaker \& Rudy, 1976; Duryea, 2000a). The presidency was no longer a one-person job, and an administrative bureaucracy was created to relieve the position of some responsibilities in order to focus on educational policies (Brubaker \& Rudy, 1976; Duryea, 2000a; Lucas, 2006). Further, the tradition of clergymen holding the position diminished as laymen with teaching and scholarship backgrounds assumed the college presidencies (Brubaker \& Rudy, 1976). It was also the age of the president as "primus" 
(Brubacher \& Rudy, 1976, p. 366), meaning that presidents could basically do what they wanted within the institution as long as they received the support of the board (Cohen, 1998).

Another phenomenon occurred within institutional walls that would prove to have lasting effects on the presidency. The university teacher became a specialist in a field of study, and, through association with discipline-specific organizations, the research scholar became a central figure in university structures. This evolution was coupled with the assumption of departmental authority over matters concerning the curriculum, research, teaching, and personnel. Duryea (2000b) noted that diffusion in power occurred, resulting in decreased influence from the board/corporation. He concluded that American universities became dysfunctional with two bureaucracies - faculty and administrator hierarchies. With different guiding values and attitudes, Duryea (2001a) argued that a "psychological wedge" (p. 13) existed between the two groups, and "centrifugal forces" (p. 13) pushed faculty from the university, fragmenting them from the university and administrators. In other words, external forces shifted faculty loyalties away from the institution, and the president was increasingly seen as the "representative of the trustees, less as a member of the faculty" (Cohen, 1998, p. 85).

Despite the growing competition for authority from the faculty, the presidency thrived through the end of World War II. Cohen (1998) noted that presidents tended to be "pragmatists, empire builders, fundraisers, and experts at public relations" (p. 152). Individuals chosen to hold this position were former faculty members with a history of scholarship; in 1933, only $12 \%$ of presidents were trained for the clergy (Brubacher \& Rudy, 1976). The literature begins to mention the characteristics of outstanding 
presidents: autocratic, compromising, accommodators (of the board), negotiators (with the faculty), innovative, and visionary (Cohen, 1998). They made small and ordinary institutions into significant ones by developing and implementing new programs, and their successes brought the luxury of longevity into their positions in order to assist them in carrying their agendas to fruition (Cohen, 1998).

Since World War II, presidents have become "macro-managers" or "managers of the bureaucracy" (Cohen, 1998) who rely upon "persuasion and coalition building" (Bornstein, 2003, p. 3) to get things done as a result of powerful academic senates and active boards. Yet, they continue with their all-purpose managerial, academic, financial, and external roles of being responsive to their boards, faculties, students, alumni, and community leaders, as well as being the major fundraiser (Bornstein, 2003; Nelson, 2007). According to Nelson (2009), the success or failure of the modern presidency is very much the same as its colonial counterpart. He opined that ineffective presidents have always been judged based on the following: "failure of fit with the institution; mishandling of crises; responsibility for repeated leadership foibles; inability to raise sufficient/timely monies and resources; blame for fiscal miscalculations; and creation of gulfs with faculty or other critical constituencies" (p. 16).

Generally speaking, the management of the institution resides with the administration, and presidents are primarily accountable for maintaining and improving the quality of their institutions (Birnbaum, 2004; Nelson, 2009). Their realms of responsibilities may include being the leader in finding new sources of revenue and directing capital campaigns, balancing budgets, establishing and sustaining relations with government officials at all levels, and creating responses to globalism, technology, and 
diversity (Bornstein, 2003; Nelson, 2009). They are, according to Fisher and Koch (1996), responsible for everything that happens on their campuses, ranging from global issues to food in the dining centers. The Association of Governing Boards (2006), in evaluating the academic presidency, wrote that the president is "juggler-in-chief, expected to meet an endless stream of individual needs and special demands within and outside the institution" (pp. 9-10). Nelson (2009) argued that all presidential functions should be carried out "collaboratively, transparently, democratically, and of course, with great élan and without ruffling anyone's feathers" (p. 20). For presidents, this is especially challenging, since an individual does not assume the position with an established set of allies (Burns, 2007).

\section{Contemporary Functions of the Academic Presidency}

As gleaned in the aforementioned literature, there is no one job description for what is expected of an academic president, regardless of institutional type. However, there are essential tasks and functions that are common to the position: fundraising, planning, leading the administration, promoting an institutional vision, and maintaining external relations. Successful fulfillment of these responsibilities appears to reflect a president's reliance on identifying and sustaining relations with individuals both external and internal to the institution.

Fundraising. Duderstadt (2000) wrote that, "a well-worn definition of the modern university president is someone who lives in a large house and begs for a living" (p. ix). While fundraising has been an essential function of a president since the colonial period, it is critical to consider the function within the larger context of higher education funding, particularly in light of today's economic environment. Every institution is faced 
with competing values and priorities from within and external to the campus and no institution has infinite financial resources. Further, an institutional leader must consider the impact of limited resources on access and opportunity, financial aid, research, technology, personnel salaries, and maintenance of the infrastructure. To support these expenditures and initiatives, institutions receive their revenue from multiple sources, including tuition and fees, federal and state governments, endowments, private giving, research, and enterprise income (Ehrenberg, 2002). Presidents at public and private institutions report that they spend one third to one half of their time seeking alternate revenue streams as a result of stagnant or decreasing revenues from traditional revenue sources (ACE, 2007; Bila, 2003). Bila further argued that fundraising allows institutions to create or continue pursuing aggressive planning agendas.

Several major factors have thrust presidents into a greater fundraising role, including budgetary shortfalls resulting from decreased funding or revenues. A 2006 study published by the Center for the Study of Education Policy (Hodel, Laffey, \& Lingenfelter, 2006) indicated that from 1974-2004 appropriations for higher education did not keep up with growth in the state economy in any state and family income and student aid did not keep up with increases in tuition following the four recessions recorded during the study period. Furthermore, higher education and student financial aid have become lower funding priorities for most states due to competing demands from other public sectors, including the P-12 educational area. James Duderstadt, as president of the University Michigan, summed up this decrease in funding by stating that, "Michigan used to be state-supported, then state-assisted, now we are state-located" (Nelson, 2007, p. 32). 
For private institutions, Ehrenberg (2002) noted that tuition at private, selective institutions had risen faster than the rate of inflation. For the academic years of 2000-01 and 2001-02, increases in tuition at these types of institutions averaged two percentage points more than inflation. Market disruptions to the stock market as a result of the events on September 11, 2001, resulted in private institutions increasing spending from their own endowments (Ehrenberg, 2002). Ehrenberg further commented that, for both public and private institutions, increasing amounts of student aid to cover higher tuition, costs were being provided by institutions through tuition increases.

A second reason for the increased importance of fundraising lies in the private and public benefits of a bachelor's degree, prompting more individuals to attend college. For an individual, these benefits may include expected employment, higher salaries or benefits, higher savings levels, better working environments, and greater degrees of personal and professional mobility (Hearn \& Bunton, 2001; Institute for Higher Education Policy, 2005). While an individual may not consider the wider effect of her or his degree attainment, an individual's human capital is directly related to lifetime earnings and her or his productive capacities in the workforce, all of which are used to improve the public good (Paulsen, 2001). Some of the positive social effects include increased political awareness, greater engagement in public service and volunteerism, increased donations to charitable organizations, increases in employment, better ability to adapt and use new technology, reduction in crime rates, improved health, and lower reliance on social services (Institute for Higher Education Policy, 2005; Paulsen, 2001). Yet, despite these public benefits, individuals seeking a higher education are expected to pay for more of their educational expenses, although it is argued that a sensible economic 
policy would be to invest more in the development of human capital (Alexander, 1976). An increasing awareness of benefits has led to increased enrollment despite diminishing financial support, thereby increasing the need for institutions to secure external funds.

Fundraising, which also is popularly known as development, becomes one of the institutional ventures to help offset the shortfalls in funding and meeting the demands of increased student enrollments. At most institutions, the president is considered the chief fundraiser (Flawn, 1990), and it is essential for the incumbent to mobilize the fiscal and human resources necessary for the institution to carry out its mission. According to Flawn (1990), funding sources include individual donors, foundations, industries, and alumni, and their funds help support faculty positions, scholarships, endowments, faculty and student travel, new buildings, new equipment, and research activities. While these are institutional needs, Bornstein (2003) opined that donors give to presidents, not to their institutions, creating an essential, fiduciary function of the position. To be a successful fundraiser, a president should be mindful of the values of higher education, as well as be sensitive to the marketplace (Kirp, 2003). With greater demands for higher education from individuals and the broader society, presidents need to be more creative and innovative to tap effectively into old and new sources of support (Slaughter \& Rhoades, 2004) by paying more attention to changes in technology, student needs, and market dynamics (Zumeta, 2004).

Planning. Kotler and Murphy (1981) projected that higher education institutions need to move towards a more systematic method of planning and operating for the longterm in order to function and thrive. Rowley, Lujan, and Dolence (1997) suggested that strategic planning is a process to help institutions better align themselves with their 
environments, take a proactive stance toward their futures, and learn how to play a role in a rapidly changing environment. These researchers remarked that strategic planning should be pursued in order to "position the institution so that it can shape and exploit its environment" (p. 3). They further argued that administrative leaders following their strategic plans can better analyze the changes in the external environment and formulate strategic responses to them. Typically, strategic planning does not take place within a vacuum of a college campus; it relies on participation from members across the community. Successful strategic planning can lead to retention of students, improved information technology, and better resource management by linking the budget to institutional priorities (Rowley et al.).

The role of the president in strategic planning is considered essential to the process. As the chief administrative officer, the president's role is to be visible and provide legitimacy, importance, and urgency to the process (Kotler \& Murphy, 1981; Rowley et al., 1997). Rowley et al. suggested that the president's key role is to pose issues to those involved in strategic planning but not to personally lead the strategic planning effort. The president plays a central function in gathering critical information for the planning process; however, the purposeful changes as outlined in strategic plans are made by constituents, meaning that planning does not need to have a top-down effect on the campus. Further, these strategies have the potential to bring diverse groups together in a common and mutual purpose that may minimize their aversion to change or fear of change. As followers and leaders emerge from constructive discussions, they may more effectively work towards intended changes. It is expected, as noted by Borland (2003), that there will be gains, losses, or both incurred by all campus constituents. If 
certain groups will be negatively affected by parts of the plan, the president's strategy of including more groups in the dialogue and formation of the plan will have given them opportunities to respond (Rowley et al.). In the end, the implementation of the plan may have more campus buy-in as a result of the leadership generated throughout the process. Moreover, by speaking with on-campus and off-campus constituents, presidents can start discussions about their campus' missions, traditions, future plans, external challenges, and possible opportunities — all of which can assist or be addressed through the planning effort. Bornstein (2003) suggested that a president can also work collaboratively with senior faculty to form an ad hoc council to legitimate the planning process, since planning is essentially a planning and governance function. The inclusion of multiple campus leaders not only helps legitimate the planning process but also empowers others in the effort to create and sustain change.

Administrative leadership. Cohen and March (1986) suggested that studies of the presidency should always occur within a discussion of decision-making and governance. Unlike complex institutions found in the private and government arenas, the governance of colleges and universities is guided by core values that make them distinct in nature (Blau, 1994; Nelson, 2009). Free thought, questioning, and inquiry are embedded in the foundation of higher education where ideological passions and debates are not only encouraged but permitted (Nelson, 2009). Institutions are fundamentally driven to create "space for academic and intellectual discourse" (Nelson, p. 56), and within its own walls "teaching and scholarship are not necessarily tasks that are routine in nature and are difficult to regulate with administrative procedures" (Blau, p. xxv). Complicating decision-making further is the concept of shared governance, which is 
based on shared responsibility and effort, involving stakeholders from other segments of the campus community. Birnbaum (1988) defines governance as "a way to refer to the structures and processes through which institutional participants interact with and influence each other and communicate with the larger environment” (p. 4). Typically, the major players in college governance and leadership include the board of trustees, faculty, and the president. In some institutions, there may be student and staff representation, but their membership numbers are generally disproportionate to faculty.

The governance of American colleges and universities has evolved over time as new external and internal pressures and tensions were placed upon institutions and their leaders. Traditional governance structures empower the governing board (or corporation) with all executive powers either through law or by charter (Duderstadt, 2004). The function of the board is to make major decisions and to accept financial and legal responsibility for the institution (Duderstadt). The growth and expansion of higher education that occurred in the early $20^{\text {th }}$ century resulted in expanded administrative services, the development of academic departments, and the diffusion of administrative power (Duryea, 2000a). Veysey (1965) evidenced:

Every new system of academic aggrandizement, be it enrollment, athletic success, or added departments, augured on a further loss of coherent meaning. The very reasons for which the university had succeeded in winning public confidence were the sources of these men's despair. (p. 436)

Institutional leaders were being forced to solve dilemmas between organizational functions and responsibilities that appeared to run counter with institutional quality and purpose. 
In 1967, the Council of the American Association of University Professors (AAUP) endorsed the Statement on Government of Colleges and Universities, which was a joint effort by the AAUP, the American Council on Education, and the Association of Governing Boards of Universities and Colleges. The statement was:

Directed to governing board members, administrators, faculty members, students and other persons in the belief that the colleges and universities of the United States have reached a stage calling for appropriately shared responsibility and cooperative action among the components of the academic institution. (AAUP Policy Tenth edition, 2006, p. 135)

According to Duderstadt (2004), contemporary shared governance "allocates public accountability and stewardship to the governing board, academic matters to the faculty, and the tasks of leading and managing the institution to the administration" (p. 140).

As noted earlier, the principal decision makers in shared governance include board members, the faculty, and the president of the institution. Historically, board members serve as the stewards of the institution, advocates of higher education, and defenders of academic values (Duderstadt, 2004). They tend to be individuals who are political appointees or who are elected to the board by alumni or other members of the corporation. Duderstadt argued that boards pose a central problem, primarily because they are laypersons who do not have the knowledge needed to understand complex problems facing institutions. Without an understanding of academe, trustees tend to apply business solutions to solve educational problems. They may be asked to make decisions for which they have no expertise (Collis, 2004) or they may become more intrusive in the management of the institution (Burgan, 2004). To complicate matters, conflicts of interests could also occur between board members who are professionally linked with industries and organizations that run counter to educational philosophy or 
interests of individual institutions.

The role of the faculty is primarily reserved for curricular issues, admission standards, peer review in hiring and retention, and assessment of student learning (Burgan, 2004). Questions including "Who should teach?”, "What should be taught?”, and "Who Shall be Taught?" are under the purview of the faculty, not the president or board of trustees (Birnbaum \& Eckel, 2005). Campbell (2003) argued that faculty members are considered the heart of any institution, and the statement clearly represents how those individuals make sense of their roles and functions within institutions. This culture emphasizes individual freedom, debating, and consensual decision-making (Duderstadt, 2004). However, faculty culture is often mentioned as a factor contributing to ineffective governance (Collis, 2004; Duderstadt, 2004; Hirschhorn \& May, 2000; Ramo, 1997). Faculty members are often criticized for being too focused on their own research and departments, rather than on the institution as a whole (Duderstadt). Moreover, faculty participation in the broader strategic financial and external relations issues tends to be minimal (Duderstadt), while they show an aversion to being managed (Burgan, 2004).

Although presidents may not carry the same authority as they did during the era they were considered primus, they are essential to the governance process as responsibility and authority flows from the top of the organizational pyramid-presidents and the governing board (Duderstadt, 2000). As chief executive officer of an institution, the president is responsible for carrying out the policies of the board of trustees, supervising subordinates, allocating resources, and establishing systems of accountability (Birnbaum \& Eckel, 2005). In this position, the incumbent shares responsibility for the 
definition and attainment of goals, for administrative action, and for operating the communications system that links the components of the academic community (AAUP, 2006). Working within a system of shared governance:

It is the duty of the president to see to it that the standards and procedures in operational use within the college and university conform to the policy established by the governing board and to the standards of sound academic practice. It is also incumbent on the president to ensure that faculty views, including the dissenting views, are presented to the board in those areas and on those issues where responsibilities are shared. Similarly, the faculty should be informed of the views of the board and the administration on like issues. (AAUP, p. 138)

Kezar (2004) found two relationships that are critical to effective shared governance: the relationship between the faculty senate chair and the president and the relationship between the president and the board of trustees, but these must be grounded in trust in order to have productive governance outcomes. In both relationships, the president is clearly the common denominator that makes shared governance an effective and legitimate process.

Campus visionary. The Association of Governing Boards of Universities and Colleges (AGB) (2006) reported that one of the essential elements of presidential leadership is the quality of engagement. There is no greater factor in a president's success than the ability to "elicit and inspire the thinking of others in a shared vision of the institution" (p. 6). Nelson (2009) claimed that presidents can "form and reform sagas, but they can only do so by fully embracing the fundamental truths of a college's history and the legacies of predecessor presidents" (p. 19). Due to the aims and levels of commitments of campus stakeholders, Nelson stated:

Presidents can create a framework for participation that allows the faculty, the senior leadership team, the board, students, and other stakeholders to trust a president and accord the support required to advance the institution. Such integral 
leadership evokes not just support for a vision but also a passionate commitment to achieve it. (p. 6)

It is noteworthy that a president is only one member of the visioning process and should not lead the process; however, it is the president who will eventually put the vision into action with her or his leadership (Bornstein, 2003). Presidential effectiveness involves creating a synergy between her- or himself, faculty members, board members, and students to ensure that the primary purpose of the institution is collectively articulated and achieved (Shapiro, 1998).

External relations. Academic presidents have an obligation to represent and protect their institutional values and priorities to those external to their campuses. These constituents may include the media, elected officials at all levels of government, community leaders, accreditation agencies, corporate executives, unions, and the public at large (ACE, 2007; Nelson, 2007). Whether the purposes of their actions are political, administrative, or fiscal, presidents are expected to be the primary representatives of their institutions, sustainers of the public trust, and servants to the nation's needs (AGB, 2006). Referring to the president's office as the bully pulpit, Nelson (2009) argues that, "upholding the fundamental traditions and values of the academy is essential to a center that holds" (p. 27), and by strengthening and defending the core of their own institutions, presidents contribute the "broader foundation of and legacy of the concept of the university" (p. 27). This is supported by Harold T. Shapiro (Nelson, 2007), former president of the University of Michigan and Princeton University, who acknowledged that it was a constant struggle to find a balance between meeting the expectations of the state (government officials and the public) with the purpose and objectives of the 
institution. He recalled that it was necessary to negotiate and advocate with external stakeholders whose interests and values were not always central to the university. Duderstadt (2000) supports Nelson and Shapiro with these comments:

The president is expected to be the defender of the faith, both of the institution itself and the academic values so important to a university. I sometimes thought of this latter role as roughly akin to that of a tired, old sheriff in a frontier western town. Every day I would drag my bruised, wounded carcass out of bed, strap on my guns, and go out into the main street to face whatever gunslingers had ridden in to shoot up the town that day. Sometimes these were politicians, still other times various interest groups on campus; even occasionally other university leaders such as deans and regents. And, each time I went into battle to defend the university, I knew that one day I would run into someone faster on the draw than I was. (p. xi)

Another presidential scholar and president emeritus of Rollins College, Rita Bornstein (2003) expressed that the demands and constraints from external relations turned "the insulated ivory tower to an open and involved town hall" (p. 34).

\section{Summary}

Emerging from this body of literature on presidential responsibilities is the reliance on relationships that presidents appear to make with diverse constituents who can help them augment institutional development, thereby engendering effectiveness in their own positions. The scholarship points to the necessity of presidents to be deliberate in their attempts to engage benefactors who can provide resources that would otherwise be unobtainable due to budgetary shortfalls (Bolman \& Deal, 2003). While they are not solely responsible for institutional planning and governance, their capacity to gather information, carry out policies, and allocate resources seems to be reliant on their relations with faculty members, governing boards, and students. Bolman and Deal (2003) suggest that the capacity to get things done with or for these groups may be subject to 
how a president leverages those relationships in her or his leadership practices. Moreover, presidents are expected to involve others in the development and achievement of a campus vision, as well as to publicly defend and support their institutions and higher education with those external to their campuses. A closer examination of these responsibilities reflects a continuing commitment to intentionally engaging their leadership with others to negotiate for and to secure resources. Awareness of the resources that can be made available to presidents increases the probability of her or his success in meeting established institutional goals and objectives for raising funds, planning, and governing. The importance of relationship building to the position is also evident in the scholarship of traits and characteristics of effective presidents.

\section{Presidential Effectiveness}

Studies interpreting effective academic leadership have employed many perspectives, using leadership theories that might produce more effective presidential tenures. Despite these different points of view, scholars have collectively argued against the commonly quoted dictums that "Most are CEOs and they know it (leadership) when they see it" (Birnbaum, 1992, p. 135) or "I know leadership when I see it" (Rost, 1991, p. 7) phrases. Consideration of studies conducted on presidential leadership since the 1970s suggests that scholars are perplexed by the elusiveness of how effectiveness can be defined and measured. In their 1986 study, Cohen and March posited that, "neither presidents nor the people around them have much idea about the relationship between success and presidential behavior. Unable to point to serious attributes of success, they learn to point to attributes of effort” (p. 148). Several years later, Birnbaum (1988) seemingly agreed that studies of academic leadership tended to focus on the 
characteristics and actions of leaders, then recommended what leaders should do to be effective.

According to Bensimon et al. (1989), these prescriptions of success only led to confusion about how to build strong institutional leadership. Bensimon and her colleagues wrote that "advice for leaders is not lacking and these opinions are often at odds with each other" (p. 6). They concluded that, "no consensus presently exists — or is even likely to- on a grand unifying theory of academic leadership" (p. 80). Twenty years later, Nelson (2009) mirrored these statements in his appraisal of studies of the academic presidency, noting that "staking out appraisals of the success and failure of presidents is murky, filled with pitfalls as well as prospects" (p. 18). He wrote that many variables are involved with presidential outcomes, including the "president's personality and style, the context of the times and circumstances of their tenures, how they make decisions and shape rhetoric, and the public and critics on and off campus react and how much confidence a president inspires" (p. 18).

As a result, a confounding aspect of studying presidential effectiveness is finding a definition of effectiveness. A study driven by a predetermined definition of effectiveness has not yet been identified. However, most research takes the form of attribute studies that focus more on identifying the overall skills and traits of presidents who were perceived as effective by peers, colleagues, experts, or scholars who used their own definitions of effectiveness. Bensimon et al. (1989), Birnbaum (1992), and Fujita (1994) concur that effectiveness differs depending on the institution, level of analysis, and interpretation of stakeholders. It is equally important to note that presidents who were asked to nominate effective peers may have voted for themselves or responded 
without knowing their peers well enough to recommend an effective peer (Judge, 2001). McAdory (2004), who conducted a study of presidential effectiveness as defined and evaluated by presidents participating in her study, provided an interesting insight to the self-perceptions of presidents:

It is possible that presidents of prestigious institutions, leaders of universities that have successful athletic teams, and those presidents who are in the news more were perceived as more effective because of their institution's visibility. However, these nominees may have merely inherited coaches, public relations officers, and others who are effective employees who make the president also appear effective. (p. 82)

The difficulty of finding an acceptable definition of effective presidential leadership may be the reason why there is a lack of studies on effective presidents (Womack, 2009).

Nevertheless, studies of the skills and traits of presidents advance our understanding and conceptualization of presidential leadership by identifying significant skill sets, behaviors, and knowledge possessed by college presidents. Some studies have defined essential attributes on the basis of the perceptions of presidential peers (Fisher et al., 1988; McAdory, 2004), and other studies have based theirs on the perceptions of internal stakeholders, ranging from students, board members, faculty members or faculty leaders (Fujita, 1994; McGoey, 2007). Even though this scholarship focuses on presidential skills and traits as they pertain to effectiveness, the literature informs this study by revealing two themes on how presidents may engender effectiveness through their relationships - attributes and strategies. The former draws attention to studies that capture characteristics of presidents who were identified by themselves or by other presidents as being effective in their positions. This particular theme has two subcategories: (a) traits possessed by presidents and (b) behaviors that describe 
presidential awareness and dependence on relationships external and internal to their institutions. The latter theme focuses on presidential behaviors and practices that move institutional agendas forward and relate to presidential strategies based on knowledge of and respect for institutional relationships and processes, as well as higher education in general. In other words, what do presidents do to successfully navigate their institutional governance systems and how do they utilize their relationships and higher education knowledge to progress forward? Both of these leadership themes often seem to intersect with each other, sometimes within the same study, leading one to arrive at the same conclusion of Bass and Stodgill (1990) that "one cannot understand leadership in a vacuum" (p. xii); it is multifaceted. The following subsections introduce the scholarship and findings associated with these areas.

\section{Personal Traits of Effective Presidents}

Many studies of presidential effectiveness take into account the characteristics and attributes of presidents (Darden, 2006; Fisher et al., 1988; Fujita, 1994; McAdory, 2004). Testimonies from presidents also provide evidence of characteristics that proved to be helpful in leading their institutions. This focus on attributes is best argued by Fisher et al. (1988), who suggested that higher education depends on what can be learned about the "personal characteristics, professional attitudes, and leadership behaviors" (p. 7) that can promote presidential success. Further, it is as "logical to study individuals whose personalities and operating styles dramatically affect an institution's success or failure as it is to study institutions and generalize about the traits of their leaders" (p. 5). Attributes often mentioned in studies of presidential traits include being a visionary, a strategist, a strong communicator, a risk-taker, and an energetic, responsive and innovative leader. 
Intellectual capacity, political savvy, and collegiality have also been identified as characteristics of effective presidents, and the list continues with being charismatic, selfconfident, knowledgeable, and influential. While all were not inclusive to any one study or narrative, the wide array of attributes help identify those that are most common to effective presidents as defined by participants in a study.

Surveys of "effective" and "representative" presidents. Data obtained from attribute surveys that measure differences between presidents categorized as "effective" and those who are classified as "representative" result in empirical findings that researchers have stipulated are too often lacking in the research. Using leadership inventories, these studies often survey college presidents, asking them to identify other presidents whom they consider effective and allowing for self-nominations as well. The group nominated as effective is then compared to the group not nominated as effective and labeled as representative. Popular inventories include the Fisher/Tack Effective Leadership Inventory (FTELI; employed by Fisher, Tack, \& Wheeler, 1988; Christman, 2003; Womak, 2009) and Fisher and Koch's Effective Leadership Inventory (ELI; employed McAdory, 2004).

Of these studies, Fisher et al. (1988) is the most prominent and has been used by other trait researchers as a point of comparison for their findings. Employing the FTELI, Fisher et al. asked administrators of private foundations, scholars of higher education, and randomly chosen presidents of 2- and 4-year, public and private institutions to identify among 3,300 presidents those whom they considered to be effective in their positions. Fisher and his colleagues did not supply a definition of effectiveness, explaining that the study primarily focused on the characteristics of presidents and that supplying a definition 
could have limited the number of nominations or biased the results towards their own definition of effectiveness. Eventually, 312 presidents were marked as effective presidents, and another 303, who were not nominated by their peers as being effective, were grouped in the representative population.

The findings with statistically significant results between effective and representative leaders suggested that effective presidents exhibited or possessed two social reference and confidence characteristics: (a) being less collegial and more distant with associates and colleagues and (b) being more committed to an ideal or vision than to the institution (Fisher et al., 1988). The researchers presupposed that effective presidents are more concerned about achieving results that will benefit the institution, as well as being able to effectively communicate with constituents, than they are about being a part of the campuses' social fabric. However, there were no statistically significant results between the two groups for the following attributes listed in the questionnaire: (a) using large social functions to advance the institution; (b) believing in community involvement; (c) am rarely in keeping with the status quo of the institution; (d) often like people who are different; and (e) view myself and the institution as one. These questionnaire items allude to opportunities that many presidents, effective or representative, may consider when identifying relationships with resources to move institutions forward.

Two other presidential studies using the FTELI inventory yielded findings concerning relationships that were different from the findings in the study conducted by Fisher et al. (1988). Christman (2003) found that 22 presidents of small, liberal arts institutions labeled as effective by experts in the field used large social functions to advance their institutions and had closer collegial relationships than presidents who were 
considered representative. He concluded that the study's effective presidents understood the long-term implications of participants in social events on the advancement of the institution. In a later study applying FTELI to 64 presidents of colleges associated with the Council for Christian Colleges and Universities (CCCU), Womack (2009) found that those presidents identified as effective placed greater value on relationships than those labeled effective in Fisher et al. (1988). In comparison to the effective presidents in the study by Fisher et al. (1988), the CCCU presidents used large functions more to advance their institutions, were more likely to prefer people who were different from themselves, and were less concerned about the status quo. Similar to Christman, Womack posited that effective presidents in his study promoted advancement of their institutions beyond their existing levels of significance through relationships.

A study conducted by McAdory (2004) also yielded significant findings on relationships. The ELI, which was created by Fisher and Koch, was used to study effective presidents and their representative president counterparts. Three hundred fifty presidents received nominations as effective presidents, and 325 were not nominated and became the representative group. The results of the study found significant differences with small to moderate effects; the effective presidents were more likely to violate the status quo, become more highly involved in the community, form successful relationships with business and government organizations, have an international outlook, participate in more higher education organizations, and receive stronger support from boards of trustees. Effective presidents also considered their institutions as having more partnerships with government and businesses than their representative counterparts. The study also compared results to the 1988 study of Fisher et al. and found that ELI's effective 
presidents frequently violated the status quo more than representative presidents, while there was no statistically significant difference between the two groups of presidents in the earlier study using FTELI. McAdory also found that effective ELI presidents differed from effective FTELI effective presidents regarding community involvement. The former study found effective presidents more highly involved in their communities than representative presidents, while the latter study found no significant difference between the two groups in how they involved themselves in the community.

Interviews. Narratives of presidents and their constituents also provide insights about traits of presidents that might be challenging or difficult to discern from formal surveys (Darden, 2006; Fisher et al., 1988; Johnsen, 2006; Minor, 2001; Rosia, 2006). Johnsen's (2006) study included an array of interviews with the president, chancellors, faculty, administrators, board members, and government officials to examine the leadership characteristics and practices of Mark Hamilton, University of Alaska president, noting that he brought a "wealth of leadership strength" to the university. He was hired to help the system clarify institutional purposes and values, as well as to seek additional state revenues. One former legislator remarked that, "Mark brought vision and hope. He was the only one in the state with a positive vision, so we thought, let's give him $\$ 30$ million dollars over the next 2 years and see what happens” (p. 140).

Minor's (2001) study of successful university presidents at three different institutions reinforces the value of being a visionary. Defining successful presidents as those who have the "ability to achieve a vision and accomplish tasks related to the manifestation of their vision" (p. 30), he concluded that presidents who were described as visionary possessed a "keen sense of direction" (p. 57) for their institutions. Minor's 
definition also conveys the message that presidents needed to be action-oriented in order to achieve their institutional visions. One provost was quoted as saying that "the president has to set the direction for the university, otherwise the place would a mess because there are so many interests and things that we could be doing" (p. 58).

Several presidents in Darden's (2006) study of 18 women presidents also stated through interviews that possessing a vision was instrumental to them. One shared that having a sense of vision helped "mobilize the community" (p. 99), while another stated that a vision communicates the future. Again, the suggestion is that presidents need to be action-oriented in order to move towards achieving these visions. While Darden's presidential visions seem to be institutionally directed, Fisher et al. (1988), who also interviewed 18 presidents, found that the visions of effective presidents included the broad scope of higher education generally and not just for their respective institutions. Possessing a holistic vision can lead to creative problem solving that considers how institutions can affect or make better the lives of others across the world (Fisher et al., 1988; Nelson, 2009). This would also suggest that presidents need to initiate multiple actions, including relationship building, in order to effect this type of change.

Constituent perceptions. Finally, several studies contributed to our knowledge of effective presidents by asking stakeholders for their perceptions of their presidents rather than relying on self-evaluations of presidents. Fujita (1994) identified 32 institutions and sought to find out the dimensions that distinguish good from poor presidential leaders by interviewing 142 campus constituents (including board members, senior administrators, and faculty leaders) who were considered to have the closest contacts with their respective presidents. Despite the likelihood of biases in her data, as well as the 
differences in respondents' subcultures regarding presidential leadership, she concluded that stakeholders considered "good" presidents are those leaders who concentrated on relationships, who respected their institutional cultures by engaging themselves into their campus communities, and who were associated with positive institutional outcomes. Her findings suggest that one-way leadership is not sufficient for good presidencies, meaning that presidents need to be particularly attentive to how they share information with groups or collect information from constituents, as well as dutiful in forming and sustaining relationships with campus stakeholders, particularly faculty members.

McGoey (2007) extended the research previously conducted by in 2001 by Michael, Schwartz, and Balraj to further study the relationship between constituent perceptions relating to presidential effectiveness. While the Michael et al. study only included board members, McGoey assessed board members, faculty senate chairpersons, academic deans, senior-level administrators, and student leaders to identify the indicators of presidential effectiveness. Over 202 respondents representing 36 institutions in Ohio were asked to complete a questionnaire with questions related to indicators of presidential effectiveness - knowledge of higher education, influence in attracting resources to the institution, healthy relationships with key stakeholders, and management/leadership skills. From his analysis, a president's relationship with the governing board, level of influence within the institution, relationship with the chair of the governing board, knowledge of institutional politics, long-term institutional planning, and overall knowledge of higher education were the most important indicators of presidential effectiveness to stakeholders. All stakeholders were in agreement that other indicators of presidential effectiveness were important, including a president's level of influence in the 
public; level of influence within the institution; level of influence with politicians; level of visibility in the institution; level of resources attracted to the institution; relationship with board of trustees, chairperson, students, faculty; level of academic leadership; concern for long range planning; attention to budget details, and overall institutional management, all which have a relational-connection associated with them.

Constituent perceptions provide evidence of the importance of relationships and how certain relationships may connect the president with resources that would otherwise go unrecognized, thereby being un-utilized. Fujita's (1994) study found that presidents were judged positively if they were proactive in seeking and sharing information with stakeholders. Those who were directly available and accessible without the stakeholders having to go through proper channels were also those who nurtured their sources of information. In this same study, supported presidents were those who were considered responsive, who were interactive, and who attempted to reach out to others. These presidents consulted with groups on campus or asked others for their opinions. McGoey (2007) also found that presidents need to gain the trust of the board and engage members of the campus community in order to be considered effective. Similarly, in Michael et al. (2001), one presidential effectiveness indicator was healthy relationships with key stakeholders, specifically the chair of the board, as the position facilitates resource acquisitions and provides stability. Adding to the human relations perspective, Fisher et al. (1988) found that effective presidents were "warm, outgoing people" (p. 88), who “championed people who have different ideas, question everything, comply with little, and do not speak, look or behave like everyone else" (p. 71). They also support organizational flexibility, meaning that they find resolutions through relationships by 
"seeking out accurate, reliable information wherever and whenever they can find it" (p. 72).

\section{Strategies}

In addition to understanding the traits of effective presidents, prior research also attempts to explain the strategies for advancing institutional agendas that otherwise help the institution achieve its goals and secure needed resources. Certain themes have emerged in this research, showing that presidents appear to be deliberate with their actions and considerate of long-term implications rather than being impulsive or spontaneous. These types of behaviors are described as strategic, purposeful, or thoughtful. In some instances, the specific characteristics displayed by presidents are not explicitly described as strategic, purposeful, or thoughtful, but could be considered as reflecting those attributes. Moreover, presidents were cognizant of the strategic importance of building and fostering relationships with key constituents.

As part of her study of the work-balance and success of 12 women college presidents, Mangels (2008) interviewed one who said that, "my provost is out of the humanities and fine arts. I've got the sciences covered. I knew I needed someone in the arts to be provost. I think it makes good sense" (p. 85). Presidents in Minor's (2001) study were specifically described as strategic and critical thinkers, suggesting that they solve problems within extremely complex institutional contexts. He wrote that, "they are extremely thoughtful about critical issues that will impact their institutions" (p. 58). While not specifically addressing being strategic, Fisher et al. (1988) alluded to the strategic perspective, describing effective presidents as being "action-oriented," ready to seize and capitalize on opportunities. Rosia (2006) wrote that the four Canadian 
presidents in his study mentioned the necessity of "building a strategy to educate their various stakeholder groups about the role and value their colleges have in contributing to the economic welfare of the community" (p. 204).

Several research studies place strategizing within the context of presidential effectiveness. Darden (2006) found that 12 of the 18 women presidents in her study suggested how important strategizing is as a part of leadership, as well as how it contributed to their success in achieving a presidency at a 4-year institution. One president shared that "one of the strategies that was important to me was that I chose to take on assignments, areas of new learning, that I knew was I was going to need later on" (p. 88). Darden concluded that challenges presented to presidents require the ability to think and act strategically on a macro level; these attributes were critical in helping these presidents anticipate and/or avoid problems.

Johnsen (2007) also noted that the president of the University of Alaska's approach to leading the university started with "an analysis of financial, demographic, historical and comparative data" (p. 130). The president seemed to understand that Alaska's isolation made it "quite small in social and political senses" (p. 77). This prompted him to retain the current executive staff of chancellors and vice-presidents, many of whom were life-long residents of the state, with strategic ties to state and national politicians, business leaders, and wealthy individuals. Within his first 100 days, the president visited with many of Alaska's most influential political and economic leaders and participated in a summit of former chairs of the Board of Regents. He was diligent in his efforts, but also deliberate in choosing with whom he consulted in state government and industries, as well as with faculty and staff. 
Other presidents also exhibited this sense of purpose. Rosia's (2006) study of four Canadian presidents identified collective agreement amongst the presidents in that they were

...purposefully involved in many external areas, devoting a great deal of time in building links with board members, government officials, program advisory board committees, alumni, key industrial people, and potential donors to build strong allies on whom they could call for support and funding. (p. 247)

In their study of 27 presidents who were identified as successful in moving diversity agendas forward on their campuses, Kezar and Eckel (2008) found six specific strategies that they used to negotiate the campus politics: (a) developing coalitions and advocates; (b) taking the pulse regularly; (c) anticipating resistance; (d) using data to defuse politics and making the process reasonable; (e) creating public relations campaigns; and (f) capitalizing on controversy. The researchers posited that presidents developing similar programs should be aware of the need to utilize a range of strategies at different points of development.

\section{Summary}

While a definitive definition of presidential effectiveness may be too elusive for researchers to agree upon, their studies appear to identify relationships as a key component to presidential leadership. Effectiveness may be tied to securing resources that can lead to institutional building, and presidents may become more effective at transforming their institutions by considering how they can create opportunities through relationships that can lead to productive outcomes. While a successful tenure is undoubtedly based on a variety of variables, it behooves a president to recognize that the position and its functions are interconnected with internal and external constituents. 
While faculty members may choose to work within the silos of specialization, a president needs to transcend divisions to forge relationships with different groups for the unifying purposes of institution and higher education. Advancing agendas can strengthen, improve, and transform institutions, and presidents would do well to identify and develop relationships with stakeholders who possess needed resources to meet those objectives. Another body of writings includes testimonials of academic presidents, reinforcing the importance of various constituents to their presidencies and conveying their own awareness of the critical importance of these relationships in effectively performing their functions.

\section{Presidential Testimonials and Recognition of the Role of Relationships}

Testimonials, including autobiographies, of academic presidents provide eyewitness accounts of what they experienced in their positions, sharing key insights to the necessity of relationships to their governance. Presidential narratives support LipmanBlumen's Connective Leadership Model (Lipman-Blumen, 2000), which highlights relationships as an instrumental tool:

Social achievers are cartographers who draw elaborate social maps in their heads. Everyone they meet becomes a pinpoint on that map. Each new acquaintance is entered into their mental database, replete with detailed descriptions of the new entry's special talents and connections. Faced with a new task, social achievers search their date base for those individuals whose specific characteristics match the task. (p. 209)

The social achiever seeks a diverse network of individuals across social and political members; the more diverse and personal the relationships, the greater the "counsel, affirmation, solace, privileged information, and access to related networks" (p. 209), all of which are considered resources for any organization. 
This was an early recognition made by David Gardner who started his presidential trajectory as assistant to the chancellor at the University of California at Santa Barbara, later assuming the presidencies of the University of Utah and the University of California system. Gardner wrote in his autobiography that he came to "apprehend both the need for and the difficulty of seeking counsel and advice from all the major stakeholders, and to glimpse the intricacies and interplay of power among and between the university's own bureaucracy and the state's bureaucracies" (2005, p. 69). Upon becoming president of the University of Utah, Gardner sensed a:

Disquieting level of distrust between several powerful legislators and the university, a less than fully committed relationship between the business community and the campus, an uncomfortable level of tension between the university and the state's other colleges/universities, and a sense of unease between town and gown in general. Relationships needed tending. (p. 76)

Coming from the University of California system, Gardner also expressed an initial concern about his Utah presidency that "we're not professionally or socially acquainted with anyone either on or off campus. We knew none of the state's leadership in government, business, academic or religious circles" (p. 72).

The literature offers additional testimonies from presidents who, upon assuming their positions, recognized that they must also formulate relationships and networks to perform their administrative functions. Margaret Lee, president of Oakton Community College, stated prior to her installation that "presiding effectively, especially at a college or university, is not something that one can do alone," and that it is work that needs to be shared with other members of the campus (ACE, 2005, p. 5). For James Jones (ACE, 2005), becoming president of Trinity College meant knowing who made up the institution's constituent base of trustees, faculty, students, parents, alumni, 
foundation/corporate entities, and citizens in the surrounding community. Peter Flawn (1990), who was the president of the University of Texas at Austin and the University of Texas at San Antonio, reiterated that a new president should "begin the first day by developing and sustaining a friendly collegial relationship based on 'we're all in this together' approach" (p. 12). He also spoke to "building a sense of community within the institution; building a bridge between town and gown in larger society" (p. 12). Juliet Garcia's tenure at The University of Texas at Brownsville started with "the first lesson (I learned) was that you can do absolutely nothing of significance by yourself....What I learned right away was that I needed a whole lot of people moving in the same direction if we were to accomplish anything important" (Turner, 2007, p. 18). Assuming his presidency during the contentious decade of the 1960s, Theodore Hesberg (1999) wrote in his autobiography that, "I realized that I could not run Notre Dame all by myself, and so I placed heavy reliance on the people around me - the vice presidents, the deans, the department chairmen, and the directors of the important non-academic functions" (p. 67).

Gardner (2005) used a systematic and strategic approach to build his networks and relationships that could help inform him of the needs of constituents, but, at the same time, also better identify how these could assist him in moving forward the campus agenda. First, he used what he termed "pre-effect" meetings that took place upon assuming the presidency. His intent was to establish relationships with department chairs, to get to know the regents and members of the Institutional Council, to meet and learn from the academic and staff leaders in order to establish institutional priorities. Gardner's second step was to become acquainted with legislative leaders: 
I met one-on-one with over 60 of them either at their homes, ranches, schools, farms or other places of business, at breakfast or lunch, wherever and whenever it was convenient for them during my first five months. I asked them to share with me what they liked about the U (university) and what they didn't; where they thought our strengths rested and where our weaknesses lay; what I could do to help improve relations with the legislature and what they could do to learn more about the $\mathrm{U}$; these meetings were invaluable and put me on a first-name basis with each of them, to share confidences, seek advice, hear them out, and become friends with many of them. (p. 83)

His third step was to visit with every community college and university president in the state. Gardner's purpose was to speak with presidents to discuss common or unique problems, tour campuses, affirm his desire to have better relations between institutions, as well as within the system of higher education. It is evident that he sought these connections in order to create a means of gaining information that could secure not only credibility for his position but also resources for the institution.

\section{Summary}

The personal narratives of academic presidents describe the value of relationship building to academic presidents. It is obvious that these presidents assumed their positions knowing that they would need to develop and sustain relationships with crosssections of their institutions, as well as with the broader, external communities. They convey a shared sense that they could not lead their institutions without the help of campus stakeholders, politicians, business leaders, community leaders, governing boards, and even other educational leaders. The general process of identifying these critical relations is best evidenced by David Gardner who revealed a comprehensive list of steps he took to meet with particular stakeholders upon entering office. What is left unknown from his account, as well as from the others, is how some relationships were identified to be more essential than others and the process that was undertaken to secure resources 
from those relations. The presidential effectiveness scholarship is scant on this aspect of presidential leadership, but it is no more apparent when the focus on instrumental relationship building is turned to women academic presidents.

\section{Women's Leadership and Strategic Relationship Building}

Although more women today are represented in academic presidencies, the position continues to be dominated by males, as well as by leadership images and norms based on male patterns and standards of leadership (Allan, 2011; Chliwniak, 1997; Eddy, 2009; Niddifer, 2001). These conceptions of leadership devalue the leadership of women by comparing them to masculine stereotypes, and women are often criticized for attempting to embrace them or faulted for not adopting or willing to accept those standards (Chliwiank, 1997), forcing them into a double bind. However, further research on women presidents can challenge and dispel the trappings of assumptions and perceptions of how women lead as the "other" (Baxter Magolda, 1994), and as more women assume presidencies, there are additional opportunities to study how they demonstrate their strengths in the position and their potential to lead from the position (Allan, 2011).

This section examines several areas related to women presidents and instrumental relationship building. First, new scholarly ground is explored by re-examining the biographies and perceptions of women presidents to learn how they strategically identify and create relationships with individuals who possess valuable resources for their institutions. While past research has highlighted the value of relationships for women leaders and presidents (Astin \& Leland, 1991; Darden, 2006; Eddy, 2009; Madsen, 2008; Mangels, 2008; Turner, 2007; Wolverton, Bower, \& Hyle, 2009), scholars have not 
specifically examined the deliberate processes they engage in to secure resources from relationships that may help move institutional agendas forward. Second, despite the evidence of successful relationship building (Darden, 2009; Kuh \& Natalicio, 2004; Madsen, 2008; Mangels, 2008; Turner, 2007; Valdata, 2006; Woodlee, 1992), the research on women presidents and leaders and relationships sometimes conflicts with one another, leading to the need for further research.

\section{Affiliations, Stakeholders, and Partnerships}

From studies of the academic presidency, we learn that the possession of a composite skill set and the ability to realize relationships appear to be critical in developing and sustaining an effective presidential tenure. Prior studies (Astin \& Leland, 1991; Darden, 2009; Eddy, 2009; Kuh \& Natalicio, 2004; Madsen, 2008; Mangels, 2008; Turner, 2007; Valdata, 2006; Woodlee, 1992; Wolverton et al., 2009) of women leaders and presidents provide a sense of what they do and how they lead, but the presidents were not directly asked how they formed instrumental relationships with others. Through a reexamination of those narratives, their strategies, such as becoming affiliated with certain professional and community organizations or associations and creating connections with individuals who have access to desired resources, are revealed in ways that provide a sense of the importance of developing relationships for resources that will lead to productive results.

Affiliations. The academic presidency is generally regarded as a high-status position, and organizations may actively seek out presidents for their knowledge, skills, and influence to help enhance more than just their membership roles. There is also evidence documenting women presidents who may also seek leadership roles on the 
boards of community, national, and even international organizations or businesses. While presidents may also belong to a particular organization for personal interests or rewards, the scholarship, albeit limited, supports women taking a deliberate approach towards this type of involvement to network and/or gain insights from key stakeholders (Darden, 2009; Madsen, 2008; Turner, 2007; Woodlee, 1992).

In a career pathways study of three presidents who are women of color, Turner (2007) found strategic networks and relationship building were reported through community and professional groups so the presidents could affect educational issues at the global, national, and local levels. These presidents mentioned involvement in organizations, such as the United Way, Asian Americans for Community Involvement, and the Ford Foundation. In addition, they remarked that they were also involved in community boards or organizations dealing with specific demographic populations. As a result of their leadership participation in these organizations, the presidents believed that they could use influence to cultivate and progress their own institutions. Since this study focused primarily on career paths of first-time presidents who were women of color, there is little known about how they identified and extracted resources for their institutions.

In her study on the retention of women presidents, Woodlee (1992) found that all six presidents in her study expressed involvement in community, state, and national organizations. Their memberships ranged from economic development councils, bank boards, the United Way, and even a museum. One president mentioned her involvement in the Chamber of Commerce was both rewarding and important to the college. Several shared that they strategically chose the Rotary because "it helps create important opportunities for networking" (p. 66); one commented that the Rotary was an 
organization that "had the most influential people in it" (p. 66). Additionally, a president remarked that she felt compelled to attend cocktail parties, because they were intended to welcome any new corporate or bank president in the community. Similar to Turner's study, Woodlee focused on only one aspect of women presidencies, so while we know that affiliations were important to them, we do not know of the resources that could be secured as a result of their leadership roles in the organizations.

Based on the types of corporations or board memberships they sought out, women presidents in these studies appeared to be strategic in their actions to connect with specific professional organizations and foundations that could move their institutional agendas forward. What is unknown from the literature is how women presidents approached and used these relationships in terms of obtaining resources.

Stakeholders. The scholarship also includes presidents forming relationships with various campus constituencies. Stakeholders can include campus constituents, such as faculty or boards, as well as donors or friends of the institution. Again, the literature is scant regarding how women presidents identified and cultivated these relationships as their comments are generally made in the context of a larger study. Yet, through their narratives there is evidence that presidents have something to gain from relationships, including information, insights or goodwill.

Governing board support or expertise is critical for presidents, and Mangle's (2008) study of 12 women presidents included one president who felt over a period of time that she was able to "spread out and get specific expertise we need to move ahead" (p. 125) with the board. However, no further explanation concerning the capabilities or knowledge of what those individuals possessed that were instrumental to the president as 
provided by the comment can be ascertained, since they were made within the context of incumbent's time in the position.

There are examples of presidents who created new communication avenues on their campuses for the purpose of hearing from more individuals. Swisher, upon becoming the president of Haskell Indian Nations University, said she wanted to be inclusive and that, "it's very important for me that people who are affected by decisions have some input, and so I set up a structure that gives people a voice" (Valdata, 2006, section 4, I[3). She restructured a decision-making council that originally had only five members: the president and the directors of facilities, administration, academic affairs and student services. Upon assuming the position, she expanded the council to include representatives from the faculty senate, the union, and the athletic director, increasing the number of members to 15 . This may also reflect an awareness of the president that the relationships established through the council could result in better outcomes for the institution.

Woodlee's (1992) study also documents presidents who scheduled meetings with academic departments or offices or who cited changes to their campuses governance structures specifically for the purpose of providing information to constituents or increasing participation in the decision-making process. According to one president, her strategy to increase faculty participation was successful, although there were no insights to what and how she developed and pursued this strategy. Turner's (2007) study did provide an example of a specific strategy that was implemented to secure certain resources. At the University of Hawaii at Hilo, Tseng started her tenure by surveying stakeholders to help her assess and define university goals. The results assisted her in 
identifying goals related to such issues as enrollment, the campus image, the problem of diminished resources, and seeking new sources of revenue from the private sector and through fundraising in general. She said that the survey became a "to-do list for me....I didn't have a specific vision except to make the university a better place-for the people, for the community, and for the state" (Turner, 2007, p. 23). Beyond campus stakeholders, presidents are also cognizant of the importance of external constituents, including politicians. In Darden's (2006) study, the president of a public university said that, "relationships with the broader state community and legislature are critical" (p. 166). A president in Woodlee's (1992) study expressed the concern of going unnoticed by legislators, which prompted her to frequently travel to the state capital in order to visit legislators.

Partnerships. Partnerships for the purpose of fundraising support are one of the essential functions of academic presidents and necessitate the president to make external connections. Woodlee (1992) cited one president who said she "took our major fund drive from 1.2 to 13 million dollars, and we have added almost a building every year and they are completely paid for without contributions" (p. 62). Over a period of 5 years, Tseng was able to secure state and external resources for the institution by meeting with foundation representatives and eventually securing over $\$ 10$ million in grants (Turner, 2007). While no specific strategies are discussed to describe the actions these presidents undertook to secure those resources, the studies do support the necessity of building successful relationships with donors or partners.

This purposive action was reflected in an interview with Diana Natalicio, president of The University of Texas at El Paso, who said she converted her passion for 
the university into seeking different relationships and networks by "traveling to Washington, New York, and L.A. I'd go anyplace where I felt there were people who could help our faculty members make connections and position them and the university to compete successfully" (Kuh \& Natalicio, 2004, p. 48). Over a period of 5 years, mainly through trial and error because there was no precedent to presidential outreach, she met with representatives from federal agencies, such as the Department of Energy or the National Science Foundation, "articulating our assets — our traditional academic strengths and changing demographics - in a way that allowed us to capitalize on them." Further, she stated that in seeking funding to support research, she was also working on relationships with faculty members. In one instance, in which she helped secure a million dollar laboratory equipped with an electron microprobe, she built a relationship with a faculty member who, in turn, encouraged other faculty members to explore similar funding opportunities.

\section{The Relationship Building Paradox}

The scholarship on women presidents, similar to the scholarship on the presidency in general, supports the importance of relationship building as a critical strategy that targets and attempts to harness the resources of key stakeholders in the pursuit of institutional objectives. These presidents give both attention and voices to their experiences as related to a critical function and expectation of their positions. Yet, this scholarship on women presidents is also part of a continuing discourse on gender and relationship building. Several themes emerge that disclose divergent views of facilitating and valuing relationships for leadership purposes. 
Facilitating relationship building. One theme reflects the perception that relationship building is characteristically a disposition of women that brings them into connection with others (Gilligan, 1993). Generally, women tend to be more processoriented, use networks, and establish relationships to generate cooperation from others than men (Chliwniak, 1997). Studies, such as Thomas' (2008) research on women's college presidents, show that by the 1970s their women presidents used coalitions and networks as strategies to support their institutions. Moreover, relationships were found to be critical in a cross-cultural study of 75 women leaders from across industries in which several women opined that they supported developing networks with "like-minded people and worked together within and outside the system to transform it" (Astin \& Leland, 1991, p. 158). The researchers found that women utilized meetings and conferences to establish the necessary networks to exchange ideas and materials with one another.

Valuing relationship building. Another theme reveals that women may downplay the ends of their relationships and that others underestimate their leadership practice of relationship building. Lipman-Blumen's (2000) study of 5,000 women and men managers found that women ranked social style near the bottom of their leadership strategies and men ranked it as their lowest strategy although they indicated they used relational styles more frequently than women. Surprised at the results for women, she posited that women managers may be rejecting the sex stereotype that they prefer to work through critical coalitions and alliances.

Eddy's (2009) research of nine community college presidents revealed that women and men sought to develop relationships with campus constituents but considered the outcomes of those relations differently. The former considered their relationships 
instrumental in developing campus community, whereas the latter used their relations to achieve strategic outcomes. Even though the intended outcomes of women presidents may have required them to form relationships that were no less important or necessary to achieve institutional outcomes, campus constituents were less impressed with the male presidents who also appeared to work towards relationship building on their campuses.

\section{Perceptions of Women and Relationship Building}

The lack of clarity between facilitating relationships and valuing relationship building may lead to the perception that women presidents are perceived as weak in this function. In her research on the academic presidency, Bornstein (2009) posited that presidential search committees may consider women presidents as “inept in developing relationships of importance to the institution, because many women are averse to the external requirements of the presidency" (p. 210). Bornstein's comment is a reflection of how gender traits may be essentialized as a result of culturally held beliefs that women's characteristics and leadership skills are weaker and less preferred than those possessed by males (Eddy, 2009; Niddifer, 2001; Valian, 1999). When women are evaluated based on gender-normative patterns and norms rather than on actual effectiveness in their positions, they are negatively affected professionally (Chliwniak, 1997; Valian, 1999). It is also a reflection of how women's competencies can be marginalized even if a competency is a desired qualification and expectation (Eddy; Valian), which is the case with relationship building and the academic presidency.

\section{Summary}

Although women are making headway, albeit slowly, towards increasing their presence in the academic presidency, there is still much to unveil about their ways of 
leading. Once women reach the highest administrative position of an institution, what do they do once they are in office and to what ends do their actions take them? The strength of women presidents in this leadership role can be further examined by considering their strategies and processes undertaken to achieve outcomes through relationship building for instrumental purposes. A re-examination of presidential studies of women presidents and the biographical narratives of women presidents suggest that they are aware of and sensitive to the intentional and calculated nature of their actions to build both on and off campus relations that will serve their institutions. They are strategic and deliberate with their relationship building, understand how those relations affect their institutions, and are able to achieve success in their attempts to secure resources. In order to achieve these outcomes, they undertook diverse approaches to develop those connections that could lead to productive outcomes. Even though an examination of women presidents might suggest a study guided by feminist frames (Allan, 2011), a study focusing on women with a social capital framework may be able to dispel stereotypes and avoid essentializing women's strengths and weaknesses, thereby leading to new leadership patterns (Dean, Bracken, \& Allen, 2009).

\section{Theoretical Framework}

While not oft cited as a leadership frame, social capital provides a lens to consider how women academic presidents identify, build, and foster relationships to secure institutional resources. In his conceptualization of social capital, Lin (2001a) posited there are resources that an individual can access and use through the resources' locations in a social network. This idea originates from Burt (2001) who stated that, "social capital is a metaphor in which social structure is a kind of capital that can create for certain 
individuals or groups a competitive advantage in pursuing their ends. Better connected people enjoy higher returns" (p. 32). Individuals can capture these resources through the ownership of materials or symbolic goods, such as diplomas, and through social resources, such as those accessed through social connections. The latter, according to Lin, have greater potential usefulness than personal resources or human capital.

Lin (2001a) builds upon the works of Burt and Granovetter, both of whom explored resources embedded in social structures and network locations. Burt (2001) suggests that an individual seeking resources should first identify a potential agent with resources and assess that agent's strategic location, meaning that the individual should examine if that agent has access to a greater diversity of valued information. Granovetter (1995) also argues that an agent's position in a network determines the value, hence usefulness of their position to an individual.

Similarly, Lin's (2001a) conception of social capital also considers the importance of open networks, but he contends that the action to seek networks and relationships is a collective set of conscious actions on the part of individuals. He argues that the conscious action of an individual is the focal point of his theory of social capital and attempts to answer the question: "How, then, can actors/occupants appropriate such positional resources for their own interests instead" (p. 54)? To answer the question, Lin assumes that individuals are "rational and motivated to maintain or gain valued resources in order to survive and persist" (p. 45). He describes the maintenance of resources as expressive action, in which the individual only has to express acknowledgement of another agent's resources or sentiments. In order to seek and gain new resources, an individual would invoke instrumental action, which is driven by a purposive and 
motivating force. This latter action is when "motivation guides interactions. Instrumental action, in particular, motivates investing — seeking out and mobilizing — in relations and connections that provide access to social resources" (p. 53).

The basic premise of Lin's conception of social capital is that investment in social relations has expected returns. He contends that social capital enhances the outcomes of an individual's actions because social ties provide the individual with information about choices and opportunities that would not otherwise be available; exert influence on agents who play an important role in decision-making; add to an individual's credentials, which reflects the person's accessibility to resources through networks and relationships that can enhance the organization; and reinforce identity and recognition through an individual's claim to certain resources. Lin (2001a) states:

This theory, and its research enterprise, argue that social capital is best understood by examining the mechanism and processes by which embedded resources in social networks are captured as investment. It is these mechanisms and processes that help bridge the conceptual gap in the understanding of the macro-micro linkage between structure and individuals. (p. 3)

In studying the academic presidency, the dilemma of bridging the gap between institution and position is an interesting one; presidents work towards institution building, because their effectiveness and success may be gauged on how successful they are at achieving institutional goals.

Burt (2001) argues that social capital is most valuable to managers, such as CEOs, divisional vice presidents, or entrepreneurs, because they have the most to gain and benefit from information and control derived from social capital. According to Lin (2001a), top-level executives are expected to possess rich social capital as they need to deal and manage people both inside and outside the firm. In fact, he argues that 
universities need presidents who have the social skills to negotiate with faculty, students, parents and alumni, as well as raise funds rather than produce distinguished scholarship. Lin states that presidents should have an awareness of their positions in the social structure and other positions in that social structure that can lead to a capitalization of the resources available to them. This can lead to accessing and mobilizing resources that can accumulative capital. Eventually, a return can be generated as result of their efforts.

The utilization and application of social capital to the functions of development, vision, and managing external relations is fairly uncomplicated and unproblematic to support. Presidents are undoubtedly aware that the current economy is slow to recover, resulting in traditional funding sources and streams that are shrinking and/or unreliable. However, holding the highest position at a university provides the president with the stature and the social credentials necessary to access resources through social networks. Moreover, the president embodies the vision of the institution, which emanates from institutional members, and the incumbent uses the vision to articulate the message that her/his institution and higher education play critical roles in the development of technologies, job skills, and research and development to external agents, who may possess economic, political, or social capital resources that can be utilized by the president. This flow of information/resources from the president to internal and external stakeholders provides the incumbent useful information about opportunities and revenue streams that may not have been available without the connection. The president's concerted and strategic effort to make these connections with one agent can then be exerted to influence other agents who may be responsible for making decisions that can have an effect on the distribution of capital. Finally, the social capital earned through this 
process can reinforce the president's claim to future resources from that agent/s in the future.

The application of social capital to the planning and administrative functions can be merged as both functions focus on structures and processes within an institution. While a president may not gain any additional authority through the use of social capital, the incumbent can use her/is position to link or bridge to agents who may have resources that are valuable to the president (Granovetter, 1995). These resources may include an agent's influence or credentials or information that may help to increase the president's capital, thereby increasing her/his effectiveness in the process. Lazega and Pattison (2001) suggest that returns can also include goodwill, cooperation, advice, and even emotional support, leading to strong work-ties that extend beyond the short-term. With a social capital lens perspective, presidents may also be more likely to build relationships and networks outside the central administrative hierarchy to include faculty, directors, or other individuals who may be able to improve the efficacy processes and governance.

For a president to embark on building a common agenda, he or she attempts to identify the institutional constituents/stakeholders who possess or who have access to those who possess the resources and networks that may be needed to achieve that goal. Lin (2001a) explains that social ties located in strategic locations and/or hierarchical positions can provide useful information about opportunities and choices otherwise not available. By identifying these sources, a president may be able to recognize and connect to resources that would otherwise go unrecognized, thereby being un-utilized. While academic presidents possess social capital by virtue of their hierarchical positions, they need to build upon their capital by adding more resources to it. 
Presidential narratives are built around the idea of recognizing social capital through network and relationship building and suggest support of Lin's argument concerning why social capital can enhance the outcomes of actions. However, recognizing the need for social capital is different than building social capital, and the latter requires a president to be actively engaged in the work of the university (Kirschling, 2004). The engagement through interactions and networking allows the president to benefit from investing in those contacts (Lin, 2001a).

\section{Chapter Summary}

Relationships and networks are central in creating and sustaining foundations for the incumbent's leadership capacity. While a successful tenure may be based on a variety of factors, it behooves a president to recognize that the position and its functions reside with a community. Advancing agendas can strengthen, improve, and transform institutions, and women presidents would do well to identify and develop relationships with stakeholders who possess valuable and needed resources to meet those objectives. The narratives of women presidents profiled in this chapter were sensitively and strategically identifying sources that could move their institutional agendas forward. Moreover, while these strategies were not expressed as social capital, presidential actions appeared to support the processes that seem to support the work of social capital being generated or having the potential to be generated. 


\section{CHAPTER III}

\section{RESEARCH METHODOLOGY, DESIGN, AND PROCEDURES}

This chapter describes and justifies the qualitative methodology used in this exploratory study of instrumental relationship building as practiced by 12 women presidents. The research methodology, including research design, participant selection, data gathering strategies, and analysis are presented and discussed. Patton (2002) suggests that qualitative researchers "want to understand how the world operates. They are interested in investigating a phenomenon to get at the nature of reality with regard to that phenomenon" (p. 215). To reach this depth of understanding about relationship building for institutional resources, the study was crafted to capture the experiences of presidents by seeking their perspectives, meanings and motives.

\section{Purpose of the Study and Research Questions}

Researchers suggest that one effective leadership practice of academic presidents is intentionally developing relationships with stakeholders who may possess valuable and needed resources to meet institutional objectives. However, such studies offer few insights into how women presidents purposefully identify, build and foster these relations. The purpose of this qualitative study was to explore how those practices strategically were developed and used by women presidents of 4-year public and private colleges. The following research questions guided the study: 
1. How do women presidents identify social relations that have embedded resources?

2. How do women presidents build and foster relationships with individuals who possess resources that can help achieve institutional objectives?

3. How do women presidents capture embedded resources in their relationships to generate a return on that investment?

\section{Characteristics of Qualitative Research}

Books about qualitative research methods often begin with compelling vignettes describing a problem, issue, or question that a researcher seeks to understand or explain without using statistical methods and procedures. These illustrations serve as examples of the breadth of topics, individuals, groups, and settings that may be studied through a variety of lenses, approaches, designs, and perspectives. Hesse-Biber and Leavy (2006) refer to qualitative research as a "craft" that is practiced "in an exciting interdisciplinary landscape rich with perspectives on knowledge construction and enabled by a multitude of techniques available for generating knowledge" (p. 5). The construction of knowledge using qualitative data may lead to "serendipitous findings and to new integrations; they help researchers get beyond initial conceptions and to generate or revise conceptual frameworks" (Miles \& Huberman, 1994, p. 1). Creating new pathways to unforeseen findings may be a result of not being bound by hypotheses and standardized modeling; instead, a qualitative researcher is given the freedom to explore people, places, practices, and structures through participant-observations, in-depth interviews, focus groups, field work, biographies, and archives. Findings, however, are a result of rigorous and complex processes and are "organized into incidents or stories, have a concrete, vivid, meaningful 
flavor that often proves far more convincing to a reader-another researcher, a policymaker, a practitioner — than pages of summarized numbers" (Miles \& Huberman, p. 1).

The following represent four common characteristics of qualitative research; however, it is important to note that studies using this type of methodology may not use all these features on the same scale:

1. Research is conducted in natural settings. Qualitative researchers will seek their sources from natural settings (Bogden \& Bilken, 2003; Miles \& Huberman, 1994; Bryman, 1999), so that they can learn and understand how human behavior may have been influenced by the environment in which it occurred (Bogden \& Bilken; Denzin \& Lincoln, 2008). The researcher (or research team) becomes the main instrument to collect data using various efforts, such as conversing with participants about their experiences or taking copious field notes of where people live, work, or play. Moreover, the researcher may engage with artifacts left behind by people, including records, diaries, photographs that may help her or him gain a better understanding of the contexts of their studies.

2. Data are descriptive. Patton (1990) notes that qualitative researchers place the “emphasis on illumination, understanding, and extrapolation rather than causal determination, prediction, and generalization" (p. 424). While findings may include numbers, qualitative research findings tend to be rich in details and description. Patton suggests that "sufficient description and direct quotations be included to allow the reader to enter into the situation and thoughts of the people" (p. 430) in the study. Thus, it is critical in data collection and in the presentation of findings that researchers bear in mind the importance of details, because the particulars may contain evidence or signs to 
construct knowledge (Bogden \& Bilken, 2003; Patton, 1990).

3. Concerned with process. Bogden and Bilken (2003) share that qualitative researchers are concerned with outcomes, but they seek a holistic or integrated understanding and explanation of their participants or the phenomenon that cannot be quantified into distinct variables (Hesse-Biber \& Leavy, 2006; Miles \& Huberman, 1994; Patton, 1990). Hesse-Biber and Leavy suggest that qualitative research constructs "culturally situated and theory-enmeshed knowledge through ongoing interplay between theory and methods, researcher and researched" (p. 5).

4. Analysis is inductive. Rather than collecting data that will test hypotheses, qualitative researchers tend to begin their studies without assumptions. Using an inductive approach creates a sense of freedom from the linearity associated with deductive analysis, allowing for multiple dimensions to surface and be examined (Bogden \& Bilken, 2003; Patton, 1990). As a result, the qualitative researcher is situated to consider the nexus between "events and activities and to explore people's interpretations of the factors which produce such connections" (Bryman, 1999, p. 43).

This study utilized levels of these characteristics. Nine of the 12 presidents were interviewed in their inner or outer offices on their campuses, while three presidents requested telephone interviews as a result of being on vacation, on medical leave, or having limited time to dedicate to the interview. Campus visits created opportunities to survey the landscape of the institution-where it was situated in relation to the community; the initial observation of the condition of the campus infrastructure; and the office from which presidents conducted their work. Taking time prior to and after each interview to explore a campus allowed the researcher to experience the environment in 
which presidents conducted their work and to consider the meanings imposed on the researcher by being in a president's office and having her undivided attention. Another methodological decision was to interview participants using open-ended questioning, allowing the participants to consider and reflect on how they built and sustained relationships for institutional purposes. Despite using an interview guide, some participants needed prompting by the researcher to reconstruct their relationship-building experiences, or the researcher asked a line of questions that emerged as a result of experiencing a feeling or being presented with an issue that appeared to be important to a participant (Seale, Gobo, Gubrium, \& Silverman, 2007; Seidman, 2006). Finally, the researcher approached the study from a phenomenological standpoint to understand instrumental relationship interactions through the experiences of participants. From the time the data were collected through the analysis and interpretation stages, the researcher reflected on the meaning participants assigned to constituents and the strategies they engaged to build relationships. These thoughts and notes were compiled in a research handbook that the researcher maintained and stored in a secured environment.

\section{Qualitative Research Strategy}

The researcher used a phenomenological framework to study the instrumental relationship building of women presidents of colleges and universities. Using a conceptual model or framework provides a qualitative researcher with an array of means to become involved in the research, as well as a variety of methods to contemplate what and how knowledge is being constructed by participants (Hesse-Biber \& Leavy, 2006). Grounded in $18^{\text {th }}$ century philosophy, phenomenology was advanced in the 1900 s by Edmund Husserl, a German philosopher, who was concerned with understanding social 
reality through how individuals "experienced experience" (Hesse-Biber \& Leavy, p. 24).

Four themes are considered essential to the core of its philosophical roots:

These are description, reduction, essences, and intentionality. "Description" in phenomenology is concerned with describing things as one experiences them...the consequence of doing this is to place a person's experience at the centre of any investigation. "Reduction" or "bracketing" refers to the need for individuals to temporarily suspend taken for granted assumptions and presuppositions about phenomena, so the things themselves can be returned to. "Essences" refer to the core meaning of an individual's experience of any given phenomenon that makes it what it is..."Intentionality" refers to the consciousness and that individuals are always conscious of something. "Intentionality" is the total meaning of an object. (Krishnaveni \& Ehrich, 2010, p. 70)

In contemporary research practices, the fundamental purpose of a phenomenological study is to describe the "what" and "how" of an identified phenomenon by collecting data from those who have lived experiences of that phenomenon (Creswell, 2007).

For this study, a phenomenological approach was appropriate in light of the fact that this study attempted to understand the "meaning of events and interactions to ordinary people in particular situations" (Bogden \& Bilken, 2003, p. 23). The phenomenon examined in this study was how women presidents identified and cultivated relationships with stakeholders whom the presidents thought possessed invaluable resources for their institutions. Consistent with phenomenological studies, participants were asked describe their experiences and share their insights as they related to instrumental relationship building. The analysis of their narratives led to interpretations of the tasks involved with this critical presidential function and revealed the multiple practices participants relied upon to eventually secure resources, including how participants maintained their authenticity throughout the process of relationship building. 


\section{Participant Selection}

Another part of the research design included using purposeful sampling as a strategy to create a pool of "information rich" (Patton, 2002, p. 46) participants with experiences that will allow them to explain instrumental relationship building processes as they practiced them as college presidents. The use of this sampling technique also allowed the researcher to take into consideration her available resources to conduct this research study (Silverman \& Marvasti, 2008).

The sample of presidents was selected from 4-year public and private colleges and universities in Illinois, Indiana, Iowa, and Wisconsin. These four states were selected because the researcher could commute to and from her home base to most institutions located in those states in a 1-day period. In addition, public and private institutions were selected to create a diversity of institutional types, allowing the researcher to draw comparisons between presidential experiences. It was also important to identify presidents with at least 2 years of experience in their current positions. This criterion was believed important as it was thought that presidents would have had adequate time to build a base of internal and external constituents.

The presidents were identified using the membership directories of the Association of American Universities (AAU), the American Association of State Colleges and Universities (AASCU), and the National Association of Independent Colleges and Universities (NAICU). The membership directories were accessed through the organizations' respective websites and each provided the names of presidents, as well as institutional internet addresses. By linking to an institution's website, a president's sex was confirmed through a visual representation and a corresponding biography. The 
websites also contained contact information, including mailing addresses of the presidents and telephone numbers of presidential offices. After the criteria were applied, the sample totaled 26 potential participants, which included 10 presidents of public institutions and 16 presidents of private institutions.

Based on the pool of prospective participants, presidents were then sorted by institutional types, using current Carnegie Classification categories. These categories were deemed appropriate for this purpose because the classification is intended to enable researchers to "identify groups of roughly comparable institutions" (Carnegie Classifications of Institutions of Higher Education, 2010). Categories for this study included the following: (a) Research University, High Research Activity, Public or Private; (b) Research University, Very High Research, Public or Private; (c) Doctoral/Research University, Public or Private; (d) Masters Colleges and Universities, Public or Private; and (e) Baccalaureate Colleges, Public or Private. A matrix was created by the researcher that included the president's name, name of institution, the institution's Carnegie classification, type of institution (public or private), location of institution (state), higher education membership organization, and the year the president started her tenure.

\section{Data Collection}

In order to create a diversity of relationship-building experiences, all 10 presidents of public institutions were selected and 10 presidents of private colleges were selected to receive an invitation to participate in the study. This initial pool included institutions from each aforementioned Carnegie type. The presidents in the sample were contacted by mail to introduce them to the purpose of the study and to determine their interest in 
being a participant. The mailing was sent in May 2012 and included an insert with IRB information (Purpose of Study, Study Procedures, Recruitment of Study Participants, Risks, Steps to Minimize Risks, and Benefits); a response form; and a postage-paid envelope to mail the response form to the researcher (Appendix A).

After 6 weeks, six presidents returned responses agreeing to participate and two sent response forms declining participation. For the 14 presidents who did not respond, the researcher contacted each president's office to determine if the invitation packet was received. If the packet was received, the researcher asked if the president could respond to the invitation. A response was relayed through email, telephone call, or a returned response form of the president's decision. If the invitation packet was not received or could not be located, the researcher confirmed the mailing address and resent a packet to that address. After the initial follow-up contact, the researcher did not receive responses from three presidents. The researcher then exhausted the inventory by sending invitations to the remaining group of seven presidents of private institutions in July 2012. This resulted in four more positive responses, bringing the total number of respondents to 10 .

In May 2013, the researcher was introduced to a development officer who was a former college president to discuss her dissertation topic. The former president was familiar with two presidents who initially declined or did not respond to the initial participation request; one was president at the institution she currently worked. Acting on behalf of the researcher as a gatekeeper, she contacted each president, both of whom expressed an interest in participating in the study. Initial contact for one president was through a request to her direct email address, which included an invitation, plus all supporting IRB documentation. For the other president, the researcher contacted the 
president's assistant, and after electronically sending the invitation and supporting IRB forms, affirmation to participate was secured over the telephone. The confirmation of these two presidents brought the total number of presidents to 12 .

\section{Data Collection Procedures}

Nine of the 12 interviews were conducted on the campuses of the presidents. These interviews were scheduled for 2 hours; the shortest was 1.5 hours in duration and the longest was 2.5 hours in length. Telephone interviews were also considered one of the primary tools for data collection. One president retired the week the interview was originally scheduled and requested that it be substituted with a telephone interview as result of being on vacation and her time limitations. Another president was on medical leave and requested a telephone interview. The third request for a telephone interview was from a president who could only devote one hour to an interview.

Interviews conducted in person or over the telephone were audio-recorded as a result of receiving signed permissions allowing the researcher to record the conversations (Appendix B). The researcher gave each participant, institution, and any person(s) mentioned during the courses of the interviews pseudonyms. The interview protocol was created based on the literature on presidential leadership and the questions focused on the strategies the presidents used to identify and cultivate relationships with stakeholders whom they believed possessed resources and how those resources were leveraged in their leadership practices (Appendix C). During the interviews, the researcher took descriptive notes and interpretive field notes as necessary, all of which were maintained in a research journal. Backgrounds of presidents and institutional contexts were also important in understanding the phenomenon of relationship building. Documents substantiated 
observations and interviews, as well as supported the trustworthiness of the findings by "identifying a relationship of ideas or events previously assumed unconnected" (Glesne, 2006, p. 65). The researcher also examined biographical data, including vitas, from institutional websites prior to each interview.

\section{Data Analysis}

Patton (2002) suggests that "qualitative analysis transforms data into findings" (p. 432). While he states there are no rules regarding the analysis of data, Patton stresses that researchers have "an obligation to monitor and report their own analytical procedures and processes as fully and truthfully as possible” (p. 434). Analysis for this study was considered an ongoing process that started with the first interview, allowing the researcher to reflect on the data being collected and to record those thoughts as subsequent interviews were being conducted. After each interview, the researcher typed field notes, then listened to the audio recording to confirm the accuracy of those perceptions (Patton, 2002). As a result, the researcher started to consider patterns and perspectives but was careful not to make hasty and untimely conclusions about the data. By not being committed and restricted to these initial analyses, other interpretations of the data were explored in relation to the research questions. Once the formal interviews were concluded, the researcher had multiple sources from which the final analysis could be considered.

Each interview was transcribed by the researcher, which was a decision based on a suggestion to "get a sense of the whole" (Patton, 2002, p. 440). While transcription was a time-consuming task, it provided the researcher with additional opportunities to become better acquainted with the data, to consider additional potential themes and 
interpretations, and to become more familiar with the voices, accents, and inflections of each participant. The transcriptions were double-spaced and contained 2-inch right margins for coding purposes.

Prior to coding a transcript, the entire interview was read, and general notes, patterns, and thoughts were recorded as the first step in developing the study's coding system. Transcripts were then hand coded using Bodgen and Biklen's (2003) guide in which perceptions, strategies, activities, relationships, setting, context, processes, and any other emerging coding schemes were first identified, then bound together into a common schematic. The list of codes was created that assigned a number to each code and defined each code. Consistency in coding was achieved by routinely comparing codes with passages previously coded. This allowed the researcher to consider alternate interpretations of the same phenomenon that could exist. Once the coding was complete, the researcher interpreted the data in relation to the framework of research questions and the theoretical framework to generate meaning. Initially, broad categories were established and, as unique patterns or themes began to emerge, the researcher segmented them into specific categories or subcategories. In addition to transcripts, the researcher also analyzed field notes and included those interpretations into the code list.

\section{Validity Strategies}

The strategies utilized in this study to validate findings included those suggested by Creswell (2009) and Patton (2002):

1. Triangulation. Data and evidence were compiled from multiple sources, including interviews, biographical data, institutional websites, and detailed field notes to justify the creation of established themes. 
2. Rich Descriptions. The researcher attempted to provide a reader with in-depth descriptions of the profiles and shared stories of participants as they related to relationship building, offering the reader to share in that experience.

3. Data Collection and Analysis. The researcher maintained meticulous notes throughout the data collection phase. A field log was utilized to record detailed observations and accounts of interviews and campus visits. Moreover, in the analysis phase, the interviews were transcribed verbatim by the researcher and the data were continuously reviewed and coded.

\section{Ethical Issues in the Study}

The researcher utilized the following Illinois State University Institutional Review Board's (IRB) protocol to minimize the risks to the presidents participating in this study:

- Participants were required to provide a signed consent form in order to participate;

- Each participant was given a pseudonym, as well as one for her institution and any named person(s) she mentioned during the course of the interview;

- Participants had the freedom to withdraw from the study at any time with no consequences;

- The researcher's field notes, tape recordings, and transcriptions were held in a locked cabinet in the researcher's office at Illinois State University (Schroeder Hall 441) with only the researcher having a key to the drawer or were secured in the researcher's home;

- The researcher honored participants' requests to withhold confidential information about personnel matters or other issues that participants deemed too sensitive to share in the final report.

\section{Limitations of the Study}

Several limitations were associated with this study. One was the use of purposeful sampling using the membership directories of the National Association of Independent 
Colleges and Universities (NAICU), the American Association of State Colleges and Universities (AASCU), and the American Association of Universities. A second limitation was interviewing only women who occupied academic presidencies, instead of including stakeholders who may possess insights to how effectively the participants forged relationships and acquired resources. Another possible limitation was the lack of follow-up interviews given the limited time available to the interviewees.

\section{Chapter Summary}

This chapter summarized the research methodology, approach, and procedures used in this study. A qualitative study utilizing a phenomenological framework was designed and utilized to generate insights on how women presidents identified and fostered relationships with key stakeholders whom possessed resources that could be acquired for their respective institutions. Twelve presidents participated in the study, and they were identified using purposive sampling with specific criteria established to identify a diverse pool of potential participants with relationship-building experiences. Individual, semi-structured interviews were conducted with each participant, and the collected data was then meticulously analyzed and validated, resulting in rich descriptions of their practices and methods. The next chapter introduces the presidents in this study and describes their journeys to their current positions. 


\section{CHAPTER IV}

\section{BECOMING PRESIDENT: TWELVE DIFFERENT PATHS TO THE POSITION}

\section{Chapter Overview}

This chapter introduces the 12 presidents who participated in the study, using personal narratives to describe their journeys to the presidency. Following the career path of each woman elicited significant details from her personal and professional experiences that helped frame her journey to the highest administrative position in higher education. When asked about her path to the presidency, each president spoke freely, candidly, and at length of her story, weaving valuable lessons, insights, and strategies into and through it. The development of each president's portrait reflects her aspirations, transitions, challenges, and personal and professional circumstances, as well as the relationships that prompted or compelled her to consider higher education as a career path, pursue or accept various leadership positions, and ultimately assume the presidency.

Due to the high regional and national profiles of each participant, the following steps were undertaken to maintain the confidentiality of each president's identity, her previous and current institutions, and any other individual she may have named during an interview. First, each participant was assigned a pseudonym (first and last name) by the researcher. Since she could be also be identified by years of service, the number of years she had held the presidency were described in general terms. For instance, "6 years of service" may be referred to as "over 5 years." All the participants also mentioned the 
states where they were raised or where they had previously worked, but these states are not identified. Instead, the profiles that follow identify geographic regions. For instance, if California was mentioned, it would be referred to as "as a state in the West." Second, each institution was given an alias by the researcher. To maintain further confidentiality, general geographic regions rather than specific states were used to identify the locations of institutions. Third, any person named by a participant was given a pseudonym or given a generic professional title.

\section{Participant Profiles}

The sample for this study includes 12 women who were presidents of 4-year institutions at the time of being interviewed. The selection of these individuals was based on purposive sampling as described in Chapter III.

\section{President Rebecca McKay}

Rebecca McKay has served almost 10 years as president of Rosemount College, which is located in a large Midwestern city. McKay earned her doctorate in Higher Education Leadership, Management, and Policy from a religiously-affiliated institution on the east coast where she also worked in central administration.

Rosemount College is a 4-year institution and offers both undergraduate and graduate degrees. It is one of two single-sex institutions in the city and one of over 60 in the country. Student enrollment exceeds 2,600, and almost 40 undergraduate majors are offered. There are also graduate programs that welcome both women and men. Rosemount's enrollment has increased by almost 40\% during McKay's tenure. She admits that: 
It's a struggle. Not that many people are interested in a [single-sex institution]. We just went through a planning process, and we really polled the entire campus to talk about planning assumptions. They were saying things like, "Let's not spend a lot of time on things like should we remain [single-sex] if we all think we should."

McKay's journey to the presidency. Her story started on the east coast, and her

narrative describes the distinctiveness of her career path:

I have a very non-traditional background. I started out after graduate school in the mental health field, so I'm a licensed mental health practitioner... My first position is where I had done my second-year clinical internship in graduate school, and they just kept me. So then, I was just promoted through the ranks over a period of years and ended up being president of the hospital [psychiatric focus].

After being approached by a religious order to assume another hospital presidency, McKay accepted their offer and returned to school to get a degree in hospital administration, because "I didn't really know anything about hospital administration."

While in this position, she was also serving as a trustee on the board of directors for Saint Augustine University (SAU), McKay's alma mater. SAU is a religiouslyaffiliated, doctoral/research institution located in the same city where she was working.

Her service on the board led to a turning-point event in her career that ultimately led to an intersection with administrative leadership in higher education:

They named a new president in the [late 1990s]. He took me out to dinner [I thought he was asking, you know, for the annual donation that you give when you're on these things], and asked me if I would come be the executive vice president of the university. Now, mind you, I had no background in higher education what so ever, but he felt that I would be a good fit. So, I went. He had known me for a number of years, because of other jobs and work that I had done, but he knew of me professionally, and I think thought I would be a good fit for his personality.

McKay reflects that her acceptance was interesting, because she was not looking to make a move professionally but now found herself suddenly in higher education in a position as 
a chief operating officer with "everything reporting to her." She was "in house doing the nitty-gritty," while the president who was "very charismatic and a very good fundraiser" was "out a lot just doing what presidents do," because he "didn't really like the day-today stuff." While she professed that she learned her position "in the trenches," McKay admitted that the shift from hospital to academic leadership was not much of a leap as "I think many leadership skills are transferable. Hospitals are not terribly different from colleges. In fact, faculty and doctors have a lot in common. For example, in how they approach, you know, their work and their professionalism." Plus, as president of two hospitals, she understood the role of fundraising. She jokingly added that "many people think [being president of a psychiatric hospital] is good preparation for my current job [as president]."

The offer of the position would also lead to another major event in McKay's professional career. Since she was not familiar with higher education, she asked the president after assuming the position, "if it was alright with him, if she could pursue a doctorate in higher education." As a student, she said, "We studied in a couple of my courses Rosemount College, because of [their] learning outcomes. I knew a lot about the school from my doctoral work." What now seems serendipitous, in the mid-2000s, Rosemount College began a presidential search and McKay was contacted by a presidential search firm to consider applying for the position:

I wasn't really interested in leaving [I was at SAU for over 7 years], but I was impressed with the school. I explained that to them. I came out, and I withdrew from the search, and they asked me to reconsider. I would probably still be there [SAU] had I not been encouraged to do this. And I really tried to turn the job down. I was scheduled to have my knees replaced. So, I said, 'You'd have to wait a year,' and I really thought they'd say, 'No,' and they said, 'That's fine. 
We'll wait a year.' So, they actually waited a year for me. I used to joke that 'I'm not that good. Really, I don't know why you're waiting? You could do better!'

"Really, the first job I'd ever officially applied for was Rosemount College," shared McKay. The statement is prefaced with "really" perhaps to dispel any possible incredulousness of hearing that a college presidency was the first position that "I actually had to compete against other people." She professed that it was "pretty unusual, I guess, for someone my age to have had that kind of ...good fortune, but it was!" Thinking about why she was chosen for the position, McKay said:

I was probably an appealing candidate to them because it's a [single sex institution]. Of course, they wanted a woman. It's also a [religiously affiliated college], and I had been president of a [similar religiously affiliated] hospital. And by coincidence $[\mathrm{I}]$ had been the first non-nun or lay president of the hospital. So, I think that experience made them feel I would be able to make the transition. I never thought 20 years ago if somebody said I'd be running a college, especially in the [Midwest], I would not have believed it!

She mentioned several more times in the course of her interview that her career path was “very non-traditional," emphasizing that she "didn't come up through any normal pathway" to a presidency but having served almost a decade at Rosemount, she proudly exclaimed, "So, here I am all these years' later. It's been a good move for me." She added with a chuckle, "God's ways are mysterious."

\section{President Juliana Fletcher}

Juliana Fletcher has been president of Weldon University for more than 6 years.

She is a member of a religious order that is not related to the congregation that founded Weldon. Fletcher earned a bachelor's degree in graphic design, a master's degree in theology, and a doctorate in higher education. 
Weldon is a co-educational institution with over 1,200 students, offering undergraduate, graduate, and pre-professional programs. It is situated on the bluffs of an urbanized area that runs along a river. Fletcher describes the campus as a "relational place" that is "pathological about friendly and caring, so it's really a different kind of place. The sense of relationship that exists on this campus [works well with me]."

Fletcher's journey to the presidency. Fletcher shares that her story "unlike most people mine's very diverse." Not wanting to return to the Indian reservation where she had spent some time working, her religious order also preferred that she remain in the medium-sized city in the Midwest where they were located. She accepted a position as an admissions counselor at her congregation's sponsored college:

If you're a good student of what that is, there's no place better to learn the institution than from that position, because you have to understand the product if you're going to sell it. It really was, in my opinion, one of the very best places to start. You're at the bottom of the totem pole, but if you're going to go out and convince 18 year olds to come to your institution, you really do have to understand it.

In this position, she revealed that she also "spent a lot of time watching who had power and those kinds of things," because "I'm a person that's really aware of power," adding "and how they use it." After a year in this position, she became the director of marketing and admissions for the college's adult week-end college. Fletcher said, "I did that for a number of years. We had an alternative week-end college, evening college. Learned a lot [about] the adult ed. issues that today are just part of our life, but it wasn't so then." Then, she "totally jumped ship" and became the assistant dean of students. Student activities and residential life reported to her, and she enjoyed her time as, "I was the right age. I was 28 years old. It was fun to do. You know, I had the energy to stay 
up at those kinds of times." It was in this position that Fletcher began to see a career path in higher education beginning to develop:

[I] really wanted to focus on the traditional aged student, and I know I didn't, didn't want to spend my life in the adult side of the market. By that point, I was beginning to think I wasn't going back to the Indian Reservation. I was going to have a career here.

Her president also saw promise in a career in higher education and that Fletcher's vision should include being a college president:

I was lucky. I was the president's fair-haired golden girl. So, I got put on just about every major committee. So, it's one of the mentoring advantages of convent living that doesn't exist anymore, but it did when we ran institutions. I was one of the few sisters that wanted to work in an institution. [I] didn't have to go work directly with the poor. So, [the] president very much mentored me. I went on "ask calls", you know, gift calls and those kinds of things very early. So, the president knew long before I did that I wanted to be a president.

Realizing that a career in higher education should be supported with advanced

degrees, she left the Midwest and began her master's studies in Theology at an institution on the West Coast. She chose the discipline, knowing that she wanted to work at a religiously-affiliated institution and that it was "terribly important to be able to understand [Church law and Scripture] and talk that language" and sounding equally defiant, "to be able not to be cowed by a bishop." Upon completing her degree, she remained on the West Coast and accepted a position at a religiously-affiliated college as assistant to the dean, but was successful in changing the position to assistant dean before she took the job. In this job, she had "a ball. It was just the greatest thing. We had inept senior leadership, but they didn't seem to get in our way. We did absolutely, positively wonderful things for that institution. It was great!" Fletcher said that the position gave her great confidence and the opportunity to "demonstrate my competence to [faculty] and 
my utility to them, which I did quite effectively."

After 2 years in this position, she decided it was time to begin her doctorate, so Fletcher returned to the Midwest to begin her studies at large research institution. There she made several more decisions critical to her future. She decided that she was not going to be a theologian, because "a woman ethicist is not where I was going to be successful. My mother kept saying, 'You're going to get excommunicated!'” Moreover, she began to see herself as an administrator, not a faculty member. She also discovered that she preferred mid-majors because people in those institutions seemed more concerned about theory to practice. In her last year, she was assistant to the associate provost for undergraduate education, which she described as "quite phenomenal," particularly to work at the provost level at a large research one institution.

After graduating, she became the department chair at a regional institution in another Midwest state in its Department of Educational Leadership, Administration, and Foundation. As chair, she knew she wanted to go to the next level, as she described herself as "pretty planful." Fletcher then became provost at a single-sex, religiouslyaffiliated institution in the same state. There she was the "strategic person. I was the planner there. I loved doing it. We did some great things. Did a great strategic plan. I wrote $\$ 3$ to 4 million worth of grants, so we funded things." She also had to take the institution's adult program co-educational, and that was "a painful experience for many people." She would not "care to do that ever again [chuckles]. I have that on my resume, and that's a good thing, but I don't want to do it again!" When she told her president that she was ready to begin her search for a presidency, the president said, "Fine, I think you're ready." Weldon University was seeking a president, and she was drawn to the 
campus because:

I mean I'm always pretty clear about what I wanted. I wanted a religiouslyaffiliated institution. I won't go anyplace else that - that's too difficult for me to negotiate my identity as a woman religious. It was an institution founded by a woman's congregation. [Would not prefer] a man's congregation or diocesan, because of the culture that comes with that.

After being announced as the new president, "the ovation I received was overwhelming. When I walked out onto [the] stage, because they didn't know who had been picked, it was probably a 3- or 4-minute ovation. When I did my first opening of school meeting, I got another ovation after that. I do not get 3- or 4-minute ovations anymore" [chuckles].

\section{President Sarah Drummond}

Sarah Drummond served as president of Westchester University for several years before recently choosing to resign and return to the faculty. She is a life-long resident of the state in which Westchester is located and received her doctorate in educational leadership and policy studies from a public institution in the same state.

A total of 14 institutions in the United States are from the religious-affiliation associated with Westchester University. It is over 135 years old and is located in the center of a small town with over 11,000 residents. The total enrollment on campus has increased $150 \%$ since the early 2000s. Plus, an additional 300 students are enrolled in its distance education and adult education programs. New construction is evident on the campus with a recently opened new residence hall and other new buildings in the master plan. Town and gown relations have historically been strained as a result of tension created during World War II and the Vietnam War. Activities by local residents to support the war efforts and the institution's commitment towards peace and non-conflict were often at odds with each other. Drummond remarks, "Westchester is not 
introspective, but we're looking outward. We're looking at involving more people whether that's alumni or business people or the federal government and granting writing, non-profits."

Drummond's journey to the presidency. Drummond begins by sharing that her story is "very different from the traditional, and especially male dominated journey in higher education to the presidency." She was married right out of high school and worked on the family farm until her children were in school. Being a "farmer's wife" meant knowing the business and the industry:

Farmers, I think, are much maligned as far as the stereotypical, you know, hay seed look. Farmers now are very-have to be very savvy. They have to know the board of trade. They have to know the future's prices. They need to know the different options for fertilizer and chemicals. They have to know chemistry. They have to know biology and botany as well.

As a result of her experience on the farm, she went to work at the local grain elevator, receiving her custom applicator's license and learning bookkeeping, accounts receivable, accounts payable, and how to grade grain. In addition, she also had to have a working knowledge of:

What the price of futures were. We had to know what the margins were. We had to know where we could get the best price for our grain-whether we took it locally or farther away. Figured out the price of shipping, knowing that so you knew what all of your variable costs were, as well as your fixed costs.

Drummond would leave the grain elevator position to open her own commodity firm. After receiving her SEC license, she hedged for farmers who chose to use the markets that way. In addition to managing her firm, she "was on a 5-county water quality board. I was on the local county economic development group. I played the organ for church. I was involved in my children's activities in school. So, it was not a quiet life. It 
was a busy life." After several years, her former employer at the grain elevator contacted her about a possible return as an accountant. Drummond placed certain conditions on her return, which included having a computer to better track inventories and receipts, receiving medical insurance, and participating in a profit-sharing plan. The last two requests she made not only for herself but for everyone who worked at the elevator. Each request was subsequently approved by her employer.

The family farm fell upon hard times and went bankrupt, forcing her husband to drive semi-trucks across the country and leaving her at "home with the dog." With the children in college, she decided to go to college herself and started at the local public institution a day after she turned 40 years old, majoring in agri-business. While an undergraduate, she was a recipient of a Truman Scholarship, which supported her last 2 years of college and 2 years of a master's degree. Without the scholarship, she thinks she would never have gone on for her graduate degree. While a graduate student, she spent a year in the Ukraine developing a $\$ 40$ million corn-planting venture.

While finishing her master's, she went to work for a large foundation that wanted to examine agricultural education and what it should do for the people of the state. The position started her thinking:

...about the role education plays in the economy in general and in society in general. Should we be taking a look at educating students to be the critical thinkers, to be the entrepreneurs, to be thinking about how to make things different, not just about continuously getting bigger and bigger?

With that question in hand, she began a collaborative effort that would involve three public universities and 15 community colleges in the state. It was an opportunity, she said, to get people to talk to each other and to say to one another, "Guess what? We're all 
in higher education together."

After completing her master's, she started her doctoral work in education. She worked part-time for a non-profit organization and received a grant to develop a leadership program for women and minorities in higher education, because they "were more represented at the professor level but less represented at the administrative level." Moreover, she added "higher education wasn't preparing our own people for those [administrative] jobs they needed to go to." During this 8-month long program, participants met monthly and were presented with:

Materials on how the legislature works, how does the politics have to do with funding education, federal politics, statewide politics. They took the MyersBriggs test on personality. How can you make a stronger team by having people with different learning styles? We talked about teaching in a classroom and the newest assessment laws and rules and how do you do assessment [and] student learning outcomes?

After finishing her doctorate, Drummond wanted to find a part-time job while working for the non-profit. Westchester was seeking an adjunct for their evening adult program, so she accepted their offer until the grant project was complete. She was eventually offered a full-time adjunct position and shortly thereafter applied for and received a tenure-track position. As a faculty member, Drummond was elected faculty council chair and named to the building committee when the campus was developing new buildings. From that committee, she met some of the board of trustees. She was also asked to review the financial aid process, putting her project management skills from the grain elevator and grant work back into play. She was eventually asked to be interim president, then the president. Drummond laughs, "So, from a farm wife...doing the budgets and doing taxes and doing the accounting at the grain elevator. Who would have thought?" 


\section{President Katharine Hamilton}

Katharine Hamilton has been president of Bedford University for over 7 years and is the first woman to hold that office. She received her master's and doctorate in communications studies. Hamilton is an alumna of Bedford and her family's legacy to Bedford includes her father who served on its board of trustees.

Established over 170 years ago, Bedford is a religiously-affiliated institution located on 120 acres in a rural town of over 6,000 residents. The institution offers undergraduate and master's degrees on its main campus. A second campus was opened several years ago in a nearby city to accommodate the institution's new professional doctorate program. One of only six institutions in the country affiliated with a peace church, Bedford, similar to Westchester, has experienced town and gown relations that suffered during periods of war, but Hamilton admits that it continues to an extent even today. Hamilton says,

We all know now [when] the university succeeds, their businesses succeed. We all succeed. I think even from the first day I began to try to help the college become more of a part of the community rather than this [perceived] identity that [we were] against community values.

Hamilton's journey to the presidency. Hamilton started with "The journey-it

was not a straight road." She began her career as a high school teacher when she decided to return to graduate school to work on her doctorate. After graduating, she became a professor at a branch campus in the university system of her home state. During that time, she returned to Bedford to teach for several years and received two separate invitations to become its dean of academic affairs. Each time she turned down the offer but accepted their third invitation several years after having secured tenure at her home 
institution. She agreed to work in the position for one year:

[My institution] gave me leave, so I just gotten tenure in the system a year or two before that. [It] has very high hurdles that you have to jump to get tenure. I just wasn't willing to leave that and go into administration full-time if I didn't know I would like it. So, I came over and said I would stay for the year. Then, they ran a national search. I really did enjoy the work, and I actually enjoyed the culture on campus a whole lot more than what I had been in. So, I applied for the job, got the job, and did that for [over 10 years].

When the president of Bedford announced his retirement, she did not consider applying for the position, although she admitted she "loved the academic leadership. It's hard, it's complicated, it's varied, and I really enjoyed being the academic v.p. But I just had person after person come and encourage me to apply for the presidency." While many people encouraged her to seek the position, she said:

My husband and I talked at length about it, because there [chuckles] was this chance that I might get it, and if I did, our lives would be different. His life would be dramatically different, because he was working at Institution X. When I was the academic dean here, you know, my job other than having long days and evenings and stuff, [it] didn't affect our lives very much. Presidencies $d o$ affect families a lot, so we talked and finally agreed that I would put my hat in the ring.

Hamilton went through the search process and was offered the position, which was supposed to take effect the following summer. However, the board of trustees removed the sitting president in the fall, and she was asked to assume the position 7 months sooner than expected. Undaunted, she said, "It was not an easy start to the presidency, although I felt well-equipped, because I knew the institution so well. I mean I graduated from here. Taught here. Was dean here.” Reflecting on her journey, Hamilton chuckled and said:

More men I think than women say [deepens her voice], "You know, when I was in high school I decided I wanted to be a college president. So, if I did this, then got my Ph.D., then I was department chair, then associate dean."

She continued with: 
When the doors opened, I walked through them. It was much more of a meandering journey than one guided by a sense of this is what I wanted to do. Like the pinnacle of my career. I would have been happy to end as a professor [taps her finger on the table]. I would have been happy to retire as a dean [taps table with her finger again]. There was nothing about the prestige of the office that drew me. Some of the access to the information drew me, because I was very curious to know what went into these decisions, because the higher up you get, the more you get to know. That's both a blessing and a curse I know now [laughs]!

\section{President Gloria Kahn}

Kahn is the third president and the first woman president of the University of the State (US). She has served in this position for almost 5 years, originally going to US as provost and vice president for academic affairs. Kahn is a native Midwesterner and has her bachelor's, master's, and doctorate in political science from the same public institution, which is also located in the Midwest. She said with a laugh, "I think politically. I get people saying, 'Don't you miss teaching political science?' I look at them and I say, 'I do politics every day.'”

Kahn described US as having "humble beginnings." It was created in the mid1960s as a branch campus in one of the largest cities in the state and the largest city in the region. It was started with the help of local business leaders who advocated for a public institution in the area, although it was established with great controversy since a private institution already existed in the city. The campus became independent in the mid-1980s

and, according to Kahn, has been transforming itself to raise "its visibility and reputation" beyond the region. Today, State is a residential campus, boasts a student enrollment of almost 11,000 students, and offers undergraduate majors, master's programs, and a doctoral program. Kahn said, "We run on lean, and we run on mean. Relationships are extremely important when you have limited staff. We don't have the hierarchy here that 
you would find [elsewhere]."

Kahn's journey to the presidency. Kahn is a first-generation college-student. Neither of her parents finished high school, and her mother "did not even know there was something called tuition." When her high school counselor encouraged Kahn to apply to an elite woman's college on the east coast, she recollected, "that was so far out of any kind of concept that I had of going to an Ivy League, private women's college." Instead, she decided to attend the local public institution, because she was born and raised in the city and it was a "fine choice" for her.

After receiving her Ph.D., she started her teaching career at a private liberal arts college and taught there over 10 years with 2 years as department chair. She expressed her gratitude towards the institution by saying, "it really socialized me into an academic community and an academic profession. I forged relationships there, and I saw a different way of having community that I've taken with me to every public university I've gone to." With this sense of collegiality and community, she even took vacations with her colleagues.

From there, she accepted an administrative position as department chair in a different state but at a public institution. She described it as a, "highly dysfunctional department. Highly contentious department. One of the senior faculty members was suing four other senior faculty members and the dean! Bless his heart!" Using her political science background, she jokingly recalls the department members as “Hobbesian. It was like a war against all!” Despite the tension, she admitted that it was a "very good learning experience for me. Very good for me" but further described her experience as "very bruising." In this position, she formed an influential mentoring 
relationship with her dean. Despite her desire to stay at this campus, because her husband taught at a near-by institution and they could visit his daughter and grandchildren who lived conveniently near them, the dean encouraged her to begin to consider a college presidency:

I looked at him like [she made a distorted face], because I'm still a department chair, and I thought, you know, I'm just trying to make [chuckles]. We're in [this city]. My husband's happy. You know, he doesn't have to commute so far to come home for dinner and the grandkids are across the river. I mean life is good. 'No,' he said, 'you've got to be thinking about this.'

After being department chair for 3 years, Kahn was offered the deanship of the largest college at a public institution in a Mid-Atlantic state. It was there that she "loved being the 800-pound gorilla [laughs]. I like those [continues to laughs].” She also became:

Very deliberate in all my choices that I was going to be a college president. I was determined to make it, and I was very fortunate because my husband totally supported it. To the point where he took early retirement to come with me eventually. I mean he did not want us living apart again. Yeah, and so he took retirement sooner than he wanted to, sooner than was good for him to come to [Mid-Atlantic region].

Being deliberate meant attending leadership workshops for deans who aspired to be presidents. These provided opportunities for her to meet other women who had similar aspirations. She also credits this university for providing a development officer in college office, which meant:

I travelled across the state meeting donors [and] prospective donors. I liked it. I'm slightly competitive [said softly and slyly]. Those years when we beat the College of Business was golden to me. We stomped the College of Business a couple of years [laughs]. I worked with a great development director there, and we had a lot fun during our road trips. That became really solid experience that I had coming here to convince a board. That experience was key for me. 
She then applied to State for the provost and vice president of academic affairs and served in that role for over 5 years. She described the position as a "disruption for me. Suddenly I was invisible. Not invisible, that's not fair, because I was on the development board. I was visible to donors, but donors understand students, faculty, department chairs, deans, and presidents. Provosts are out there. You know?" After being provost for several years, the president who knew she aspired to a presidency asked, "What experiences do you feel you need?" She replied, "I need to connect with the business community. I need to be able to hear and to learn from that." The president gave her his seat on the Chamber of Commerce Board:

I don't think he minded giving it up [laughs]. For the first few years on the Chamber Board I didn't really say a lot. I just sat there and listened. It was interesting, because I started learning about the different businesses and some of the challenges and how they viewed things. Now when I walk in a lot of those business leaders around the table know me. Never underestimate the power of just showing up, of just being present and listening for a period of time. That was hugely important to me.

Kahn was dedicated to her aspiration to become a university president, so when the presidency at US opened up, she became one of two internal candidates for the position:

This is what I wanted. This is the kind of institution I wanted, because I knew it [finger taps table], and I knew I was the right fit for what they needed. I knew they weren't sure of that. The board members told me up front in the search process they weren't so sure. They didn't know who I was. I was a vice president [and] as vice president you're to be a loyal team member. I mean that's your role. You're not to stand out. So, they had no idea what skill sets I had and whether I could manage being president of the entire university. So, they seem happy with their choice! I'm certainly grateful for the opportunity!

\section{President Carolyn Callaghan}

President Carolyn Callaghan has been president of Eastman University for over 10 years. She is its ninth president and the first lay person to be in the position. She has 
an undergraduate degree and a master's in business administration from public institutions in the Midwest.

Eastman is a religiously-affiliated institution that was established over 80 years ago as a college for women and 35 years later it transitioned to a co-educational campus. Today, total enrollment numbers over 1,100 students, and Eastman offers undergraduate majors, master's programs, and a professional doctorate program. It is located in a metropolitan area with over 140,000 residents.

Callaghan's journey to the presidency. Callaghan mentions that her journey took an "unusual" path and a "non-traditional" one, particularly since she came from the "corporate world." Starting her career as a tax accountant in the utility industry, she was:

Very sensitive to the fact that I was working in what was a predominately a man's world, and I never made that issue. The very first conference that I was sent to [was] this national conference and was, quite literally, with the exception of some of the vendors, I was the only woman there. So, I always tell people that was actually a benefit, because everyone knew who I was, and there was no line at the restroom [laughs].

She continued to work for 23 years for in the natural gas and electric utility field, moving through the ranks of management of a large Midwestern gas company. She held various executive positions in the company, becoming president of the gas business unit that had over 500,000 customers in four states. She was also senior vice president for its electric and natural gas distribution, senior vice president for regulatory and legislative activities; senior vice president for energy delivery; and senior vice president for support services:

Now, you're talking about, oh goodness, millions of customers. It was huge. Basically, I worked in all aspects of this organization except for the power plant [laughs]. The company that I worked for had been through numerous acquisitions and mergers, and when you're a senior executive you're most at risk for losing your position in a merger, because there's only going to be one president, only one CE, your know, responsible for a particular aspect of the business. 
Fortunately, for me, through all of that I managed to retain my position or move into something else at a senior level that gave me an even broader experience.

Deciding that she had been through enough corporate consolidations and purchases, she made the decision to leave the company.

During her tenure in the utility industry, she served on the board of trustees of Eastman, because her company was a "good friend of Eastman." Callaghan was also busy with multiple community service organizations in the area. In this "previous life," she: ....chaired the Chamber of Commerce board of trustees. I chaired the United Way Board; I chaired the community-wide campaign. In other words, very connected. I knew the importance of relationships with legislators, and I knew some of our elected officials both at the federal and state level.

After learning that the current president of Eastman would be leaving, the board of trustees asked Callaghan to be the interim president, because:

They knew I had this background, and I wasn't working full-time at the time. I'm not from [here], but we had lived here, so we had been here for many years, and I had been engaged and attached. So, I think they saw that as an advantage.

She agreed to the position until they could find somebody else. A year later a presidential search started, and she had been the position long enough that "I found there were many aspects of this position I truly enjoyed and decided to put my name in the hat." When asked, "What makes you think you can do this job?" she responded:

First of all, I'm not sure I can [laughs], so let's deal with that first! But I pointed out that I do have background and experience that could be helpful here. I understand the importance of teamwork, and when I was president of a gas company I wasn't an engineer [whispering]. I said I had a team that I worked with and through that process I became educated and we ran the place. I mean that simple. Things are different in higher education than it is in the corporate world, and I do appreciate that, and we've tried to meld the best of both.

She added, "To make a long story short, they did select me for this position," and she has served in that position longer than the national average for academic presidents. 


\section{President Lauren Murphy}

As Columbus Hills College's $11^{\text {th }}$ president, President Lauren Murphy has served in this position for 4 years. She has a bachelor's degree in English from a private institution and a master's in English and a doctorate in Urban Education both from the same public institution.

Columbus Hills University is a religiously-affiliated, single-sex institution in a large metropolitan area with almost 600,000 residents. It is one of two such institutions in the city. Student enrollment is slightly over 1,000 undergraduates and almost 600 graduate students. It offers undergraduate majors, master's programs, and a professional doctorate. Columbus Hills does welcome men into its graduate programs. Murphy emphasized that "we hire for mission. So, if we interview a faculty member, and it isn't clear that person has a passion for social justice, we don't even consider that person. It [social justice] is in the water."

Murphy's journey to the presidency. Murphy thought her path to the presidency was a "very unusual one." Similar to Hamilton, she began her career as a public school teacher and taught English in one of the local high schools for over 20 years. She was an adjunct at the local public institution, then after completing her doctorate, she went to Columbus Hills as a part-time adjunct. When a full-time position opened in its Education Department, she became a faculty member and eventually became Director of the Graduate Program, gaining administrative experience. As a faculty member, she was asked to meet with a major donor who wanted to start a program to prepare career changers who wanted to work in the urban, private schools in the city. The donor refused a second meeting with the department chair, telling the president, 
"Don't ever send her again," because of her negative attitude towards the program. So, the president sent Murphy, who told the donor, "Of course, we can do that! No problem!" This relationship with the donor continued for several years, and Murphy was successful in securing several more multi-million dollar funded projects from him.

About 5 years into her tenure at Columbus Hills, the president asked Murphy, "Have you thought about administration?" She said, "Not really." With that the president responded, "You're good at [it]. I'm going to make you a dean." Murphy coyly added that her successful relationship with the major donor may have prompted the president to think that she possessed the skills for more administrative duties. Then, the vice president for academic affairs and student affairs decided she was going to be an art therapist, so the president made Murphy acting vice president. A year later she was appointed vice president and provost and continued to work with donors.

Then one day, Murphy received a call that the president had resigned, and she became acting president. A year later she was appointed president:

I had never thought about being a president even, you know, when I was vicepresident I thought I would go back to the faculty. We have a history of that here at Columbus Hills with the sisters who were deans. They would go back to the classroom to teach. So, we have a former president whose teaching in the Education Department right now. When I was provost, I certainly intended to go back to the classroom and to teach.

Murphy was never prompted to move to the next level:

Actually, I've never applied for any of these [administrative] jobs. In every case, I was promoted by the president, then finally the board. So, the board asked me to be the acting president in [the fall], then in [the following semester], they appointed me, but there was no search. The only position I've ever applied for at Columbus Hills is a faculty one [chuckles].

While no formal search processes were in place, Murphy clarified that: 
At every point there was a vetting process. There wasn't a search, but when I moved from acting vice president to vice president, the president met with all the department chairs and asked them for their thoughts. When I was acting president, the chair of the board and the provincial leader, a sister was the provincial leader, went around and talked to everyone on campus to see if they were supportive of that move. So, I think I'm right in saying that it was well-received in each case [chuckles].

\section{President Hillary Sinclair}

President Hillary Sinclair has served as Harley State's University for 4 years and is its sixth president. She is a native of an east south-central state, retaining an accent from her home state. She has a bachelor's degree in guidance and counseling from a private institution, a master's in College Student Personnel Administration from a public institution, and returned to her bachelor's institution for her doctorate in education.

Harley State University is a branch campus of the state system and was established almost 50 years ago to serve residents of the southeastern region of the state. There are two major cities in Harley State's region, and Sinclair said part of her responsibility is to "understand how to leverage the strengths of our institution with the needs of our business and community." Harley State's student enrollment includes over 5,000 undergraduates and over 120 graduate students; over $60 \%$ of its undergraduates are first-generation college students.

Sinclair's journey to the presidency. President Sinclair repeats what many presidents have said about their trajectories, saying that "how I got here was probably more non-traditional than some other folks." After she graduated from with her bachelor's degree, she knew she wanted to help people and had been active in various activities on campus. Upon graduation, she enrolled in a master's program in College Student Personnel at a university in the Midwest. This is where she formed a mentoring 
relationship with a faculty member who is now serving in his second academic presidency and who was a nominator for her current position.

With master's degree in hand, she moved back to her hometown to work at a small, private institution while working on her doctorate. At this campus, she held several positions, including coordinator of student development and dean of students. After she completed her Ph.D., she wanted alignment with the other senior staff positions, which were at the vice presidential level, so she and the president created the vice president for student affairs-dean of students joint position. While here, she also taught undergraduate and graduate courses. The president gave her opportunities to work outside of what would be "normal student affairs or the normal student affairs functions," giving her exposure to other facets of university administration:

I oversaw and negotiated contracts with the vending partners, the bookstore and the vending contracts. Those kinds of things. I also oversaw facilities management and custodial services for a period of time when a new president came in. I aligned with enrollment management and learned about advancement. [I was] on some "asks" with potential donors and how they could enhance what we were doing in student affairs.

After the college received a major grant to do some work in enrollment management, Sinclair said that she would be ready to "go and grow" after the completion of the grant. During this time period, she also decided that she wanted "to be a college or university president, and I wanted to go to another institution and find another mentor who could really help me get there.”

She left this position to become vice president for student affairs at a larger, public institution in the South. One of the reasons she was attracted to the position was its influential president who eventually became one of her mentors and presidential 
nominators. In this position, she was again asked to "do things that were not in my

normal purview," including:

Oversee[ing] Environmental Health and Safety for a period of time, which ended up being a 2-year assignment. I tell folks about that a lot, because that was during the time when we had the hurricane there, and so that unit was the lead unit in the preparations, response, and recovery of the hurricane from a campus-wide perspective. Plus, we did a complete review of the unit during those 2 years. When we hired a new director, I gave it back to the other department.

Moreover, she continued to teach undergraduate and graduate classes. While there, she participated in ACE's Advancing to the Presidency Workshop to further explore her interest in leadership in higher education and to create a path to the presidency. At one of the workshops, she re-engaged with her faculty mentor from her master's program who was now a faculty member in the ACE program.

Sinclair thinks that people tend to "underestimate a little bit about the knowledge" she possesses about her current institution as result of her pathway. However, she claims:

Those of us from student affairs, we have breadth of the campus that our academic colleagues do not have, because in student affairs we're looking at the whole institution. We have to partner. I mean when I was in student affairs I had to partner with everybody, so that's what was good for students. I think one of the best characteristics that I bring is this big picture view of the institution.

She continued with:

Another piece is most people in the community... it doesn't matter what path I took to get here. As long as I'm effective in what I'm doing. So, they don't ask me. They ask me about my discipline. But the mayor, the mayors of the communities, they don't care as long as we can have a dialogue and develop a partnership and move forward. So, it doesn't matter to them.

\section{President Kathleen Childs}

President Kathleen Childs has been serving as president of Mathias University for over 5 years and is its $13^{\text {th }}$ and first woman president, succeeding a president with a 20- 
year tenure. This is her second presidency, serving almost 8 years in her previous position of president of a woman's college. Her bachelor's and master's degrees are in English from the same small private institution. Her doctorate is from an elite institution in English literature. She was called to religious life when she was a senior in high school.

Mathias University is a religiously-affiliated, co-educational liberal arts institution that was created as a seminary over 130 years ago. There are over 2,700 undergraduates and over 800 students studying at the masters and doctoral levels. A friend and fellow president told her about Mathias by describing it as, "There's a place you don't know anything about, but it has your name written on it. It's Mathias University, so start studying up. My friend, the president, was right. This one did have my name on it."

Childs' journey to the presidency. Childs assumes that people will think she had a classic move to the presidency, but she actually started her career, similar to Hamilton and Murphy, as a high school teacher with no perceived aspirations to be a college president. After receiving her bachelor's degree, she taught English in an innercity high school, learning how to teach in those couple of years. She recollected, "I was 21, you know, and had all the energy in the world." As often happens in religious life, she received a call from her Religious Superior who said, "We'd like you to pack your trunk, and you're going to come and get a master's degree and a Ph.D. You're going to teach at the college level." When Childs completed her graduate degrees, she returned to her alma mater and "thought I had died and gone to Heaven," because she was content teaching in higher education.

In her late 20 s, she was still teaching at her alma mater and "thrilled out of her mind," when her department chair told her: 
We would like you to be our next department chair. I'm in my late 20s, and I said, 'I can't do that, because all 10 [we were a department of 11] of you have been my professors. How can I possibly be your boss? 'We wouldn't have asked you if you couldn't. We think you can do this.'

As the youngest department chair in the college, she "literally learned administration, and I discovered I had some talents for administration. Loved my teaching and my scholarship. Life went on, and I was a happy camper." After 3 years, she was asked to be division director, "thinking this is what I'll do forever."

More people, including those in her religious community and the vice president, began to prompt Childs to consider higher education administration and encouraged her to apply for deans positions, which she did only to think to herself, "I won't get them but it will get them off my back." To her astonishment, she was offered the position of associate provost of a religiously-affiliated institution in the Midwest. Leaving her home institution with a 2-year leave absence, she worked with an "incredible" provost who had the "greatest professional integrity of any human being I've ever worked for." She taught and worked in administration, discovering "I was good at this administrative stuff." During her first year evaluation, her supervisor told her:

So, you want to stay another year? I said, 'I do. Absolutely.' I don't think you should do that, because you really should be doing my job. You really should be a vice-president-academic affairs. You were born for this job. I'll nominate you, because you really should be doing this [finger taps the table]. We need good vps, provosts.

Childs applied for provost positions, thinking, "I'm not going to get any of these jobs," but secured a vice presidency position at another liberal arts institution in the Midwest. She was able to teach a class each semester and "really, really found, especially working with faculty, this was terrific and had some real gifts for it evidently." Thinking this is a 
job "I will do for the rest of my life," a new president stepped in and said, "You're magnificent, but I have two questions for you. One is why weren't you a candidate for this position when it opened up?" She replied that she was only in her first year and just started to work with trustees and donors. To which he replied, "You ought to be a president someday. Why [not]?” She responded, "Because I'll never teach again, and I would not be able to stand that." The president acknowledged her concern, but added "you really ought to think about it."

She heard these same types of comments for several years, each time responding in kind that you cannot teach and be president. An epiphany came when she celebrated a milestone birthday by skydiving. As I did that I thought, "Oh, Lord. Just apply for a presidency. You won't get it." Her president explained that it would probably take 2 or 3 years before she reached the finals and that it was important to know what type of college she wanted to preside over. She told him, "Small and [religiously-affiliated]. It better be small. I don't know what I'm doing here yet!" She applied for seven presidencies saying, "I won’t get any of this stuff, and I get everybody off my back." Childs became a semifinalist in all seven, but ended up withdrawing from four. She became a finalist in the remaining three and was offered the presidency of each. The one she chose was experiencing many problems, but "I could see so much potential in it." The board satisfied her need to teach by telling her, "Our presidents have always taught." It had a climate that looked upon presidents as part of the faculty, as well as part of the administration. She added:

I went there and intended to go 5 or 6 years. They were in a campaign, and I'd thought I'd see it through. And then we were highly successful. We got in the 
black. Our numbers went back up. All those things that we set for goals, and by the end of 5 years, we'd accomplished all those goals I had sort of set for myself.

After nearly 9 years in this presidency, Childs informed her institution that she was interested in a second presidency and applied to four institutions, including Mathias, and was offered positions at each. I said to the board when they offered me the position, "Only if you let me teach a bit." Mathias had no history of a teaching president for at least 35 years, and so the board was very skeptical of her request. One of board members asked, "How will you have time to do this?" to which she replied:

That's the easiest question to answer. There isn't time to do it, so you just do it, and it will make me happy. It will keep me satisfied. It will connect me with faculty and students in ways that nothing else can.

Childs concluded that her story is a long one, but "it's always a case of somebody called me from the outside. I never thought it up myself."

\section{President Elisabeth Eyre}

President Elisabeth Eyre served 7 years as the president of the University of Bahn and was its first woman president. She has a bachelor's degree in English from a private institution and her master's in journalism and doctorate in higher education are from the same public institution.

The University of Bahn is over 110 years old and offers undergraduate majors, master's degrees, and five doctoral programs. A church-affiliated institution, it has always been co-educational. Of the over 5,200 students enrolled, over 4,000 are undergraduates. Recognizing its strong ties to the community, Eyre mentioned that when she assumed the position, "I needed to kind of invest a little in the city, because we carry the city's name; the university carries the city's name." 
Eyre's journey to the presidency. Eyre begins her journey with, "Actually, my ultimate job was being a tenured full professor. I always thought that was the perfect job." She found herself relatively early in her career with the opportunity to have an administrative position. She was a department chair, and then another administrative position opened. The steps towards administration started, and she ultimately ended up as Provost and Vice President for Academic Affairs at a Research One institution. Being provost was her favorite position and thought she would retire in this position. However, there was an abrupt change in presidents, and Eyre was named the interim president, which "gave me a whole new look at things. I actually found that I really liked the administrative responsibilities of the president and that work."

A number of opportunities came her way as institutions were seeking qualified applicants to fill empty presidency positions. She said:

A number of opportunities came to me, and I decided to give it a try. Was in probably, I'm going to say, 15 or 20 searches at the end of that year. I was not a candidate for the presidency [at her home institution]; I didn't have to leave, but I thought I would. At the end of the year, the University of Bahn presidency came up as one of those. I thought I don't have a shot because it's a private school and I had been at a public institution for 20 years but before then I had been at a private school which was a nice little help to me.

Eyre became the successful candidate, and "it ended up kind of being the perfect job to end my career on, because it took advantage of all the things I had been doing all along the way."

\section{President Ruth Graham}

President Ruth Graham was president of Post College for over 20 years and was its first woman president. She earned a bachelor's degree in English from a private institution and a master's in business administration from a Research One institution. 
Graham, like Callaghan, has retained her regional accent from her home state in the South.

Celebrating its $100^{\text {th }}$ anniversary, Post College is a 4-year, private, liberal arts institution and is one of only seven institutions in the United States that is federally recognized as a work college. As a work college, Post allows each student to receive a tuition discount on the hours they work in the program. Post is also the least expensive private college in the state. An essential part of its history is the college's rise from financial exigency in the early 1980s. After assuming the helm during this financial crisis, Graham asked the board of trustees, "Do you want me to close this in a loving way or do you want me to try and make it work?" The answer was to keep the institution open, and today there are approximately 650 undergraduates.

Graham's journey to the presidency. "The first thing you need to know is that there's nothing usual about me or my presidency or my style or how I got here. You got to know that up front," shared Ruth Graham. She was raised on the campus of a work college in the South where her mother taught nursing and was chair of the department; Graham's father passed away when she was 9 years old. She attended a private liberal arts college where she was a resident assistant and graduated in the early 1970s. Graham remained at the institution as an intern with the Administration and Higher Education program. The president established the internship program, reserving two spaces for men and two spaces for women:

The idea was that it was an introduction to administration in higher education, but also we had extraordinary access to the leadership of the institution, because they wanted the communication and did not want to have the problems that erupted on other campuses through the late $60 \mathrm{~s}$. 
She spent 2 years in the position when she was asked by a friend to be the director of student activities at her mother's institution. Her responsibilities would include supervising dances and keeping track of clubs and organizations. During the 10 years she was in this job, she thought about

...a career path in higher education and had close contacts with small college presidencies and both through my experiences at [my alma mater] [and] because my sister babysat for the [college] president for years, I knew what that life was like. I had no interest in that.

Her boss was "always trying to grow the job as I grew, and I became involved in conference coordination, helping [the college] tell the story about work/learning and that's an essential part of who they are."

There was also a hotel on campus and just before the opening of the World's Fair the manager was fired and Graham's boss asked her, "Why don't you go out there and help out for a few weeks. Life happened, and a few weeks became 4 years." The position "had all the pieces and the pressure of being in a very public, high profile role for me and for the institution." She added:

There was a bed tax, so usually that means you serve on the tourism commission. Gets you into the community meeting community leaders, figuring out how you work with businessmen and women. You're a public figure. People seek you out at church or at Wal-Mart wherever. Just the complexity of managing all those relationships and personalities.

After a new president started at the college, she discovered they did not share the same philosophy, so she decided that "I wanted to go into the hotel business." She started and completed an MBA when she thought a major hotel chain was interested in hiring her, but the phone call from the company never came. 
Instead, she was contacted by the newly hired president of Post College. He was an attorney, former deputy mayor of a major eastern city, and teacher at an institution on the east coast. He wanted two people to be on his leadership team and wanted both of them to be "women because there weren't many women in leadership. He wanted both to be single because the institution was so fragile that he didn't want to move families [tapped her glasses on the table]." The president began his search by recruiting at work colleges. He was told that "Ruth is the person you want. She fits your criteria exactly but she won't go because her mother is ill. He made up his mind on the spot that he was going to hire me." When he finally tracked her down, he invited her to dinner, and they “just talked and talked and talked and talked. And [his] final argument was: "You can't let another work college die. This is your passion. If you don't do this, this college is going to die and you can't let that happen."

Through a student who worked under her, Graham learned:

I knew how much trouble they were in, and I really didn't want any part of that. There had been a lot going on in my personal life. I wanted, you know, a job that was a job I'd get paid for and didn't worry about [pauses then begins to speaks softly] having my heart all wrapped up in. But anyway, he talked me into 2 years.

Ruth was hired and arrived at Post without having been interviewed, without having submitted a resume, and without being vetted in any way. During the first year, Graham was responsible for student life, which "was really everything except academics and development. [Included] physical plant, student life, maintenance." At the end of the first year, Post was in financial exigency. The president decided to:

Let the whole advancement staff go and decided he and his wife would go on the road and raise money. I would run the institution on a day-to-day basis. That was kind of an interesting job. [The president] was not good with people, but he was very bright, and he really analyzed what was needed here, including some pretty 
Draconian cuts. And I was good with people, and my job was to implement. Even in my second year, I didn't have any real input on academic policy curriculum, but you know, I prepared all the documents, managed all the stuff, and hired people, and so forth.

Over the next 6 months, the president's wife experienced health issues that resulted in her leaving the area after Christmas to return to their home on the east coast. Graham recalled that the president "stayed either with her [his wife] or on the road that spring." During the June board of trustees meeting, the president went to the executive session and said, "I'm giving you 30 days' notice. You need to make Ruth the acting president. And he was gone in 30 days, and that's how I became president." She added:

The Higher Learning Commission was scheduled for a visit. So, when they [trustees] came back in October they had no money or no option but to make me president. I mean what were they going to say to the Higher Learning Commission? We were in this huge hole. We hired this guy to save the college. He's left and we don't have a president?

Reflecting on her more than 40 years in higher education experiences, Graham said:

I would say that there is not a single experience in my life from some very extraordinary training opportunities over the years with AGB and CIC and things like that. There's been no better preparation for a presidency than being a hotel manager. You just dealt with the whole gamut of things, which is what you do as president.

\section{President Pat Hutchins}

Pat Hutchins has served as president of Hilliard College for 9 years and is the first lay alumna to occupy this position. She received her Juris Doctor degree from a prestigious private law school in the Midwest, which is located in the same town as Hilliard.

Hilliard College is a religiously-affiliated, single sex college with 1,500 students studying at the undergraduate level. It is over 165 years old and is located in a town of 
almost 6,000 residents and three institutions of higher education. Hilliard is associated with a religious order, which is also located on the campus grounds, but operates independently of the order. The college owns the land on which its buildings sit and the connecting land, but the property around the college is owned by the sisters. Hutchins suspects the leadership of the order may move outside of the United States in the next 20 years, leading her to question, "What does that mean for all that land that surrounds us and all the rest of it?"

Hutchins' journey to the presidency. Hutchins starts her story by sharing that "other than the fact that I do not have a Ph.D._-I'm a lawyer-my pathway is fairly typical" and emphasized that she "didn't seek administrative positions." She became a member of her law school's faculty in the early 1980s and was eventually asked by the dean of the law school to assume an assistant deanship:

I had gotten tenure in the spring. The dean came to me three times over the summer to take this administrative position. I said "no" three times I went home to my husband and said, "What am I going to do? I know he's coming back. I just received tenure, and I'm going to make him very angry, because I don't want to do it [chuckles]. He said, "Sit down and make a list of everything you want in exchange for doing it," which I did. He gave me everything I asked for without batting an eyelash! I learned my first lesson, and that's that I didn't ask for enough [laughs]!

Over a period of more than 15 years, she held this position and a vice dean's position at the law school and "ended up doing a lot of service to the university," because:

Well, until that year, only 11 women had become full professors at the university. When I got full professor, four or five women got it that year. In one sense, we were all kind of twelfth. Every committee in the place wanted women on them.

Hutchins admitted that she served on so many committees at the university, people began to know her. As a result of her service at the law school, when a colleague from one 
committee assignment became the university's provost, he asked her to become vice president and associate provost. In this position, she was responsible for "all faculty personnel issues - hiring, firing, retiring, and rank and tenure. All that for 1,200 full-time faculty." She also reflected:

When I got the vice-presidency I realized that when you care deeply about a place, as I did [this university], and you think you have ideas that can help make it better, then you actually want to do that [chuckles]!

She grappled with the issue of power, then she realized what a position in administration could do:

You know, what surprised me actually was that I never understood a desire for power. It always seemed a little ugly to me, and administration gave me the ability to try to do some things that I thought improved the place. So, I was surprised by that actually, by that part of myself. I realized that sometimes a desire for power comes out of a caring for the institution. Getting things done is not always as straightforward as the world would have you believe [laughs].

During her eighth year as vice president, a presidential search at Hilliard College, her alma mater, opened. She hesitated at first:

My husband and I had a discussion, and he asked me if I was interested. I said about this much [holds up two fingers]. I thought of myself as a very good second fiddle, which is really what I was to the provost and was hesitant about being the out-front person. Just too much invasion of my personal privacy.

Friends suggested that she apply, then "finally a person, who was not my friend," but a colleague" who was a dean at the university said, "You'd do a wonderful job at this. May I nominate you?" She finally said, "Yes," saying “once I made up my mind to apply that was it. I wanted the job." Hutchins was eventually selected to be the ninth president of the institution. When asked about now being the person out-front for the institution, she responded: 
It's still uncomfortable at times, but I've drawn a pretty careful line for myself that's proved useful. That is the world doesn't — most of the time - really care about what Pat Hutchins wants or thinks. They care about what the President of Hilliard College wants or thinks. Sometimes those are not identical, because I may have a personal opinion about something but know that for the good of the institution, the institution needs to do something else. So, that's how I've dealt with that - my personal opinions are not really what's at issue or what's important. It's the president's opinions that matter.

Like I said, those can be different, because my obligation to Hilliard College means that sometimes as president I choose a path that's best for the college but not necessarily what matches with my personal objections.

\section{Chapter Summary}

This chapter introduced the 12 presidents who agreed to participate in this study. Demographically, nine women possess doctorate degrees, two hold MBAs, and one earned the Juris Doctor. Of the seven women who came into their positions directly from a vice presidential position, Sinclair and Graham came from student affairs. Four women held interim presidential positions before being appointed president. Of these, three women were moved up through their current institution; Drummond came directly from the faculty; Callaghan came from the board of trustees via a corporate position; and Murphy's appointment was after being dean of the college of education. The fourth, Eyre, came from an interim presidential position via a vice president of academic affairs and provost position at another institution. Hutchins was the only president who came into her position as an administrator at the associate's level. Sinclair and Kahn are presidents of public institutions and 10 are presidents of religiously-affiliated colleges. McKay, Murphy, and Hutchins are presidents of single-sex institutions. Childs and Fletcher are members of a religious order and Hamilton and Hutchins returned to their undergraduate 
alma maters as presidents.

These women were candid about how they reached the presidency; their stories reflect distinct pathways to their current positions. Many suggested that they were encouraged by mentors or colleagues to pursue administrative positions they never would have considered for themselves. Childs, Fletcher, Kahn and Sinclair had presidents who recognized their administrative skills and abilities to work with others and prompted them to consider moving their careers towards a presidential position. As such, they became more intentional about their career paths to the presidency. Not possessing any aspiration to become institutional leaders, McKay and Graham were identified by presidents who encouraged them to move into higher education administration because of skill sets, including relationship building, developed respectively in health care and hospitality. Eyre, Hamilton, and Hutchins wanted to be faculty members, not administrators, but found that administrative positions provided the opportunities to serve their institutions in meaningful ways. Their administrative successes and abilities to interact with others led to them being encouraged to continue their paths to the presidency. Callaghan, Drummond, and Murphy developed successful relationships with their respective board of trustees through their service activities that led to appointments as interim presidents; Drummond and Murphy were subsequently appointed president by their boards without searches. It is interesting to remember that Childs, Hamilton, and Murphy were once school teachers, Drummond was in farming, and Callaghan was in the utility industry. While a vita chronicles a professional pathway, an interview provided a degree of freedom for each participant to reflect on her aspirations, triumphs and challenges, weaving those into a journey marked with milestones. As such, these narratives help 
inform us that presidents accumulated knowledge on their unique pathways (e.g., academics, farmer, hospital administrator, hotel manager, oil and gas executive, and school teachers) that helped them transition to their presidential responsibilities. These included experiences with managing and projecting budgets and resources, maintaining facilities, developing client bases, collaborating with individuals who may have possessed divergent needs, meeting a variety of different expectations, and being sensitive to relationship building and public relations. Their backgrounds led them to developing an understanding and appreciation of institutional governance, community relations, campus relations, and a sensitivity to the importance of relationship building with a wide array of stakeholders. Even though their backgrounds vary and their institutions fulfill different missions, all the presidents were deeply committed to the position of the presidency, their institutions and to their surrounding communities. This dedication appears to drive their motivation to fulfill the myriad of responsibilities of being a president, including a concern for and respect of constituents both on and off their campuses. The next five chapters reveal the relationships with stakeholders that are significant to the presidents, how presidents identified and fostered those relations, and how they retrieved resources from those relationships. 


\section{CHAPTER V}

\section{WITH WHOM DID THE PRESIDENTS DEVELOP INSTRUMENTAL RELATIONSHIPS?}

The research questions focus on the processes used by presidents to identify and cultivate instrumental relations as well as on the ways presidents capture embedded resources from those relationships. As the first step in answering these research questions, the presidents participating in this study were asked to identify the relationships they have had to build in order to achieve their goals as presidents. On the basis of responses to this question, this chapter details the varying internal and external constituents on whom the presidents were dependent and explains what the interviewees had to say about their relationships with these stakeholders and why they were important. Subsequent chapters explain the ways presidents identified the relationships they felt would be needed and the ways they built and fostered those relationships to acquire institutional resources.

\section{Instrumental Internal Stakeholders}

Table 1 lists the seven internal stakeholder groups with which one or more of the presidents had developed instrumental relationships. These groups are identified as internal, because they are either employees of an institution or are students enrolled in an institution. Each is discussed below. 
Table 1

Internal Relationships Considered Instrumental by Presidents

\begin{tabular}{|c|c|c|c|c|c|c|c|c|c|c|c|c|}
\hline \multicolumn{11}{|c|}{ Private College and University Presidents } & \multicolumn{2}{|c|}{$\begin{array}{c}\text { Public } \\
\text { University } \\
\text { Presidents } \\
\end{array}$} \\
\hline & 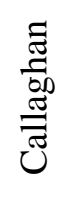 & $\frac{n}{\tilde{U}}$ & 空 & $\frac{\bar{d}}{\frac{\overline{0}}{\frac{0}{I}}}$ & 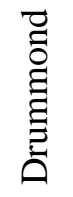 & 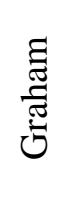 & 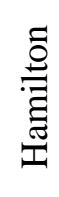 & 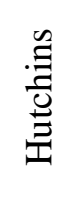 & 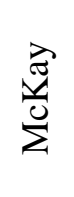 & $\frac{\grave{2}}{\stackrel{2}{2}}$ & 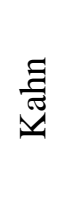 & $\frac{. \bar{J}}{\stackrel{\Xi}{\Xi}}$ \\
\hline Administrators & $\mathrm{X}$ & $\mathrm{X}$ & $\mathrm{X}$ & $\mathrm{X}$ & $\mathrm{X}$ & $\mathrm{X}$ & $\mathrm{X}$ & $\mathrm{X}$ & $\mathrm{X}$ & $\mathrm{X}$ & $\mathrm{X}$ & $\mathrm{X}$ \\
\hline $\begin{array}{l}\text { Advancement } \\
\text { Officers }\end{array}$ & & $X$ & & $X$ & & $X$ & $\mathrm{X}$ & $X$ & & & & $\mathrm{X}$ \\
\hline Coaches & & & & & & & $\mathrm{X}$ & & & & & \\
\hline Faculty & $\mathrm{X}$ & $\mathrm{X}$ & $\mathrm{X}$ & $\mathrm{X}$ & $\mathrm{X}$ & $\mathrm{X}$ & $\mathrm{X}$ & $X$ & $\mathrm{X}$ & $\mathrm{X}$ & $\mathrm{X}$ & $\mathrm{X}$ \\
\hline Staff & $\mathrm{X}$ & $\mathrm{X}$ & $\mathrm{X}$ & $\mathrm{X}$ & $\mathrm{X}$ & $\mathrm{X}$ & $\mathrm{X}$ & $X$ & & & $\mathrm{X}$ & $\mathrm{X}$ \\
\hline Students & $\mathrm{X}$ & $X$ & $X$ & $X$ & $X$ & $X$ & $X$ & $X$ & $X$ & $X$ & $X$ & $\mathrm{X}$ \\
\hline
\end{tabular}




\section{Administrators}

Participants mentioned that relationship building with administrators was critical to the overall leadership of the institution, because these individuals oversaw all aspects of the institution that were critical to its success. Presidents relied on administrators to negotiate members who were from a variety of college positions, including those in traditional administrative slots (e.g., the provost or vice president for academic affairs and the vice presidents for student affairs, business and finance, and advancement), as well as the directors of offices that presidents deemed essential to the mission, such as enrollment management, athletics, and campus ministries. Director titles at one institution may be vice presidential titles at another institution, and vice versa, depending on the campus and president. At one religiously affiliated institution, the vice president responsible for mission was appointed by both the president and the president of the congregation.

Regardless of title and appointment authority, according to Bornstein (2003), presidents should consider individuals for these posts who have the knowledge, skills and expertise that offsets what the president does not possess. In several cases, presidents mentioned that they changed some incumbents after a period of time, including adding members to the cabinet or encouraging some members to step off the cabinet. As McKay observed, "some decided that they would be more comfortable doing something else, working for somebody else. That was fine. Some I encouraged to work for somebody else."

Presidents recognized that they needed to have productive relationships with these administrators and set aside time each week to meet with them. Childs shared that when 
she was a vice president her president never gave her any structured time, so when she became president, she was determined to give them "predictable time." This meant dedicating 30 minutes every other week for directors and an hour for vice presidents, unless they needed to meet sooner. Childs indicated that by providing administrators a specified amount of time each week "they're not picking me to death and I'm not picking them to death, because we both gather our stuff together and when we meet they got their stuff, I got my stuff...” Several presidents shared how they developed those relationships when they first assumed office, such as Callaghan:

What I had to do [deliberately stated] is to really work to develop those relationships with my team, which would be built on respect. So, hopefully as we worked together I would come to understand the work that they do, what they do, and how they do it, and at the same time they would come to understand and respect my background, my experience and how we could hopefully meld the two and create a stronger unit.

Team building was also deemed an essential part of a president's relationship building practice with administrators, as mentioned by Sinclair:

I got a fairly new team. It's taken 3 years to get the team in place. I got some new people starting in August. Building it not only as a team but also building one to one relationships and aligning the vision of how we're going to move forward and maybe not repeat the same mistakes [as other administrations]. We'll repeat other mistakes. We'll do other mistakes but not the same ones that the institution has had.

Kahn was presented a team building challenge when she assumed her position. She was the provost and vice president for academic affairs at State and found herself leading a group of vice presidents who were, the day before she became president, her colleagues. She said their relationships fundamentally changed and the transition had its challenges, because they worked so closely together as peers. 
Presidents also acknowledged that they spent time managing the relationships between their central administrators. As Sinclair commented above, building a team was important, but performing as a team was also critical. Fletcher mentioned that "part of a president's job is to have relationships with each of them, but also try to manage the relationships between them, which is also unique and distinct." Consider Hutchins' comment:

They're in charge of their divisions. They make the decisions. I don't second guess them... I think for me one of the things I did not realize was the time and attention it takes to manage vice presidents and their sibling rivalries with each other. Who does Mom like best?

One president, Graham, recalled what it was like for her during the period of fiscal exigency not to have any direct reports to manage or, more importantly, to rely upon when making the difficult decisions needed to save the institution from insolvency:

There wasn't some kind of executive leadership team that I could count on. There was only [one other administrator] and [myself]...There wasn't any choice but to go to the faculty leadership and staff in key positions and sit down in a room together and say, 'What are we going to do? How are we going to deal with this? And we're going to have to make some tough decisions here. What's in the best interest of the institution?

Once Post stabilized and was no longer in exigency, Graham said she faced a new problem:

As we became more healthy and began to hire vice presidents, then one of the things I really had to do was to step back from that in order to give the vice presidents space just because everyone was used to coming to [me]. I really had to distance myself in order to allow them to take on some of that. Today, there is a layer between me and most of everybody else on campus.

\section{Advancement Officers}

Although the presidents are the major fundraisers for their institutions, they rely on advancement officers whose responsibilities include helping presidents broaden their 
pools of resource rich constituents, businesses, and organizations. Seven presidents considered their relationships with advancement teams as essential to their effectiveness in securing resources for their institutions. Even though presidents developed their own relationships with stakeholders, advancement professionals were also building and cultivating relationships that presidents further fostered to realize resources.

Sinclair said that before she created the position of assistant president for university advancement, there was "no intentionality about stewardship, no intentionality —not enough intentionality around doing what needed to be done" with relationship building. Intentionality was also emphasized by Fletcher, who said that fund raising involved "building a development machine that pulls in good annual funds, identifies and cultivates those kinds of donors." As a result, several presidents noted that they took their direction from advancement officers in terms of managing time and relationships. Consider Childs, who spoke about her development office.

The advancement team runs this whole show...Advancement runs 60 to $70 \%$ of my time, so...I'll give them whole days [looking at calendar]. Like there's a day this week that just says local advancement visits. They handle it. I say to them, "Tell me what you want. Tell me where I'm supposed to go. Give me the briefing materials to do it. Tell me the objective of the visit." So, they are responsible to make all those things happen, and they do. They're terrific.

Hamilton made a similar comment of her advancement staff:

I kind of take orders from the advancement person [chuckles]. Some presidents think they know more than the advancement person. I know I do not know more than the advancement person. I trust his judgment. He and I sometimes go out together, so I know how good he is. I wish I was as good as he is, so I could make you make a donation if I was as good as he is [chuckles].

\section{Coaches}

The only president who mentioned coaches was Hamilton, whose college plays in Division III (DIII). In comparison to Division I and Division II athletics, athletes in DIII 
are not awarded scholarships or other special incentives (Hendrickson et al., 2013).

Bedford fields 19 teams and has 29 head and assistant coaches. Plus, nine staff members, including a director of athletics, are associated with the athletics department. When asked if there were any other relations she thought were instrumental to her, Hamilton said:

Um well the athletic coaches and so on. I don't know all of them, but I try to have a presence with athletics...try to go one of each sport every year. We have 19 sports, and I actually go to a lot more basketball games than football games than that. A little tennis goes a long way! [chuckles] Cross country [laughs]. And wrestling - whoa! [laughs] ...We have a big wrestling meet once a year, and there's [the] morning, it just about knocks you out [walking into the gym] [chuckles]! Whoa! There's a cost to some of this! These are the joys of the presidency we don't tell you! [laughs]

Although Hamilton did not provide any details about her relationships with coaches, she shared that athletics provided her multiple opportunities to be present on campus. She also suggested that these events gave her the opportunity to engage in the life of the institution by doing what some of her constituents expected her to do as president.

I don't [believe] anyone here would say that the president is aloof. You do hear that on a lot of campuses, especially obviously the bigger ones, but you hear that on small campuses too. At a big school, though, I've always thought there was some advantage because either at a big school or a small school in a big city people always assume the president isn't at their event, because the president is at someone else's event. [laughs] Here they go, "There's no place else. She should be here." [laughs].

\section{Faculty}

All presidents mentioned relationship building with the faculty as instrumental to their abilities to meet institutional objectives. According to Bornstein (2003), presidents focus time, energy and other resources towards external constituents, but they should not forget to forge relationships with faculty in order to work towards internal goals. Murphy said that presidents must have the "support of the faculty. The support of faculty is critical in a college or university. [Um] they can block progress [um] very easily, so 
you're not going to accomplish anything without the support of the faculty." The presidents said that they worked through faculty senates or faculty committees, which allowed faculty to contribute to the decision-making culture of an institution (Hendrickson et al., 2013), and several presidents mentioned that the governance structure was how they mainly relate with faculty.

However, not all issues concerning faculty were formally funneled through committees, councils, or senates. Sometimes, presidents in this study worked through informal channels. In this example, Fletcher described how she considered the unique circumstances of departments in determining resource allocation:

The chair of biology teaches a class with 90 students in it. I mean that's unheard of for an institution like us. She has every right to gripe about a load issue. Biology faculty are all sitting with pretty much full loads. Although they have what are called contact hours instead of contract hours. Nonetheless, they are fully employed. When I first came they were an endangered program, but they aren't any more... We hit capacity for them.

As a result of meeting enrollment targets, Fletcher said more resources were directed towards biology. Yet, the Department of Music was under capacity, resulting in fewer resources being channeled to the area. Thus, Fletcher did not include the department in the university's strategic plan, resulting in disgruntled music faculty:

I mean they could quadruple their enrollment and not be even close to reaching capacity, and they [music faculty] just gripe and gripe, but they're in a different place [than biology]. I approach them in a different way, because they do have to get head and hearts around the fact that they aren't paying for the faculty they have and that doesn't mean I don't respect them and I don't love them. There's some tough love in that message. At the same time helping them understand what they do is valuable and important.

Imparting to music faculty about their value and importance was partly done by Fletcher who attempted to educate them about the distinction between what Weldon did 
operationally and strategically. Despite the low number of music majors, she told music faculty that the program remained a critical part of the institution and would continue to be funded. Yet, Weldon would focus on departments, like biology, that were better positioned to meet institutional strategic objectives. Even though she informed the Music Department about the differences between operational and strategic needs, Fletcher recalled one member of the music faculty who continued to publically criticize her decision:

...I mean he's a just a little booger. I have several of them, but he's arrogant, arrogant, arrogant, however it's mainly about being insecure. He's also one of the youngest faculty. So it's a millennial, and they all have a gross overestimation of their abilities. That's a characteristic of the millennials, and I'm not making that up. It's in the research. They really do believe they are God....So, he's screaming and yelling and carrying on, stomping his feet and not doing what everybody wants him to do.

Knowing some of the issues of the music faculty, Fletcher invited the young faculty member to her office with the intention of meeting one of the faculty demands, as well as getting him to back down:

So, I call him in and say, "Okay, so let's talk about new choir robes," and he's like, "What?" "I told you we were going to do operational things. You need new choir robes? Tell me what you want?" And so it is about listening to them and so he's got new choir robes. Suddenly, he's a happier boy, and he's playing a little bit better in the sandbox.

\section{Staff}

Most presidents expressed the importance of staff members to their institutions. Resnick Pierce (2013) stated that presidents generally acknowledge staff by recognizing "their value to the institution, students, faculty, alumni and more" (p. 69). Eyre admitted that "one of the things I kind of discovered in the presidency (and really both of them) and now realize more than ever that the president's real allies and kind of connectors in 
the university" include the staff, because the "day to day work of the presidency depends on the institution operating well." Retiring several days after her interview, Eyre made an interesting observation about her successor:

This is his first presidency, and you know what he is doing? First, he met with all the vice presidents, and now he's meeting with all the academic deans. You know who he oughta be meeting with? You ought to be meeting with, and he is actually meeting with her, communications director, the admissions director, the dean of students, because they are the ones who carry out that work to fruition...Those relationships I think are strategically very important to the president. You'd better have very, very good relationships with the people that are leading those areas.

Those relationships can extend further to include the employees in those offices. For instance, Kahn said, "I try hard to think about this in terms of the people who are delivering on the mission and really providing the hard work that makes us run." She relayed the value she placed on their knowledge and expertise:

Every fall I sit down with the entire admissions staff and talk about what's happened. What's going on, what trends they see, and if you want to learn some things talk to your admissions staff. Wow! They will tell you what's going on on the ground. So, you know, spending that time [with staff].

Childs recognized the value of institutional staff by helping them create a governing body, which allowed them to have a voice in shared governance:

The staff were a disorganized crowed. They didn't have their own assembly. First thing I did I met with all the staff-hourly and exempt. "You folks don't have an assembly, a body, do you?" "No." I said, "We need to change that. You need to elect officers. I'll help you work together to put by-laws together, but you folks need a group that represents the things you think about."

The governing body was well-received by staff, and she required at least one vicepresident to attend each meeting, increasing the recognition and value of the entity. Due to her travel schedule, she committed to attending one meeting a year. 


\title{
Students
}

Students represent many institutional priorities, such as diversity, access, and quality, making student admission, retention, and graduation critical measurements for presidents at any type of institution. All the participants in this study expressed that their relationships with students were essential to their positions. According to Sinclair, "How do you work in a university and not have relationships with your students? So, for me, it's not that difficult." Eyre shared that a "happy student body [is one] who respects the president and sees the president as a leader and taking the university where they want it to go and listens to them and is open and accessible." Moreover, Kahn reflected that students helped her reconnect with the mission of the university:

If you get out of the office, sit down at a table, grab your lunch, students will come around and talk with you [or you can] join somebody. Listen to what they're talking about and after awhile it's like "this is interesting." Because you get so wrapped up in the external pressures and all these things that you forget what is the mission of your university. Go back and listen to those other voices. It's why you got into this in the first place. It's a hell of a lot of fun.

\section{Instrumental External Stakeholders}

Table 2 lists the 13 external stakeholder groups with which one or more of the participants indicated they developed instrumental relationships. They are identified as external, because they are not employees of or students at any of the institutions. Each is discussed below.

\begin{abstract}
Alumni
All 12 presidents considered their alumni as key constituents, because many of their former students were also their institutions' major donors and supporters. Alumni, in general, consider themselves as the guardians of their institutions' customs, rituals, and
\end{abstract}


ideals (Bornstein, 2003) and possess substantial influence that places demands on a president's time, energy, and attention. For Hutchins, being the first alumnae president of Hilliard gave her instant credibility with her alumnae base:

The alumnae think it's a triumph. It was long overdue and that somebody who sat in the same seats as they did, lived in the same housing, and the rest of it. Loves the place like they did. Pleases them a great deal. It really has made my relationship with the alumnae quite easy.

McKay mentioned that Rosemont College's alumni were the institution's largest donor group, and Hamilton acknowledged how important her alumni base was to Bedford:

We have a pretty high donor [rate]; our alums give at about $30 \%$...The majority of people who come to homecoming or alumni events are donors even if they're small donors. We graduate a lot of school teachers and social workers, so we have a lot of donors who aren't big donors but are loyal donors.

However, alumni also tended to present challenges for presidents because, although the institution may have changed since the alumni were attendance, the alumni may still remember the institution in terms of what it was like at the time they attended. McKay mentioned that her alums were "more difficult than people who aren't, because alums have their own sense of what they want it [Rosemont] to be and often times it's not realistic." Fletcher said she had to contend with alumni memories in relation to changes made to Weldon since the alumni last attended:

We went co-ed in 1978. There are women out there who will say, "I love Weldon, but it's not Weldon to me anymore. You let men in and that's it." It's like [to me], "Man, you know, you freeze an institution anytime, and you kill it." Other people [alumni] say, "Now that you do nursing and all that stuff... it's just like a community college." [Saying to herself] "No, it's not." 
Table 2

External Relationships Considered Instrumental by Presidents

\begin{tabular}{|c|c|c|c|c|c|c|c|c|c|c|c|c|}
\hline & \multicolumn{10}{|c|}{ Private College and University Presidents } & \multicolumn{2}{|c|}{$\begin{array}{c}\text { Public } \\
\text { University } \\
\text { Presidents }\end{array}$} \\
\hline & 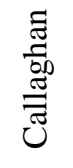 & $\frac{n}{\partial}$ & 空 & $\begin{array}{l}\frac{\overline{0}}{\bar{U}} \\
\frac{\bar{U}}{\bar{I}}\end{array}$ & 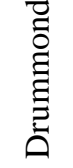 & 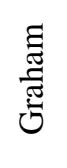 & 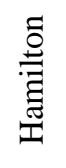 & 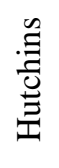 & 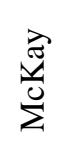 & $\frac{\overrightarrow{2}}{\mathfrak{D}^{2}}$ & 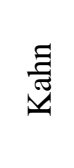 & 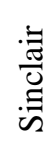 \\
\hline Alumni & $\mathrm{X}$ & $\mathrm{X}$ & $\mathrm{X}$ & $\mathrm{X}$ & $\mathrm{X}$ & $\mathrm{X}$ & $\mathrm{X}$ & $\mathrm{X}$ & $\mathrm{X}$ & $\mathrm{X}$ & $\mathrm{X}$ & $X$ \\
\hline Board of Trustees & $\mathrm{X}$ & $\mathrm{X}$ & $\mathrm{X}$ & $\mathrm{X}$ & & $\mathrm{X}$ & $\mathrm{X}$ & $\mathrm{X}$ & $\mathrm{X}$ & $\mathrm{X}$ & $\mathrm{X}$ & $X$ \\
\hline Board Chairs & $\mathrm{X}$ & $\mathrm{X}$ & $\mathrm{X}$ & $\mathrm{X}$ & $\mathrm{X}$ & $\mathrm{X}$ & $\mathrm{X}$ & $\mathrm{X}$ & $\mathrm{X}$ & $\mathrm{X}$ & & \\
\hline Business Leaders and Economic Development Groups & & $\mathrm{X}$ & $\mathrm{X}$ & $X$ & $\mathrm{X}$ & $\mathrm{X}$ & $\mathrm{X}$ & $\mathrm{X}$ & $\mathrm{X}$ & $\mathrm{X}$ & $\mathrm{X}$ & $\mathrm{X}$ \\
\hline Church Leaders or Members & $\mathrm{X}$ & $\mathrm{X}$ & & $\mathrm{X}$ & $\mathrm{X}$ & $\mathrm{X}$ & & $\mathrm{X}$ & $\mathrm{X}$ & $\mathrm{X}$ & & \\
\hline Community Leaders and Service Organizations & $\mathrm{X}$ & $\mathrm{X}$ & $\mathrm{X}$ & $\mathrm{X}$ & $\mathrm{X}$ & $\mathrm{X}$ & $\mathrm{X}$ & $\mathrm{X}$ & $\mathrm{X}$ & $\mathrm{X}$ & $\mathrm{X}$ & $\mathrm{X}$ \\
\hline Donors and Friends & $\mathrm{X}$ & $\mathrm{X}$ & $\mathrm{X}$ & $\mathrm{X}$ & $\mathrm{X}$ & $\mathrm{X}$ & $\mathrm{X}$ & $\mathrm{X}$ & $\mathrm{X}$ & $\mathrm{X}$ & $\mathrm{X}$ & $\mathrm{X}$ \\
\hline External Organizations & & & & $\mathrm{X}$ & & $\mathrm{X}$ & & $\mathrm{X}$ & $\mathrm{X}$ & & & \\
\hline Higher Education Commission and System Administration & & & & & & & & & & & $\mathrm{X}$ & $\mathrm{X}$ \\
\hline Parents & & & & & $\mathrm{X}$ & & & $\mathrm{X}$ & & & & \\
\hline Political Leaders & $\mathrm{X}$ & $\mathrm{X}$ & $\mathrm{X}$ & $\mathrm{X}$ & $\mathrm{X}$ & $\mathrm{X}$ & $\mathrm{X}$ & $\mathrm{X}$ & $\mathrm{X}$ & $\mathrm{X}$ & $\mathrm{X}$ & $\mathrm{X}$ \\
\hline Predecessors and Presidential Colleagues & & & $\mathrm{X}$ & $\mathrm{X}$ & & & $\mathrm{X}$ & $\mathrm{X}$ & $\mathrm{X}$ & & & \\
\hline
\end{tabular}


Despite the challenges alumni relations presented institutional leaders, presidents tried to find a balance in their relationships with former students, because alumni contributed to the mission of an institution. Thus, the relationships built with this stakeholder group were critical to presidential effectiveness. Sinclair mentioned how she considered this stakeholder group:

...You want them to remember and to have an affinity for their experience but also to be an advocate for what the needs are for today, which may have transitioned over that time period. [Um] so providing, exposing them to the assets of the institution, so that they have stories to tell is one of the key aspect of that work.

\section{Board of Trustees}

The most strategic relationship for participants, both those leading public and private institutions, in this study was the one between them and the institution's governing board, known as the board of trustees. The duty of the board, in general, is to "provide support, guidance, and oversight" for the institution (Resnick Pierce, 2012), and its role in improving the institution, as well as its responsibility for hiring and firing the president, makes that relationship a vital one for presidents (Hendrickson et al., 2013; Resnick Pierce, 2012; Trachtenberg et al., 2013; Trow, 2010). Consider Graham's comment about her relationship with the 26 members of her board: "If there's one [relationship] that's more equal than others, it's your relationship with your board." With a board of 35 members, McKay advised new presidents that "the most important relationship that you're probably going to have, even though you probably want to say with your faculty and students, but it's probably with your board." Murphy of Columbia Hills provided a similar comment, "As president, certainly the faculty is important, but there's a shift in [um] making sure that my relationship with my board [23 members] is 
strong and with the [religious members] who serve at the leadership level."

The composition of boards is determined by the type of institution, and who makes up the board is critical to presidents. Public institutions have politically appointed boards whose members reside within the state and are selected by the governor or legislature; they can have connection to the institution either as alumni or students but are, generally, individuals who are politically and financially connected to the governor (Resnick Pierce, 2012). Board members at private institutions utilize a self-perpetuating process to nominate, vet, and elect new members who commonly live out of state (Trachtenberg et al., 2013); it is noteworthy that several of these participants admitted using their influence to determine who gets on their boards.

Presidents in this study described their board members as belonging to a variety of notable constituent bases, including major donors, alumni, business and community leaders, former college or university presidents, spouses of important constituents, and leaders or members of the institution's church affiliation. Participants said that board members typcially had some type of connection to their institutions and that members tended to be diverse in gender, race, ethnicity, and religion, representing the diversity of their campuses' student bodies. Their trustees were prominent and powerful individuals, who were expected to bring their expertise, political cachet, networks, ideas, and money to their board memberships. Graham said, "You will always have people on the board who are there because they bring certain kinds of expertise that's important to you for various reasons." McKay summed things up by noting, "We look very strategically at where we're going and what do we need to get there? And who in the community is the best fit for this particular point in time." Accordingly, she said that her board was 
considered one of the more high-profiled boards in the metropolitan area but not

necessarily because of monetary donations:

For example, we have the head of the genetics lab from the medical college, and he's often on the Discovery Channel. He has more interns from Rosemont than any other local college, and he's great with students. He doesn't give us a ton of money....He'll always say that he's on the Rosemont College board of trustees, and that's worth a lot to us. We have the head of the largest Hispanic organization in [the state]. He is gold. I mean the governor loves him. The mayor loves him. He loves us. He can get us in front of the media.

Even though political appointees make up her board, Kahn mentioned that most of

her board members were alums, and that:

We've deliberately reached outside the region for a couple of board members, so we're not just the local region. But in fact one of our board members-she's fabulous - is from [the largest city in the state] and is the wife of the former [judiciary member of the state's highest court], and she makes wonderful contributions.

Because trustees can bring a combination of political, social, intellectual, human, and economic capital with their memberships and serve in a volunteer capacity, a president strives towards building positive relationships with board members. Sinclair's institution, Harley State, was part of a multi-institution system that was governed by one board. Nonetheless, she said:

Every time I would go to [the capital] for a meeting whether it be to meet the other [presidents] or [board members] I would go early enough to have conversations with the folks that oversee HR or the folks that oversee that capital planning or the folks that oversee academic programs. So, when a name was mentioned or when I met them or I needed something I had established a relationship, so that I could move some things forward and they could help me. They could help me understand the history of maybe why something didn't happen here or the history of our engagement with [the administration of the system].

Murphy commented that relationship building with trustees takes time. This was not simply because of the large number of members on many boards (Murphy's board has 
20 members), but also as a result of the time needed to truly understand the perspectives and motivations of each member. As Graham noted, "You got to get to know them well enough to know what it is about your institution that is meaningful enough for them to give their time and money. And you got to make that case. And that's true of both donors and volunteers of any kind, but particularly trustees." This was why Hutchins personally visited each member of her board of trustees when she became president:

First, you inherit a board then you build one. So, um when I arrived one of the things that I did the very first couple of months I was here was go and visit every board member. That meant moving around the country. Our board members are in New York, Minnesota, LA, and Florida, but I went and visited every board member. Made a personal visit. I preferred to see them either in their home or their office. So, really on their turf to get a better sense of who they were. [Um] a few um wanted to see me in a neutral kind of place, like a restaurant. So, I met them at their request, but I tried to get to see them, because that helped me get a picture of who they were.

While participants placed emphasis on the social capital of board members, they also shared their respect for their board's role in shared governance and for the responsibility of their boards to provide strategic direction for their institutions. Hendrickson et al. (2013) state that there are five responsibilities of the board, including fiscal and mission oversight, institutional leadership, public relations, and evaluating their own performance. The critical component of its duties lies in its relationship to the president, who is entrusted with the responsibility for achieving and moving the institution's mission forward (Resnick Pierce, 2012). As Callaghan said, the board is "dealing with high-level policy issues," not the day-to-day management or operations of the institution, which were under the purview of the president and her cabinet. According to the Association of Governing Boards (AGB) (2006), the scope of issues facing higher education institutions and their boards, both public and private, include: 
Access, student success, state funding, academic priorities, fund-raising, technology, resource allocation, and many more," and the president and the board have "responsibilities in developing and implementing solutions. Together, working in a culture of shared commitment and partnership, [presidents and boards] achieve institutional success." (http://agb.org)

Respecting the nature of shared governance, these presidents understood that they did not govern unilaterally; they sought advice, counsel, and support from their board members. Eyre considered her members "as the oversight people for the university—-the planners and the big thinkers." The role of the board in strategic planning reflected a statement from Hamilton, whose predecessor had a contentious relationship with the board, "As far as I'm concerned the board [37 members] and the president are a team working together to advance the institution. So, we're pulling together now, and going in the same direction." It behooves a president to have a board that is engaged with the governing process and one that is focused on both the mission and success of the institution. As Fletcher posited:

That's hugely critical. I'm lucky because I have a good board. An [um] engaged board. More so than when I came here. It was pretty much rubber stamp. They're much more engaged and active and responsive and responsible board...keeping their eyes on the prize and not about their individual agenda. It's about look at Weldon overall, and they're pretty good about that. They are pretty good about not micro-managing.

\section{Board Chairs}

Although the presidents diligently worked to develop solid relationships with all board members, they worked particularly hard to create relationships with the board chairpersons. All participants noted that another fundamental relationship was with the chair of their boards of trustees, who was considered a president's "professional boss," according to Eyre. An effective board chair, according to Trachtenberg et al. (2013), 
fulfills the following charges:

Keeping members focused on policy and strategy rather than insisting on consultation on every decision a president is called on to make; ensure that board committees and members undertake their written charges and other tasks promptly and thoroughly; abjure gossip and innuendo; get and give factual information from and to board members; work with the administration to provide board members agendas and other materials well in advance of meetings and insist that members prepare for meetings by reading those materials; and collaborate with the president to inspire the campus and the community as they are the two primary public faces of the institution...(p. 127)

Typical responses from presidents on the role of the chair included "shaping the direction the board takes on an issue;" creating "an environment [in board meetings] that lets people open up and get their perspectives and people aren't intimidated"; and "being on the same page [with the president] about where the college is going, where the board is going." Should a chair neglect to fulfill her/his role, Callaghan (reflecting the viewpoints of other interviewees) shared that an ineffective board chair leads to a dysfunctional governing board, because it is the board chair who engages the attention and talents of the board members. Moreover, as Hutchins commented, "the board relies on the chair's opinion of how well the president is doing. Obviously, they make up their own minds, [but] they know that the board chair knows a lot more about what's going on." Understanding the role of the board chair was essential to their success, so the presidents in this study thoughtfully crafted their relationships with their respective chairs.

\section{Business Leaders and Economic Development Groups}

All but one president mentioned relationship building with leaders from business and industry or partnering with economic development groups that brought together regional business leaders and other invited stakeholders, including education and 
government, to consider expansion projects that could bring more businesses and jobs to regions or communities. Colleges and universities can provide human capital and research facilities to business and industry (Cole, 2009); in return business and industry can provide funding for scholarships, equipment, and grants, as well as internships and jobs. Moreover, the presidents participating in this study turned to business leaders for leadership positions on their boards or for advice and counsel. Functionally, business and industry allowed these presidents to expand their donor and constituent bases. To eventually reap the resources of the business and industry community, Kahn said that she needed to begin to identify and cultivate those relationships with enterprises by describing the potential partnership benefits:

In fact, I'm getting ready to travel to the east coast, and it is literally to sit down with a CEO of a firm that's moved here to town....I'm going with the dean of business. I'm going to lead off by saying, "What can we do better for you? Talk to me." Explain to him where the institution is and how we are trying to position ourselves and how we're trying to elevate visibility and reputation and why we need that help and why we need it from outside the region. We need to be seen as not just a regional institution. We need these kinds of contacts. So [um] these are going to be very key, so I'm working on those now. These kinds of relationships [are needed in order] to build that support network and that advice network for me as a president and everything connects for the university's sake. So, I'm working on building those relationships now.

Sinclair, whose public institution is situated between two major urban areas, also spoke

about the relationship between her institution and business leaders:

I serve on either five or six economic development type work groups in our region....So they made a place for the higher ed leaders at the table for these organizations, and so that's where the nexus of the network [exists]. So from there the movers and shakers in the community may be serving, so I've met then met business leaders who I'd said, "I'd love to come and take a tour of your facility and learn more about your business or have you come here [to campus]." 
Even presidents from private institutions or from rural areas strove to make similar connections. Hamilton, who lived in a region in which many of the automotiverelated manufacturing enterprises declined and relocated off shore, and in which a major farm implement manufacturer moved out, said that when she entered her position she "called on one guy who has a factory here that makes [a product]. It's like a real specialized firm, and I just called and said, 'Would you be willing to show me through your factory?" She did this to get to know business leaders in the community, and she also took steps to introduce herself to the newspaper editor in the city nearest to Bedford.

Yeah, good publicity, you can plant seeds with them...It's actually almost all about visibility, because if we have a very good PR person, and she'll say, 'You know I think the [newspaper] is going to do a story about something, and, you know, our environmental studies grant on the river would be a great example if you call [the editor] and feed him that." So, I do that, and there it is in the paper the next day. So, otherwise you just don't have any other way to get that information in...You never know where it goes, especially since it's on the web. Yeah. For us, just name visibility is really important. Because we're [in an] isolated place.

In addition, most presidents belonged to the local Chamber of Commerce or other types of business-oriented clubs in order to connect with business leaders. Eyre described her participation in these groups:

Then, I ended up being on the executive committee of the Chamber, and that inside group probably gave me more insights. I also joined the [local private club], which is the kind of the business club in town. I was on the [regional economic development committee].

\section{Church Leaders or Members}

Because the mission of a religiously-affiliated college is directly tied to the mission of its church, presidents of religiously-affiliated campuses found themselves developing relationships with members of the church who served the institution in 
different capacities. For example, board chair positions may be reserved for a leader in the church; a certain number of board seats may be reserved for members of the church; a high administrative position, such as vice president of mission, may be reserved for a member of the church; and there may be a governing body that is separate from the board of trustees and that is comprised of members of the church.

Generally, the church or religious order determines the extent of its involvement in the strategic and operational functions of governance. For instance, Westchester's articles of incorporation required that 7 of its 22 board seats be reserved for church members who were selected during the church's annual meeting. Although the board did not select church representatives, Drummond said that the members' involvement in governance added unique perspectives to discussion items as a result of their religious affiliation. The only institution with two governing boards was Columbus Hills. The corporate board was comprised of members of the religious order that owned and sponsored the institution. It was led by a provincial leader who was part of the religious order. Murphy explained that "the provincial leader and the corporate board [have] reserved powers. They hire and fire the president. They have to approve loans over a million dollars or expenditures over a million dollars. [Um] they have to approve board members." This board delegated responsibilities to the board of trustees, which was comprised of business and community leaders.

The presidents, particularly several of the lay presidents, mentioned how they negotiated their roles as institutional leader and as an institutional leader of a churchaffiliated institution. Hutchins said, “It doesn't matter what I think really about those things [church-related issues]. It's about [how] the position of the president of a 
[religiously affiliated] college thinks about those things.” Moreover, Hutchins described

how complex her relationships were with the president of the congregation:

Hilliard College is the hole in the donut. That is, we own the buildings and the land on which our buildings sit and the connecting land. So, we own everything inside the donut hole, but we are surrounded by property owned by the sisters. We have only been independent of the sisters since 1996. That is, we are a totally separate corporation from the sisters since 1996, which is really a very short period of time [chuckles] because we've been here [for almost 170 years]... But the other thing is that the sisters like most women's religious congregations are diminishing in North America. Control of the congregation has been right here. Their mother house is out in the back of campus. Um lots of buildings back there. A lot of people think those are college buildings. They're not on college property, they're not college buildings. They belong to the sisters. Um and there may be at any one time somewhere between 100 and 150 retired sisters living back there. We share a power plant. How decisions get made as to whether we need add a new chiller or boiler or all those things are tricky. Ah and um [pause] we don't own any of the roads into the college [chuckles]. We have a big shared driveway [laughs], so that's a very strategic relationship that I have to manage with the congregation.

Hutchins went on to remark that the congregation had members all over the world and those members would be electing a new president in the near future. She expressed her concern with the election in light of the fact that the president of the congregation worked with the board chair and the university's president:

It's a harbinger of things to come. As long as the college has been here, the congregation has been dominated by U.S. sisters. Clearly within the next 20 years and probably sooner control of the congregation will not be in the U.S. What does that mean for all that land that surrounds us and all the rest of it?

Drummond provided an example of negotiating institutional policy, church tenets, and board and alumni relations regarding the serving of alcohol on campus. Knowing that the church "does not believe in alcohol," she explained to the board of trustees that the university was losing off-campus clients who wanted to use its facilities for 1-day events, such as weddings, because alcohol could not be served. As a result, resources 
were being unrealized due to the strict no-alcohol policy. So, Drummond proposed a 1day liquor license for any function that was not an official university event. This was passed by the board, although each member of the church voted against it. Their votes did not surprise her as alcohol consumption was discouraged by church doctrines; however, she did have to deal with the aftershocks from an alum:

So, when I was visiting some of our alumni...One of the guys, one of the staunch alumni said, "And I want to tell you that I think you're absolutely wrong for letting alcohol on campus at all." And I said, "Well, I'm glad you told me that. Glad to listen to you. You know it was a board meeting." And he said, "Yes. I know it was brought up to the board. And I know the board voted on it. I just want to tell you how unhappy I am with that." "Okay. I will note that in the notes I take."

These examples suggest that presidents needed to have meaningful relationships with their boards, board chairs, church leaders, and alumni who were affiliated with the church. Mismanaged relations can result in a web of dysfunctional relationships that could result in resources being withdrawn, under- or un-utilized, or redistributed to entities other than the university.

\section{Community Leaders and Service Organizations}

Presidents must take care not to insulate themselves or their institutions from the larger community, and the study's participants were in agreement that community leaders were essential to their positions. Several presidents pointed out the multiplier effects their institutions had on their local economies, inextricably connecting an institution and a community economically. They also understood that their faculty, staff, students, and institutional facilities were dependent on community services, such as hospitals, police, fire, electrical, public works, and schools. 
Sometimes, presidents come into their positions after having lived in their communities for years as the result of previous positions in the same area, giving them an awareness of community leaders, politics, and issues. Two presidents, Hutchins and Callaghan, were long-term members of their communities prior to becoming presidents; their relationships with the communities were well-established making them wellconnected. Hutchins remarked:

First of all I had been here 24 years before my presidency, so I had already met $a$ lot of people in the community...Um and um I served on a number of community boards where I met people. I was on the symphony board before that. Even in my old job I was on local boards and so sifting through that is not that difficult. It's interesting, my husband is very active in the community, but with a totally different set of people but that gives us contact with a whole set of different people. And we raised our children here. So, this is home, not just a community that I came to as president. I think I was very familiar. When our children were little we used to go [when] there was an outdoor festival in the summer. Every Saturday night there was some outdoor performance. Our family blanket was right next to the old mayor's and his wife and kids. So, you know, we've been here a long time!

Callaghan also remarked how well connected she was with the larger community prior to becoming president:

...I understood very well the importance of relationships, because with my previous life [as an executive] I was very engaged in the community. I had chaired the Chamber of Commerce board of trustees. I chaired the United Way Board. I chaired the community-wide campaign. In other words, [I was] very connected.

However, most of these presidents came to their positions from different regions

of the state or country, prompting them to cultivate relations with key community leaders in order to develop healthy town and gown relations that could lead to the well-being of their institutions and communities (Bornstein, 2003). For example, Eyre had lived for many years in the same state where Bahn was located but did not know any of the key 
constituents associated with the institution. After assuming her position, she quickly realized what enhanced her leadership capacity was not necessarily "what you know, but who you know." She immediately made herself highly available to community leaders by becoming engaged with local organizations. Graham shared the same sentiments as Eyre, realizing that she also needed to connect with community leaders as soon as becoming Post's institutional leader. She asked a staff member who could trace her lineage to the town back four generations to introduce her to key constituents in the local area:

Mary, you're going to have to give some lunches. I'll pay for them. I'm going to meet people [and] the wives of all these people. I began methodically making those relationships, because as a single woman in a small town you can't survive with [just making] relationships with men, you have to work with their spouses.

\section{Donors and Friends}

Another constituent base that was considered an essential relationship for the presidents was comprised of donors, who tended to be trustees, alumni, community leaders or individuals from other constituent groups, who gave financial resources to an institution. Sometimes, donors may be referred to as "friends" and may give money or time or other resources to an institution. Their donations are often referred to as "gifts" and are intended to work towards the institution's mission. 'Nothing happens until money happens" (p. 91) is an apt description for fundraising at both public and private institutions, particularly with shrinking endowments and revenue streams (Resnick Pierce, 2012). Areas that attract donor interest may include student scholarships, improving facilities, new technology, and endowed chairs (Resnick Pierce, 2012).

Bornstein (2003) posits that donors give to presidents, not to their institutions, lending support to the argument that presidents are considered the major fundraisers for 
their institutions. Emphasizing the importance of increasing the financial capacities of their institutions, several presidents estimated the amount of time they dedicated to fundraising: Drummond - 40\%; Hamilton—20 to $100 \%$; Hutchins—-40 to 50\%; Murphy— $50 \%$; and McKay-60\%. Fletcher estimated that she spent 2 to 3 weeks of every month in the spring devoted to fundraising. Sometimes the amount of traveling confused presidents, as described by Childs:

I attend around the country a couple of alumni events a year, but most of what I do [is] targeted major development-major donor cultivation. Like last week I was in St. Louis [taps table] and in Chicago. This past weekend I was in [pause]. Where was I? [pause] Florida.

Relationship building was constant with members of this group, because if an individual was targeted as a potential donor, then the president strategized, sometimes in partnership with their advancement officers, to tend to the relationship until a donation was offered That process may be fraught with challenges as fittingly described by Graham who said, "Identifying donors who can really make a difference to you, and then it's, you know, with them it's a question of access and a question, increasingly, of how do you get to know them well enough?" Once a donation was made, if it was ever tendered, a president continued to cultivate the relationship in order to ask for another gift in the future. Sustained efforts by these presidents led to significant gifts, such as the $\$ 3.5$ million donation Sinclair secured for a fine arts theatre or the unexpected and unrestricted \$1 million gift that Fletcher used for scholarships and towards replacing windows in the biology building. 


\section{External Organizations}

Participants also indicated that they formed relationships with community members and other educational leaders through external organizations. Memberships in these organizations provided presidents opportunities to connect themselves and their institutions to constituents in the community. Several mentioned accepting invitations to attend meetings for the Rotary, Lions Club, or the United Way. For Hamilton, these invitations allowed her to expand her network and provided her institution with an audience:

So, I just worked hard to get out. I actually am happy to give speeches at little Rotary Club things and outlying communities, because the more the word gets out about Bedford [the better it is for the institution]. I mean it's about 2 hours of my time and then 50 people know more about Bedford, so those people as a group aren't shakers and movers, but they're nestled in those groups.

Similarly, Kahn expressed how these groups gave her a platform to promote her institution to members of the community:

I'm constantly aware that how I represent the institution has an impact on how people think about that institution. I almost never say no to a speaking engagement. I'll talk to anybody, and so I'll go into a room and it may be the Lion's Club and there may be only 12 people there, but I'm not really just talking to 12 people, I'm talking to at least double that number, and triple that number as they talk to neighbors, as they talk to a family member, as they talk to a friend. So, I'm always aware that it's not just the people present. So, I'm very deliberate in how I think about things like that. Some people would walk into a room-big cavernous room — and see just 12 people and go "crap." It's all valuable. It's all valuable. You have no idea in terms of what setting you can help people to understand the power and importance of your institution.

Being a public figure also meant that presidents were asked to sit on various community boards, because their institutions represented education or their positions or areas of expertise brought with them a certain cachet as expressed by McKay: 
I'm on the [board of a local health care system] cause I have a health care background. I'm on so many boards here I could go on and on. I'm on so much stuff it's ridiculous [chuckles]... In a city like [this size], you just get pulled into things a lot, and it's hard to say, "No." Whether there's a task force to improve, you know, reading scores in the public schools to you name it, they expect all of us to be involved. So. I'm on local boards. I chair our seminary board cause it's a [religiously affiliated college], so I have to be active with the [church]. Sometimes I think faculty do not even appreciate how much of a president's time is spent on things that do not directly affect the school.

In turn, these board memberships provided an opportunity to spotlight their institutions as

Kahn shared, but she also concurred with McKay that these memberships vied for a president's time and energy.

Because we're a young university and we're trying to raise our visibility and raise our academic reputation, I've gotten much more visible in the local community than my predecessor was. And, you know, I'm sitting here and I'm chairing a committee for the Chamber. I'm on the local public media board. I'm the co-chair of the public sector campaign for the United Way. [exasperated tone] [chuckles] I'm sitting there thinking, "I must be out of my freaking mind!" [chuckles].

Other memberships included institutional memberships in national organizations intended to advocate, serve, and lobby for similar institutions. Most private college presidents mentioned their current involvement in the National Association of Independent Colleges and Universities and Universities (NAICU) or the Council of Independent Colleges (CIC), which collaborates with NAICU to promote private colleges. Some of the presidents mentioned that they also sat on the national board of NAICU. Other organizations mentioned by the interviewees included the Association of Catholic Colleges and Universities (ACCU), the Women's College Coalition (WCC), and the National Collegiate Athletic Association (NCAA). Presidents sat on the boards of ACCU and WCC. McKay mentioned that these "things are labor intensive, but they keep the name of your college out there, and you've got to build those relationships as well." 
In addition to being a member of some of these organizations, Fletcher was on a national ministry foundation board, sat on the board of trustees of another institution and was a member of the Higher Learning Commission board. She noted:

You have to go to the Association of Catholic Colleges and Universities. You have to go to NAICU... You got the Council of Independent Colleges meeting, and that's when you back from [holiday] break, so it starts like fourth of January. This year they're [CIC] begging that we stay for NAICU, so I'll stay for NAICU...Y You have so many things like that. I mean the longer you're president, the more you collect. You know, when I first came I said "no" to anything external...did nothing for my own congregation for 3 years, but, then, they eventually say, "We have a right to ask you to..."

The two presidents from public institutions did not mention memberships at the national level; however, both institutions were members of the American Association of Colleges and Universities (AASCU), which is the public institution counterpart of NAICU and CIC. While Kahn did not mention her involvement in AASCU, she was involved in the association's New President Academy and leadership initiatives.

Presidents mentioned their responsibilities at the state level and their activities within the state. Presidents in Iowa mentioned the Iowa Association of Independent Colleges and Universities (IAICU), and one mentioned her involvement in the Iowa Collegiate Foundation and Campus Compact. Presidents in Indiana mentioned the Indiana Independent Colleges and Schools (IICS) and involvement in the state's athletic conference. Several presidents in Wisconsin mentioned the Wisconsin Association for Independent Colleges and Universities (WAICU), which lobbies state legislators. Again, presidents noted their participation in these organizations was done with the intention of moving forward their own institutions and higher education in general. 


\section{Higher Education Commission and System Administration}

Both presidents of public institutions noted instrumental entities that were unique to their institutions and states. In addition to her relationships with board of trustee members and state legislators, Kahn spent a considerable amount of time with members of the state's higher education commission. This public body consists of 12 individuals who coordinate higher education by defining the educational missions of public colleges and universities, planning and coordinating the system, and approving budgets. She described her predecessor's relationship with the board as "combative" and admitted that hers is sometimes combative, sometimes consultative:

I'll never forget it was like in 2004/2005 a staff member of the Commission of Higher Education told our VP for Government Relations that there's [names the high research universities in the state] then there's State, and they're not sure what to do with us. [laughs]....I've said this to different commission members is that, "Please don't assume that we don't know what we're doing and yet every program you frame it's as if we don't know what we're doing and our boards don't know what they're doing. For Heaven's sake, don't assume that..."

Sinclair mentioned the president of the system to which her institution belonged,

as well as the other administrative officers in the system as essential relationships:

President [of the system], and I would say extend that to his team, which on his team would be his senior vice president for finance and his senior vice president for academic affairs. Of course, the legal council is all central for us in [the state capital], but why [the president]? One is he's my boss. He does my evaluation. But he's also an excellent mentor. He can give me perspective of things I may not see, and so I would say that one is important. If I can't meet his expectations, because he's looking out for the whole system and how [Harley State] fits, then am I doing what I need to do? He's not a micromanager at all. I have a lot of autonomy and authority. That relationship is really important to me. And I would say all of my supervisors. And he's a colleague, so not just my boss. I rarely call him my boss. I have to work at that relationship in a very positive and intentional way. So, and to understand his expectations and I'm fairly new chancellor, so I think he helps me be successful. 


\section{Parents}

Only two presidents mentioned parents as being a part of their constituent base, and only one of the two, Drummond, elaborated on why she considered them an important constituent group. There was a strong legacy factor at Westchester; therefore, Drummond considered parents as an essential relation that should be cultivated:

How we approach the parents is that this is not a time [for them] to give, because they are already giving us their students, but if we have a good relationship with our parents and getting to know the parents of our students, it is something in the end that once those students are gone if we have that connection. Westchester has a long history of multi-generational families that have attended. And so it's really nice when you talk to parents and they say, "Oh yes I went to Westchester, and now my child goes to Westchester."

\section{Political Leaders}

Most presidents indicated that relationships with local, state, and national politicians were considered instrumental, although the participants appeared to have different levels of needs from different levels of government. Thus, some presidents responded that certain delegations were more important than others for relationship building purposes. Nonetheless, McMillen (2010) posits that government relations affect all types of institutions. Graham noted her strategy in working with politicians:

Increasingly every president has to be politically working in the political arena. It doesn't matter what party it is or whether you like 'em or not. You got to work across the aisle, and you've got to be reasonable and you got to say what you're going to do. Again, trust and respect [in relationship building]. You have to [taps table with finger to provide emphasis].

At the local level, municipalities approve building and zoning permits and liquor licenses, as well as tax abatements, prompting Murphy to say that Columbia Hills tried to "be a good neighbor and to have friends in those places." Beyond her institution's necessity for permits and licenses, Graham said that she needed to be informed about 
ordinances passed by the mayor and city council that would affect her students, citing the enforcement of underage drinking laws as an example.

Presidents of both public and private institutions were attentive to their state representatives. Each of their respective legislatures provided funding for state financial aid to students, so presidents were mindful of building and fostering relationships to secure those resources for students and families. In addition to funding policies, presidents were sensitive to state legislation, such as conceal and carry gun laws that affect higher education as a whole, as well as individual institutions. As president of a public institution, Sinclair noted she was accountable to the state legislator who represented Harley State's congressional district. She shared that he "wants to know with certainty how we are serving his district."

Colleges were also affected by federal educational and funding policies. Most of the presidents said that they make a point to visit their national delegations at least once a year in Washington, DC. If they were unable to directly connect with their representatives, the presidents made sure that they made contact with the legislators' staffers. Childs appointed a "full-time government relations person in our advancement area, and we work constantly ...writing letters or making calls. Doing these visits four times a year." For all these reasons, McMillen (2010) suggests that presidents need to know their delegations and how to navigate the different levels of government to learn how things get done in those bureaucracies.

\section{Predecessors and Presidential Colleagues}

Several participants remarked that their immediate predecessors and presidential colleagues were instrumental to their leadership effectiveness. When a new president 
starts her position, she will be faced with new and unexpected challenges, one of which could be her immediate predecessor. Upon her retirement, McKay's predecessor held the longest tenure as a college or university president in the country. She was also a McArthur Fellow and was well-loved and respected by Rosemont's constituent groups. McKay recalled what it was like to follow a popular president:

...It was hard initially and still is at times. People will [say], "God, you must have been brave, because you have such big shoes to fill." And, you know, after a while-I say this half in humor-“'You know what? I'm not a big schlep [chuckles]. I mean I am competent. You know, if I was so awful [do] you think they would've hired me? I'm not a total screw up" [chuckles]. They mean well, but I tell people when you have a new president, don't keep telling her that she has big shoes to fill, because it's insulting [chuckles]! It really is!

As a result of her predecessor being "bigger than life," McKay also felt that her relationship with her predecessor had benefits in terms of relationship building with the college's stakeholders:

But I love her, and we have a great relationship... I would have to call her and say, "I need you to come to campus, because I want you to meet so and so" or "I'd like you to introduce me to so and so." So, she'd do anything I ask her to do.

Fletcher also followed a long-serving president who was popular with Weldon's stakeholders. Her predecessor was president for 22 years and had her own distinct style of greeting individuals, which included kissing people on the lips when she met them. Similar to McKay's situation, Fletcher's predecessor did “everything in her power to introduce me to people." After assuming her position, Fletcher said her predecessor distanced herself from the campus by going to "Ireland for 2 years to help me become more comfortable" but now "she works with me every day." A daily interaction between the two women included visiting potential donors together. Fletcher credited her predecessor for creating the groundwork for a significant donation: 
I mean we got one $\$ 10$ million gift that came my first or second year, but I didn't get it. [My predecessor] had built and cultivated it. It was a bequest. A widow. No kids. So, those are the ones you go after. It's really sad to think that way [chuckles].

Eyre also commented that one of Bahn's former presidents became one of her "close personal friend(s)," and "he was the one who gave me the most insight into the business network and the leadership network of the city."

Several presidents mentioned that their presidential colleagues played essential roles as confidants or partners. The presidency can be a lonely position because of the sensitivity and confidentiality of information they possess. Many presidents remarked that there were matters that could not be publically shared or even disclosed with their own campus administrators until the appropriate time. Presidents could also be viewed as the "dark side," as Drummond described herself. She shared an effect the presidency had on a relationship with a faculty member:

I had a close friend in the education division and [we] did a lot together...She would say, "People are talking about when we meet. They're talking about what I'm telling you. They're asking if I'm giving [you information]. You know it's just that people are a little bit paranoid." And so I've had to step away from that relationship. And we mutually agreed to do it, but it was kind of tough because she was my one go-to person.

As a result, several presidents mentioned that they looked towards other presidential colleagues for support and friendship to help them function better in their positions. In one example, Hamilton mentioned the names of two women presidents with whom she confided if she had questions or concerns. For instance, she called them to ask, "Have you ever had to do this? Tell me what to do here. Who's a good lawyer? (chuckles)." Kahn said she built a partnership with her counterpart at the private institution in her city to heal a long-standing rift between two sides of the municipality. She explained that her 
public institution represented the low socioeconomic area of the city and the private university represented the higher income area.

The [private institution] hired a new president 2 years after I was in, and so I immediately invited him to campus to visit and sit down. First thing I said to him was "We're here to help this town get over it [rift]." ...We're the joint co-chairs of the United Way campaign. People notice that we come together at social events. We connect and we talk and we have a good time.

\section{Chapter Summary}

Presidents in this study disclosed that they developed and sustained relationships with a variety of individuals and groups inside and outside of their institutions for different purposes. One purpose was to seek and secure stakeholders' resources that were used towards institutional building. By identifying key stakeholders, presidents were aware of the significance of certain individuals and groups to their respective institutions. Moreover, presidents made evident through their narratives how those stakeholders came to hold their values for their respective institutions. Presidents thoughtfully considered the meanings and contributions (e.g., spiritual, monetary, intellectual, leadership, etc.) each constituent group made to the vitality and growth of their institutions. By being aware of stakeholders' values and how stakeholders came to hold their values, presidents made the critical link between instrumental relationships and potential resources. Yet, this link between instrumental relations and resources is not sufficient in understanding how presidents secured resources through their relationships with stakeholders. This phenomenon is further explored in the next chapter, which examines how presidents identified constituents with resources that could lead to institutional outcomes. 


\section{CHAPTER VI}

\section{HOW DID PRESIDENTS IDENTIFY STAKEHOLDERS WITH WHOM INSTRUMENTAL RELATIONSHIPS NEEDED TO BE MADE?}

\section{Identifying Stakeholders with Embedded Resources}

Well, there are so many constituents that I think being a college president is a lot like being mayor of a small town. You got the police. You got the fire. You got the voters. You have the town council. We've got parents. We've got students. We've got alums. We've got donors. We've got board members.

-Pat Hutchins, Hilliard College

Hutchins' mayoral metaphor was in response to an interview question that was intended to learn how a president identified key individuals, external and internal to her institution with whom she could develop instrumental relationships to secure resources. There are two important parts to her reply, as it relates to relationship building. One, she demystified the academic president as the idle and sequestered "president in the tweed coat with the arm patches on the sleeves and the pipe, reading a book. In my dreams! I didn't wear the tweed jacket with the patches on the sleeves." The debunking of the stereotype was further supported by Graham who asserted, "The day of the president who is sort of an academic leader who lives in the ivory tower. That's gone. Some presidents still do a fair amount of that, but the external responsibilities of a president are now extraordinary." Thus, there is an essential aspect of the presidency that requires the president to be visible and connected to others. Second, Hutchins and Graham alluded that the position has social and public components, with Hutchins' metaphor noting 
specific internal and external constituents who are serviced and affected by the president's role.

Yet, being visible and involved in the life of the institution and its community are only means to an end. An integral part of a successful presidency is recognizing the major constituent groups of the institution and understanding that each constituent group is distinct in its goals and intentions for the institution (Trachtenberg et al., 2013). Further, individual constituents in each group may be more invested than others towards the wellbeing of the institution or have more resources or access to resources than others in the group to further the mission. Identifying external and internal relations that are essential to the institution, as well as those that work towards advancing its mission, is a primary function of presidential relationship building. In this study, presidents revealed that they concerned themselves and concentrated their attention on board of trustee members, particularly the chair or leader of the board, community members, business leaders, elected officials at all levels of government, faculty, students, staff, administrators, donors and friends, and alumni. There were also several presidents responsive to members of their respective affiliated religious orders and two others who were mindful of the roles of system administrators or members of a state board of higher education.

The profiles of presidential experiences and the characteristics of their key constituents are germane in addressing the first research question: How do women presidents identify social relations that have embedded resources? The capacities of presidents to identify essential stakeholders with potential resources to move their institutions forward are associated with three instrumental practices that drive and affect their interactions with those constituents. One practice of presidents is ascribing meaning 
to their interactions with stakeholders whom they have identified as possessing resources. Another practice focuses on the intrinsic factors that guide presidents' attention and interactions towards instrumental stakeholders. A third practice centers on how presidents create a presence on-campus and off-campus in order to engage with stakeholders.

\section{Ascribing Meaning to Interactions}

Ascribing meaning to interactions refers to the affected social relations between a president and valued constituents with whom she sought institutional resources. In Chapter V, presidents in this study indicated a total of 19 constituent groups they considered essential to their positions: 13 external constituents and 6 internal constituents. The different responses of presidents reflected the different cognitive maps they used to determine usefulness or importance of certain relationships to their institutions. Their answers also revealed the variety of relationships that were essential to a presidency, reflecting the observation of Trachtenberg et al. (2013) who posited that a presidency comes with a "multitude of constituents, each with legitimate claim to voice on institutional purpose, policy, and performance" (p. 131). For that reason, Childs from Mathias University noted "all [constituents] are crucial to you and your presidency and to the good of the institution."

After identifying the values of constituents to their institutions, presidents ascribed meaning to their interactions with those stakeholders, thereby creating a link between their deliberate efforts towards relationship building and resources that could lead to institutional outcomes. The connection was evident in presidents' responses about their constituents and how those relationships related to fulfilling the essential functions of the position as previously described in Chapter II: fundraising, strategic planning and 
administration, being a campus visionary, and external relations.

\section{Fundraising Function}

The American College President Study (2012) identified fundraising as one of the major areas for which presidents dedicated their time and attention. Presidents of private colleges depend on private funds to support their institutions; therefore, fundraising is a top priority for them. Without monetary appropriations from the state, Hutchins said, "If we need a building, we gotta go out and get some donors to do it!" At the same time, presidents of public institutions are faced with declining state funding, which places greater demands on them to concentrate their efforts on fundraising. In Kahn's state, funding was based on a model that factored in full-time enrollment. However, funding per full-time equivalent student at State was half of what it was for another public institution in her state with lower enrollment, supporting her argument that the funding model was not equitable. For presidents of both institutional types, the nation's economic recession in 2008 spurred rising costs, reduced levels of support from federal and state governments, and decreased endowments, prompting presidents to devote and dedicate themselves to fundraising.

Of all the internal constituents named by the study's participants, advancement officers were most clearly allied with presidents to help carry out the critical function of fundraising. Presidents' relationships with advancement officers were strengthened by the effectiveness of those employees to identify and connect the presidents with potential prospects. As noted in the previous chapter, presidents provided examples of advancement officers who worked towards presidential effectiveness by identifying and cultivating donors with whom the presidents eventually engaged to secure resources. The 
initial communications and follow-up contacts made by advancement officers were critical to successful fundraising efforts, because their interactions with potential donors represented the integration of the institution's mission and vision with resources.

As noted in Chapter V, external relationships that linked presidents to resources included those with alumni, boards of trustees, chairs of the board of trustees, businesses and industries, community leaders, donors, external organizations, predecessors, and politicians. Some of those constituents provided monetary funding to institutions and others served presidents by sharing their networks that led to identifying more potential prospects or providing speaking platforms, allowing presidents to further engage and develop relations with prospective sources. For instance, in a representative quote about the make-up of her board and its connection to resources, Childs offered, "Private institutions have large boards, partly because it's a fundraising factor...[Members are] chosen at least partly for their area of expertise, partly for their fundraising possibilities." Presidents were also mindful of both the realized and unrealized resources that presented themselves to their institutions from the community-at-large. This was the case with Drummond and the alcohol policy at Westchester. She identified a potential source of income from external constituents but still had to rely on her relationships with her board members to make the policy come to fruition. Regardless of which constituent group released resources to the institution, Murphy summed up fundraising best with "If you have a big donor that's very supportive of the institution, you want to maintain that relationship." 


\section{Strategic Planning and Administrative Leadership}

Presidents' relationships with their board of trustees or system's administration or higher education commission, chairs of boards of trustees, central administrators, church members, faculty, and staff were linked to effective strategic planning. This study's participants recognized that effective strategic planning and governance required an alignment between the institution and its environment, and the aforementioned constituents played a vital role in those processes. Presidents not only pursued advice and counsel from constituents with vested interests in either the long term planning or the day-to-day operations of their institutions, but they also sought the inclusion of constituents in the governance process. The inclusion of stakeholders was vital, because presidents received information in the exchange generated through constituent participation in shared governance. For instance, Sinclair pointed out that "building this base of support with the governance leaders is critically important. Getting to know what their needs are, because they're the ones then who represent the needs of this particular group of employees and stakeholders, and they can also take information back."

\section{Being a Campus Visionary}

Presidents' relationships with their internal and external constituents were also linked by the campus visionary role of the president. The study's participants understood the importance and obligation of embodying their institutions' missions, and they were equally aware and sensitive to the necessity of their constituents to adopt and support the purposes and objectives of their respective institutions. For example, McKay said that she framed what she needed to do as president through the campus mission statement. She shared that Rosemont's culture was: 
...Clearly built on assessment and continuous improvements... When you have your own culture, your own language, your own vocabulary, it's easier to get things done... The culture is a very strong culture around what's best for the students. The decisions are always framed that way. Always... Whether it is salary increases or what color to paint a wall. What will the students like? What will be best for them? And it makes my life much easier...

In another example, Hamilton said her cabinet's adoption of the mission of Bedford meant "that group...[has] been able to see a vision for the college that allowed us to keep our mission strong but takes us into some new ventures that will ensure our survivability down the road long term." Thus, a contributing factor to institutional and presidential effectiveness was the relationship that linked the presidents' leadership of their institutions to the stakeholders who carried out institutional missions through their own practices.

\section{External Relations}

Presidents in this study also created links to valuable resources through their interactions with external stakeholders. The participants presented an extensive list of external constituents, giving a sense to the number of relationships that they developed with individuals and groups outside of their institutions. In addition, the diversity of external relationships provided a sense of the potential and abundant resources held by these constituents. Specific resources named by presidents included tangible ones, such as appropriations and donations, and intangible assets, such as good will and positive publicity.

More than just being the primary public relations figure for their institutions, the presidents in this study dealt with expectations from outside of their institutions that ran contrary to internal institutional expectations, needs, or goals, creating tension between 
the institution and its external stakeholders. As a result, presidents were proactive in identifying key external constituents and establishing relationships with them. For example, Graham explained how critical an external base of support was to a small college, like Post, which was located in a small, rural community:

You got behemoths like [identifies two major research one institutions], which obviously on some level have tremendous impact on [names large metropolitan city in her state]. So, I think it varies, but, for us in a small town, you live and die by whether you have made those relationships [with the city council, mayor, school board, and public health officials].

Presidents also linked to the potential resources of external entities by serving on boards that instantly connected their institutions with multiple key stakeholders. Consider Hamilton's comment about serving on a regional economic board that created a nexus between Bedford and the northeastern part of her state:

....It's not a silo world anymore. It really isn't. To the extent that I hang out more with a wider range of people... The more you rub shoulders and hear of the common concerns or concerns you didn't even think about. I think the more then you get power to work together to help the common good. I really don't see it as a zero-sum game.

Albeit a critical factor in examining how presidents identify key constituents, ascribing meaning to interactions in itself provides an incomplete explanation of other practices involved in the identification phase. The following section explores another facet to identifying constituents, further explaining how presidents direct their attention and interactions towards key constituents with useful resources.

\section{Guided Attention and Interactions}

Although presidents in this study were motivated to perform effectively in their positions in order to retain employment, other factors and influences beside job security guided their motivations and attention for relationship building, leading to what Lin 
(2001a) refers to as "motivated action [that] guides interactions. This "instrumental action," Lin explained, "motivates investing—seeking out and mobilizing—in relations and connections that may provide access to social resources" (p. 53). Presidents described being passionate and mission-oriented, being entrepreneurial, being strategic, being perceptive, as well as building credibility, as practices that intrinsically motivated them into action in order to identify individuals with whom to build instrumental relations.

\section{Being Passionate and Mission-Oriented}

Presidents in this study were passionate about their institutions and the unique missions of their institutions. Their levels of commitment towards their campuses were often spoken of as an obligation, a purpose that went beyond their positional responsibilities. Fisher et al. (1988) found that effective presidents in their study felt there was "a sense of moral obligation, even servitude, that gives rise to the feeling that they are making important contributions to society" (p. 82). In this study, Kahn, who was the first in her family to attend college and who received all her degrees from public institutions, espoused a commitment to public education:

So, we've [University of the State] been independent since [the mid-1980s], and since that point if you took a look at this region [in the mid-1980s], one in three high school graduates went on to some form of post-secondary education. About $33 \%$. Today, it's $84 \%$. So, the power of having a public higher education. I talk about the mission of public higher education a lot, because right now it's under attack, and I think it's very important for this nation to appreciate the power and the importance of public education whether it's K-12 or public higher education. I wouldn't be sitting here if it wasn't for public education - access to that.

For Murphy, her sense of duty was directed towards the congregation that sponsored Columbus Hills: 
I think it's important for her [provincial leader] to know what we're doing. Who we are. She's from Dallas, so she had little recognition of the work we were doing. So, I just try to update her on what we're doing to help her understand who we are and to really see how we are critical for the sisters carrying out their mission. With the declining number of sisters, you know, who is going to carry that [mission] out for them? It's got to be the sponsored institutions, and I think as a college we're uniquely positioned to do that. To have that influence on the women we educate. So, I've tried to help her see that we play an important role within the congregation.

She continued with:

...I know, for me right now, knowing that I'm helping the college-leading the college in living out the cares of the sisters is very important to me. With the decline in the number of sisters who are physically on campus...so that's an obligation that I think - that may sound too negative — but that's a gift that I've been given that I take very seriously.

In another example from a president of a religiously-affiliated institution that enrolled significantly more non-affiliated students than affiliated ones, Drummond spoke about how she attempted to connect students to its mission:

...You can take a business card and on the back of my business card...it's our mission statement. And so what I do to connect with students is that I go up to the cafeteria, and I say to the students, "If you know the mission statement by heart, I'll give you a dollar." And I take $\$ 10$ up a couple times a week, and I have generally given away my $\$ 10$. Now, so they know my name. They know the mission statement, so they have to say those five [religious] principles...We provide opportunity for an educational experience. So we provide the opportunities, the students have to walk through the door. It's not only an education, but it's an educational experience, because we focus on education, focus on the social aspect and the spiritual aspect, community, and equality... [voice lowers]. So, it's something for everybody, so I challenge the students to memorize it and then live it, because as I said it's not enough just to know it...

The embodiment of the mission may lead to a "collectivity [which] is an aggregation of actors and primordial groups bound together for the sharing of social capital" (Lin, 2001a, p. 137). In this study, the collectivity was comprised of all members associated with an institution, and the resources that presidents accumulated worked 
towards the benefit of all the stakeholders. Thus, the fidelity exhibited by the presidents to the missions of their institutions was a part of the motivation necessary to involve themselves into the lives of their campuses. This was evidenced by Childs, who also had Mathias' vision statement printed on the back of her business cards. She turned the charge to develop the vision statement into a collective enterprise that involved the campus community:

You have to provide a vision for the university... When I first came, people said, "What is your vision for this university?" And I said, "Good question, but wrong question. Here's the right question. How will I work together with all of you to develop the vision for this institution moving forward?" And we engaged inlonger than it needed to be but I was also getting you know my credibility built with these folks - it was a two year [process] to develop the vision we now have for ourselves, which is to be recognized as - it's on the back of the card - as a leading Midwestern university. Okay? So, it's easy to say. It's clear, and there are a million pieces that make that up. How do I know it's succeeding? Well, I'm five years into this job now. Starting year six, and people are saying it back to me. They'll say, "Now, we're doing this, because it helps us become recognized as a leading Midwestern university."

Trachtenberg et al. (2013) comment that new presidents should seek this type of feedback from the campus community, as the outreach effort helps the president build agreement and buy-in from members. Childs, who started her second presidency at Mathias and who followed a beloved president, was able to use the vision statement exercise as a means of engaging with the university community. Five years later, with a campus internalizing its vision, Childs, who said in a later part of her interview, felt empowered to promote campus interests and to establish new relationships that brokered more resources for the campus. Hendrickson et al. (2013) suggest that "institutional leaders who clearly identify their mission and articulate in unequivocal terms what matters most to them have a greater opportunity to claim a distinctive position in the 
marketplace and to have the greatest impact on society" (p. 9). While the authors consider the mission as "providing [administrators] the rationale about every aspect of the academic, from whom the board selects to lead, to what the curriculum should be to how resources should be developed" (p. 10), these presidential reflections implied the mission was also an impetus that moved the president to seek and engage with stakeholders.

\section{Being Entrepreneurial}

In Fisher et al. (1994), presidents modestly suggest that their success could be attributed to "unadulterated luck"; however, the researchers considered a better explanation as presidents being able "to analyze, to size up situations, and to recognize opportunities and seize them" (p. 84). In regard to relationship building, some presidents in this study described these skills and actions as being "entrepreneurial" or "intentional." Murphy characterized herself as being "entrepreneurial" when she was asked if she thought about potential outcomes from her relationships. Citing a key relationship with a former trustee that resulted in three multi-million dollar projects, Murphy said this relationship started when she was a faculty member in the Education Department at Columbia Hills. She was asked by the president of the university to meet with the trustee to initiate a teacher-training program. The trustee had initially met with the department chair in education who said the program was not feasible. Disappointed with her reaction, the trustee told the president, "Don't ever send her [department chair] again." To repair the relationship, the president sent Murphy to meet with him, and she went with the attitude, "Of course, we can do that!"

I was thinking that this was a great opportunity for us. You know my background is in education so to train teachers and to be of service to private schools in [the city] and to build a relationship with him... but I've always been entrepreneurial, 
so even in my public teaching career I always started groups, so it wasn't out of character that I would just go in there and figure out how to make it happen.

Even as president, she thought of herself as being entrepreneurial "in the sense of looking for opportunities, looking for partnerships, looking for collaboration.” Her spirit to undertake and support new initiatives and opportunities also exuded her sense of confidence. Murphy's self-assurance was apparent in her remarks about her unannounced decision to name the chair of Columbus Hill's upcoming capital campaign; this person had yet to be asked to serve, but she was confident he would agree to serve in that capacity:

He's been on the board off and on mainly on for 25 years, so he really knows the college well. And going into a campaign he and his wife are really well connected in the community and so I knew that I would get her too when I got him... They're probably going to be two of the co-chairs of the campaign. They haven't been asked yet, but [laughs] I just thought they have great connections, and you know a great love of the college so.

Another example of being purposeful was Eyre, who identified a business leader in the city as one of her key relations. She said she considered him a valuable asset to the institution, because he donated to the university; connected her to more people than any other person (he was also president of a professional basketball team); hired one Bahn's marketing professors be a consultant for the basketball team; and supported student internships with the team. More importantly, for her own success, he gave her access to him whenever she needed his advice. She described how they met:

The year he came home [after a 5-year presidential appointment with the United Nations] I knew enough about him that I said I'm going to ask him to be our commencement speaker and give him an honorary degree before anyone else can... You know I just jumped in. I did. I'm going to call him.

Eyre seized the moment, sensing that meeting with him would be advantageous for Bahn:

He's coming back to [this state]. He's coming back, you know, he's going to be back in January, and we have commencement in May and just see if he would be 
willing to do that. I said "Can I come and talk with you? I'd like to talk you about something." I went to his office...I said, "You know what you've done is an amazing thing. We don't have people in [this state] often that have had that impact in the world. Would you come and talk to our graduates?" And he said "Sure [laughs]!"

She did not know at the time what eventual benefits Bahn would incur from the relationship, but she understood this relation could be an important link to resources:

If you ask anybody "Who is the titular head of the business community," it would be [him]... He's just kind of one of those people...if you don't know [him], you just don't know the city. I think I just kind of knew that right off the bat."

Murphy's and Eyre's examples were not isolated cases. In general, participants shared similar instances in which they described themselves as deliberate or intentional, reflecting Kahn's advice that "if you're not intentional, it's not going happen.” This intentionality was shared by Sinclair, who said that Harley State did not yet have a system in place to electronically retrieve potential donors:

The flip side of that [is] everybody's a prospect. So bringing people to campus, introducing them to campus, you know, sort of assuming they don't have a relationship is actually I think been in my favor...it allows us to move in a very positive and very forward direction.

The consequence of not being entrepreneurial in constituent building may be the missed opportunity to meet individuals who have power (political or reputational), wealth, influence, or who know the political landscape of the institution, community, or region (Trachtenberg et al., 2013). It is noteworthy that only two of the presidents in this study were alumnae of their institutions. The others started at their institutions without any previous histories of campus cultures or community terrains. Being entrepreneurial in developing instrumental relationships as demonstrated by these participants helped bridge those gaps. 


\section{Being Strategic}

An assumption of social capital is that "access to and use of better social capital leads to more successful action," (Lin, 2001a, p. 60). Accordingly, another proposition for presidents would be for them to be strategic in their attempts to achieve long-term goals or objectives, including having relationships that would serve as a means to achieve them. Wheatley (2006) proposes that relationships are essential in creating potential and that "nothing exists independent of relationships" (p. 69). In this study, presidents acknowledged being strategic or inferred that they were being strategic in finding potential individuals with whom they could develop relationships to enhance their respective institutions.

All participants identified board relations as their most intentional and key relationship. Upon becoming president, Sinclair said, "building those relationships and getting to know those folks, getting to understand their business, getting to understand their relationship with the university is critically important." Hamilton had a similar recollection about her board when she first assumed the presidency:

I think the biggest new type of relationship I needed to establish was with the board of trustees, board chair, and then key people on the board... That was one area where I felt least prepared moving into it. So, I needed to build good relationships with the board, obviously the board chair, and the executive committee of the board. We have a very large board. We have 37 people on our board.

Board members at private institutions are elected by current board members, unlike public institutions at which the members are often political appointments made by the governor of the state. Despite having these different appointment processes, presidents in this study considered the value of board members similarly. Kahn's board 
numbers only nine; however, she said:

It's $m y$ job I feel to put in front of them as much information as I can to give them both responses but also to call on their counsel and to ask them for direction at times. To ask them how they would look at things.

Callaghan remarked that when she looked at the 24 members of her board of trustees she did not want to see just a list of names; instead, she wanted to know "What do they bring?" Often, board members brought a variety of advantages, as shared by Eyre:

Probably most important of all [relationships] is considered insider out but is the board of trustees. In a private university, the board of trustees are your major donors. A lot of them. We have 36 on our board, so they are the key constituents, because they are both the you know the oversight people for the university (the planners and the big thinkers) and they're the major donors....

In this study, presidents of private colleges maintained that they could exert their influence over the selection process of potential new board members. McKay noted the process at Rosemont:

First of all I can nominate. There's a committee of the board that vets it. So, I can nominate somebody if I want. My opinion would have value. I mean I could say, "No I don't want that person," but I'd very careful before I would do that. I mean I would have to have a pretty compelling reason, because I use my chips carefully [chuckles]...If I'm ambivalent about them, they're not going to cause any harm and somebody else really wants them, I probably wouldn't say, "No," but I will sometimes bring to their attention somebody I know, because they would be a good fit.

A similar story was shared by Hutchins, who said that the "Trusteeship Committee would not appoint someone I objected to. Now, I would have to have pretty strong reasons to object to somebody they wanted to bring, but if I did object they wouldn't bring them on board."

Knowing the importance of board members in achieving institutional objectives, a president needed to be strategic when identifying and selecting potential board members, 
as McKay acknowledged:

I will sometimes bring to their [nominating committee] attention somebody I know, because they would be a good fit. We work hard at having a gender mix, racial ethnic mix, even though we're [religiously affiliated] we want a religiously diverse group. Students are very diverse, so we want a board that represents them. We certainly look for people who have money or can get money. That's important. So, they have to be people who have a network that are willing to introduce us to their network and everyone - we don't have a minimum amountbut everyone on the board has to give a gift to the annual fund every year, as well as to the capital campaign. We just ask that them to do the best they can. We don't have a minimum that they have to give. So everybody $100 \%$ of them give every year. And that's important because when you go out asking other people for money sometimes they'll ask well what does your board do? If you can say, $100 \%$ of my board gives gifts, that speaks to people, because why would I give money if your own board doesn't?...So we look very strategically at where we're going and what do we need to get there and who in the community is the best fit for this particular point in time.

Even though the nomination of a new board member was a shared responsibility, a president's influence in the process was respected, thus helping the president shape the

board. Hutchins concurred with McKay in the construction of her board:

We're looking for areas of expertise that we feel need to be on the board. We're always trying to make sure we keep those areas of expertise filled, and obviously those on a private college board - people who can donate money to the college are extremely important. And people who have the sort of the head who know how to behave on a board and what's involved in board membership.

Lin (2001a) notes that instrumental action "requires access to other social positions (especially those with more or better resources) — That is, for the purpose of obtaining additional resources, more effective actions tend to be initiated towards others who have dissimilar (and presumable better) resources..." (p. 58). Thus, the prominence and stature of trustees was also an essential feature that potentially connected presidents to greater resources, as described by McKay:

We also look at the top 20 largest companies in the Milwaukee area and try to have the most senior person we can from those companies. We do pretty well 
with that. But because we have such a powerful board, I mean I have a lot of CEOs and they give a lot of money, you hate losing that political cache because it's not always easy to replace people of that level.

\section{Being Perceptive}

Researchers on the academic presidency (e.g., Fisher et al., 1994; Resneck-

Pierce, 2012; Trachtenberg et al., 2013) stress that a critical responsibility of a president is to be attentive in their interactions with constituents. This was true of presidents in this study; however, these presidents also paid considerable attention to the interactions key stakeholders had with other individuals. Being perceptive of others' attributes helped presidents recognize relations that mattered to them or gave them reason to approach certain stakeholders. Even though these presidents could not predict eventual resources from these individuals, they seemed to sense that potential, but yet unknown, benefits could be forthcoming.

When she was asked how she identified a board member as a key relation during her very first board meeting as president at Bahn, Eyre reflected:

I think if I've learned anything...is to watch how people interrelate, because out of that you identify who the real decision-makers are, who the influential people are, who the shapers are. That was definitely true with [stakeholder]. I watched how people both liked him and were deferential to him....I knew immediately within the first board meeting that this was the guy who was going to help shape this place... There are about three or four of them [board members] that are the most important people, and he was one of them.

The board member was also a multi-millionaire business leader with significant ties across the state. Moreover, he and his son graduated from Bahn. Eyre shared this as example of how he could shape board decisions:

We were going to bond $\$ 30$ million for a building, and we also needed to build a kind of a recreation center for the students. On the floor of the board meeting, he said "I think we should go ahead and bond $\$ 35$ million, because we need the other 
\$5 million to have some start-up money for this recreation center." He's such an influential person there everybody voted yes. We bonded 35 instead of 30 . That $\$ 5$ million was the core money that we used [to] build. Now, this has been 6,7 years ago. We built an athletic and recreation center after raising other money and putting the pieces together. It housed [a professional football team] when they were here for a [major sporting event]. So when you look back and say "Hmmm did that pay-off? I think so."

Eyre's prediction turned out to be correct. Several years ago, Bahn was chosen by

National Football League officials to be a practice venue for one of the conference team champions competing in a major sporting event, and the local host committee provided additional funding necessary to bring Bahn's athletic facility up to league standards. The telecast was the most watched show in television history with over 160 million viewers, bringing national media attention to the campus, as well as visitors to the campus. In a newspaper interview prior to the event, Eyre said that fall admissions applications could possibly increase based on the attention drawn to the university through media coverage (Indianapolis Business Journal, 2012).

The practice of observing was also instrumental for Callaghan who identified two key board members by watching them in board meetings:

...When I observed them in meetings I found them to be insightful. You know thoughtful and these were two business people and in their own businesses they had wonderful success. So, to me they exhibited the characteristics that I would aspire to and therefore I felt they could be helpful to me.

Even though they no longer served on the board, Callaghan maintained connections with them for advice and counsel; she said that her relationships with these former board members helped her make better informed decisions for the institution:

In fact, what happens then is that I maintain this relationship with them where I can call them or call for lunch or whatever and say 'I'm really struggling with this issue. Can you help me with this?' or 'I'm thinking of this idea that's really out of the box. Okay? What do you think about that? How does that hit you?' So, I have 
continued to use them to point where one of the trustees called two days ago, and I was out, so I hope to make connections tomorrow and he just called to check-in. [laughs]... So when I'm looking at trustees I really view them as-obviously these are also individuals who make beautiful gifts to the institution; they care about the institution, and I respect that and, of course, express my appreciation of them for that - but I really look to them for help beyond that and that is how do we deal with some of these day to day issues.

Childs also took notice of board members who showed initiative during board meetings:

Well, interest, ability to help, general interest, initiative. I think that's probably the biggest single quality - they're showing initiative. There's one guy I brought on this past year, the other trustees are saying, "God, Mike is terrific, isn't he?" I said, "Lots of initiative"...Initiative is probably the biggest thing. They're all smart. They're all wealthy.... They like the institution or they wouldn't have agreed to serve, but he's showing initiative. So, last week for instance and two weeks before that he called [telling her secretary], "Somebody she ought to meet. He's a guy who's never had anything to do with the university, and I'll bet he'll get interested and like it." Both of those people are now interested, and I will do a triple set of briefings - the first one because they won't know us to introduce us and me. And now the next one will be to introduce the campaign. Then the third one will be to ask for a gift. So, he's showing initiative. That's probably the biggest, single quality.

Several presidents were not only perceptive of the resources of certain board members but of community leaders who could also provide support to their respective institutions. In the first example, Drummond identified an elderly couple with whom she had first met long before her presidency as a new faculty member at a faculty welcome picnic the couple hosted at their home. She was not a member of the university's affiliated church, so, as president, she considered the couple instrumental to her effectiveness, particularly since the couple were members of the institution's church and were well-respected community members:

They've been here long enough. They know enough people. They're in the [religious] community. They're in the community-at-large, and I really value [them]. Their son-in-law is now on the board of trustees as well. So, they get information from many different places, and it's just nice sometimes to go to somebody with an outside perspective.... 
Drummond sought their advice regarding a campus chapel that had been shuttered for nearly 5 years. The campus' planning consultants said that people on campus were divided on the issue of what to do with the building; some wanted to maintain it and others thought it no longer served a purpose.

So, I said to [the couple], "What do you think? It's going to take us a lot of money to renovate it." They said, "You have to renovate it. You just have to renovate it, because that would be one thing that [religious community] wouldn't forgive you for."

Although the number of religiously-affiliated students made up a small percentage of students on campus, there were church elders who sat on the board of trustees and other church members who viewed the chapel more emotionally and symbolically than lay persons. Because she did not want to alienate or upset church members, Drummond came up with a plan for a renovated chapel:

So, I said, "Fine. I will work very hard to make sure that gets on the capital campaign." So, what we did instead of having it as a chapel, which I'm not sure how many people would use it as a chapel, we're making it into a fine arts theatre. So, we'll use it as an auditorium. So plays, music performances. We're going to add on to the north side of the floor a back stage and put an elevator in, and so it will be much more usable instead of a church chapel.

In another example of being perceptive, Hamilton was aware of the rift between

Bedford and the town. She understood that the campus needed to avoid further alienating community members. Her campus was associated with a church denomination that was one of the historic peace churches, similar to the Quakers and the Mennonites. She said, “There's a church in town that's that denomination, so those were the people who often would be protesting a war or speaking against engagement in the military and so on." This upset the "the town leaders [who] are like navy veterans [chuckles] you know real patriotic [tapping table]. There has been a town-gown rift that was worse during the 
Vietnamese War obviously when there was a lot more protest, but it continues." In order to heal the relationship, she said she invited two prominent community members to have lunch with her.

So, my first meeting - lunch — in the president's dining room was with these two women who come from the sort of powerful family in town that's got a much more of a typical approach to military and all that stuff. Probably you know more likely to be Republican than Democrat, and a lot of these differences get blown up in a small town.

Hamilton understood that these women wielded influence in the town and that Bedford needed to repair its relationship the community-at-large, starting with them:

We had a great lunch, and quickly I think they already knew this, but I think we all know now [when] the university succeeds, their businesses succeed, we all succeed. I think even from that first day to I began to try to help the college become more of a part of the community rather than this identity that was over and against the community values. There had been so much town gown rift during the late 60s, 70s during the Vietnam War that we hadn't gotten over it yet.

\section{Building Credibility}

Credibility is considered the basic foundation for leadership (Kouzes \& Posner, 2012), and attributes that work towards a leader's credibility can include competency, compassion, honesty, trustworthiness, and inspiration. Being dynamic, visible, respectful and recognizing and rewarding others are also qualities of leaders that matter to individuals. Kouzes and Posner (1993) suggest that credibility is established with one action at a time. Moreover, the researchers posit that a person in a leadership position be sensitive to what she says and what she does, making sure there is consistency between her words and actions. A leader's credibility is typically gauged by individuals in an organization, and the more credibility the leader possesses, the more committed those individuals may be to the mission of the organization. As such, the relationship between 
a leader and individuals presumes that credibility is fostered through a sense of mutual responsibility emphasizing organizational objectives. Thus, leaders should strive towards building and maintaining the trust and confidence of others, who, in turn, will work towards fulfilling the organization's vision (Kouzes \& Posner, 1993)

For presidents in this study, credibility was understood to be an essential component of their leadership and how it shaped their relationships with constituents. Although credibility may have a direct connection to identifying constituents, a president's credibility helped her or him construct relationships that eventually led to institutional outcomes. The first stage of building credibility began with one of the most challenging periods for a new president, the presidential transition. Bornstein (2003) suggests that a new president is closely observed by internal and external constituents for several months or what is referred to as the honeymoon period. Two presidents spoke about their transitions and how they approached relationship building upon assuming their positions. Hamilton had a major advantage than most presidents when she moved into the president's position at Bedford:

They [board members] knew me from my work as the dean. My father had been on the board here back like 20 some years ago... Some of the old members of the board knew him, and so I got a little extra earned credibility that I didn't earn myself from this fact that she comes from family that you can count on to make good arguments, tell the truth, that sort of thing, the boy scout test.

Nonetheless, building her credibility with the board was essential for the start of her presidency, because the previous president had a contentious relationship with the members and left the university with financial deficits and a declining enrollment, as well as an 8-year-old capital campaign that basically stalled. In fact, the board released the incumbent from his position 2 months earlier than expected and requested Hamilton start 
her presidency upon his departure. She assumed the position understanding the importance of her board:

That was one area where I felt least prepared moving into it. So, I needed to build good relationships with the board, obviously the board chair, and the executive committee of the board. But also the we had a couple key, dominating board members that I was more worried about establishing credibility with a couple of those key people - head of finance committee particularly — than some other members.

Unlike her predecessor who saw the board members as adversaries, Hamilton recognized that the board had "good will" towards the college.

I saw right away this huge shift we needed to make, and we did say [that] the board and the president are all going in the same direction... I just pledged to transparency and that was how I would do it anyway. So, I think a lot of my natural comfort with openness and good conversations across differences and the thought that smart people can disagree on things but that they we all have the good of the institution at heart gave us a lot of power to get out of that difficult situation.

Kouzes and Posner (2007) suggest that a leader-constituent relationship based on mutual regard and trust will have a longer sustaining value associated with it, and Hamilton's approach to relationship building was grounded in her own authenticity:

Luckily, I think most people would tell you this-I am who I am. You know, I don't act one way in one setting and a different way in a different setting... but I also haven't tried to change who I am. I mean I'm an informal person. I'm fairly candid about things, and I haven't tried to become stuffy or more dignified...It's hard enough to be president, but to try to be somebody you aren't would just add too much extra to it. So, they [board members] knew who I was when they hired me, and I think that's partly why they hired me....It would be too exhausting I think not to [be myself].

In another example, Childs followed a president who was adored by his

constituents. Her predecessor's career at Mathias spanned a total of 40 years; for 20 years he was the dean of students and vice president for students, then the next 20 years he served as president. She remembered: 
People were worried. The board made him president emeritus, which they should have done - and I was going to give him an office on campus in the advancement area.[One trustee] said, "This is not good. He'll still continue to be the president. I really am [worried], because he's such a dominating figure, and he's sort of been 'Mr. Mathias' for all these years." I said, "Okay, how about this? A year from today...I'm going to give you a call, and ask you if it's unclear who the real president of Mathias University is." Two months later, it's the beginning of October we're having our first board meeting, and as you would imagine by that time I've been talking at every Rotary Club, Lions, Chamber, you name it. And at the end of the board meeting, I was, you know, standing at the door, shaking board members' hands as they're going out, and [the trustee] came up and she said, "Great meeting, and by the way you don't need to call me [next year]. You're the President of Mathias University."

While building relationships and credibility with external constituents, Childs was also trying to build her internal credibility with faculty, whom she said are "stunned to have a teaching president." When she realized that one of her responsibilities was to review tenure decisions, she said she was "stunned" to have that "enormous responsibility." Childs was also surprised to learn that her predecessor did not read any of the tenure files; instead, he relied on the recommendations of the vice president for academic affairs. During her first round of tenure decisions, she mentioned that she would need to take the entire holiday vacation period to read through faculty portfolios. She stated, "If I'm making this decision, I'd better read every word you submit and everything that everybody else submits. So, my credibility with faculty went sky-high.” As a president who started her career as a faculty member and who continued to teach during her two presidencies, Childs' credibility may have increased with this constituent group as a result of her valuing an academic process and tradition that holds tremendous meaning to faculty.

Forging shared values with constituents is the "result of listening, appreciating, building consensus, and practicing conflict resolution" (Kouzes \& Posner, 2007, p. 66). 
To do these activities means that presidents have to make the decision to commit and devote their time and energy, both of which are finite, to the practices that help deliver intended messages. For Kahn, she decided that she would personally deliver the message that State's budget could not support a permanent salary increase for a second year in a row. She spoke with employees in each individual college and in each division, including the two evening shifts, because "I felt it was important to stand there and to hear the pain from this [decision], some of the concerns from this [decision]." Kahn also used the meetings to seek the campus" "permission" to hire new academic advisors in order to increase State's retention rates, as funding models in her state were based on enrollment figures.

I just put that out in front as we were talking, saying in the long run it will position us in terms of the performance funding formulas, but in the short term it's going to be another year of difficulty. So, what I'm actually trying to do is to look at other resources we may have. We can't do a permanent increase, but there may be something else we can do.

In addition to seeking affirmation from campus constituents about long-term planning, Kahn's presence at multiple meetings at various times, including 10:00 p.m., was also intended to be a signal to the campus that the people in the organization and their concerns mattered to her. For instance, the day after the evening presentation to shift employees, Kahn said one employee told her:

What we liked is that you didn't come in with the vice presidents. You came in alone. You didn't come in with a phalanx, with a line-up of the guys. You came in by yourself and gave us the information and said this is how it is.

Establishing shared values consisted of presidents involving themselves in the life of the institution by meeting with campus stakeholders. For Callaghan, she thought that people on campus knew that she cared "deeply" for the campus, and that she would never ask 
someone to do something she wouldn't do for herself. By being an example for the campus, she believed she set the tone for others and felt people respected her for that. Part of her approach was to engage with people from across campus to seek their ideas and opinions:

I'm having lunch today with a group of staff members in my office and last week a couple of faculty. In a couple of weeks, I've got some administrators in. I always thrive on that connection with people who are serving our students every day and hearing their thoughts and observations...

Sometimes, there was no systematic process of connecting with constituents. For instance, Kahn went to a student dining center for lunch and saw one of the opinion leaders who taught in the biology department:

Got a major donor who wants to build a project on campus and is willing to fund the entire thing. Very generous. I'm concerned about the location for environmental reasons and aesthetic reasons. I'm not sure. So, [I see the faculty member in the cafeteria] I tap on him, and say "Jim, I need your help. Can you come over and look at something?" And so he comes over and looks, because I know if there is going to be a reaction to this Jim is going to have a powerful, important voice in this. So, I showed him and said, "This is not settled. You're seeing the schematics on this, because we're trying to respond to the terms of what it might look like." Initial reaction from Jim is, "Yeah, I can understand this, but there's some other people you need to talk to." "Okay, send me a list. Who do I need to be talking to?" I want to make sure that this is vetted. I don't want just to make this decision with me, the foundation president, and vice president for administration and foundation. I want the campus community to know what's going on, so that this does not seize or catch them by surprise.

In one of her responses, McKay disclosed that "listening, listening, and listening" brings greater understanding. She said that listening to others was a cornerstone of her relationships and asking for help was critical for presidents, because "you don't always have to have all the answers. I think what I've learned is not to have all the answers and just to say 'I don't know.' Presidents, she described, sometimes think they have to have all the answers, but they need to take opportunities to listen and to say, "That's a great 
question. I have to think about it or I'm going to have to get back with you."

Internal relations were critical to presidents, but so were external relationships and credibility had to be built with these constituents, some of whom presidents considered to be the movers and shakers in their communities or regions. All presidents mentioned being connected to the Chamber of Commerce or local or regional economic development corporations, business alliances, or workforce development boards in order to help build the nexus between higher education and business. Two presidents shared their experiences with these constituent groups, as they attempted to build credibility as a woman executive in a predominately male world. Graham reflected how she used Post's financial exigency history as a means of building credibility with business leaders who were initially dubious of her leadership:

It [relationship building] is different in [the] corporate world, and it's different in the political arena but one of my predecessors way back said to me, "Ruth, don't ever forget that these guys [leaders of large corporations] are really lonely and you're one of the few people who can be closest to them." And I found that to be the case...there are a lot of people who have a lot of power and money and not a lot of people they can trust. And there is a certain amount, certain degree to which [my predecessor] was right in that [pause]. I've had conversations with corporate executives transformed when the conversation somehow got to the fact where at some point I had to lay off 40 or 50 people. Not quite that many, [but] a big number. I think there are very few people for whom that's not excruciating. You do it because you have to, and it's a rare person to know what that means to those people and their families and so forth. I've had conversations completely transformed by corporate executives who took one look at me, and, you know, thought she lives in some college ivory tower and doesn't understand the real world. Then we get to talking about the early years of my presidency and suddenly it's like, "Oh, you have lived in my world." And those have led to some productive conversations... for me it's all about being real and honest and respectful.

In a second example, Eyre said that being located in a metropolitan area gave her greater access to business leaders for the purpose of developing and expanding her 
networks, as well as helping her build friendships that would identify the "players." She described how she attempted to build credibility with chief executives officers, most of whom were male.

So, you go after the big guys, and you develop those relationships on a professional level, and you get respected as a business leader yourself. You have to present yourself as an equal CEO. When I served on the executive committee of the chamber - that's about 30, 25 people I guess - they are clearly CEOs of the major businesses in town, and I'm sitting there too and I act exactly like they do. Exactly. I'm just as aggressive. I'm just as outspoken. I don't say "We're just a university," but I say I manage a mid-size business, have more employees than many people sitting around this table, I'm not that overt, but that's how I think. Then you sort of get the respect I think that you have to have. But women start one step back from men. They just do. They don't think you're not good, but I call it that "pat on the head syndrome." "Aren't you smart? Yes, I am. I am the CEO of a major business. Thank you." There's this condescension that you have to prove yourself. That's really been a goal of mine (pause) to be a player.

Regardless of the constituent group, Graham said that people, in general, want "honesty, consistency, fairness. They want to be respected, and you have to meet them where they are and really respect them" and that your relationships have to be about the "institution and about integrity and respect."

In addition to ascribing meaning to interactions and guiding their attention and interactions towards key constituents, presidents also had to create a presence in which they physically inserted themselves in the lives of their campuses and communities to identify constituents with possible resources.

\section{Creating a Presence}

Relationship building is not a passive process; instead, it requires actions on behalf of an individual. In this study, presidents ascribed meaning to interactions that then motivated them to direct her attention towards key stakeholders. Another practice brought forth by participants was creating a presence with stakeholders whom they 
recognized as possessing potential resources for their institutions, or as Eyre shared, "who can tell you who are the players." Being able to make distinctions between stakeholders is critical, as Lin (2001a) contends that this type of instrumental behavior aims to "trigger actions and reactions from others leading to more allocation of resources to ego" (p. 46). Participants admitted they could not predict what resources, if any or how much, they would be successful in obtaining for their institutions. This unpredictability motivated them to expand and to sustain their constituent bases. All the presidents realized that building a base was first initiated by inserting themselves into their campuses and into their larger communities, so that their actions could lead to relationships that produced resources for their institutions.

\section{On-Campus Presence}

Most presidents described how they engaged in the life of their institutions. They concurred that they needed to be proactive about being visible in order to connect with constituents and to learn more about institutional history, culture, and needs. Fletcher recalled her first year in office:

I said I would spend my first year listening. And so I really did spend my first year listening. I met with every single department. I met just tons and tons of folks. I mean I was introduced to everybody under the sun. I think I met-we counted up at one point -700 alums in my first year. I mean I really did work hard at going out and meeting people. But for me, the most important thing was to establish relationships on campus.

She also shared how she met new students and engaged with them:

[In my first year], I initiated [an event]. I have all new students to my home for dinner. By the time I make it through nine nights of tacos, I never want to see another one [taco]...I go to sporting events. I go to their artistic events, like I do those kinds of things that are here. 
Meeting new students and working with student leadership was also essential to Childs

who described her interactions with them:

I work very intensively with students and with student leadership. Every month I have a breakfast meeting with the student leaders. Talk about what's going on. They love that... I cook a dinner for 10 students [every month]. It's a barrel of fun, and I love it... Try to maybe one or two athletic games a semester, but that's all I manage.

Several presidents mentioned that they used formal settings to establish

relationships with faculty and staff on campus. Hutchins mentioned during her first

several years as president she hosted a series of meetings to meet with constituents:

[During] my first few years, and I haven't done it in the past couple, probably a mistake...I would announce Tea with the President [every semester]. No tea was served, but it was late afternoon, and I'd sit myself down in a room in each of the academic buildings, and I would say, " $4: 00$ on Wednesday afternoon I'm going to be there for at least an hour. If you want to see me, come." It was sort of like office hours but in different academic buildings... So, I went to four buildings, once each semester, and just sat there and talked to people, answered questions. So, I was never by myself.

In comments that reflect the observations of other participants regarding annual

convocations, faculty senates/councils, and invitations to departments, Sinclair said when she first started as president she sent a call to every department that she would attend a department meeting:

There were only a couple that [I] didn't [attend], and I think it was [due to] some internal issues. It wasn't personal. They're departmental issues. So that was a really good use of my time then was able to match up who was with what department. We're not that large, so I really should be able to call everybody by name.

In order to continue to engage in the life of the institution, Sinclair continued with making efforts to make her presence known on campus.

I go to faculty presentations. I speak at every faculty senate meeting. They have a chancellor's report. I take questions at those meetings. Let's see. What else? I 
meet with faculty governance. We have two convocations a year - one in the fall and one in the spring - and so everybody on campus is invited to that. I stop and say "Hello" to faculty, because I know them by name... I know a little bit about them-we can have a dialogue, so, I rarely try not to turn down an invitation if it's from a faculty member [chuckles]. So, you know, it's with intention.

The underlying purpose of attending these meetings was to connect with campus

constituent groups, as well as identifying key people in those areas. Consider Hutchins comment:

I mean I've chaired search committees before I even arrived I had to find a CFO. We were without a CFO, so I had to chair a search committee with faculty to find a CFO. You know you just kind of start meeting people. Then, you see who the faculty elect to various things. You know who they respect. So, you watch! Their signals are pretty clear - the signals are pretty clear-about who's respected and who is not.

Several presidents also mentioned informal measures that are used by them to connect with members of the campus, such what Hamilton did at Bedford:

We only have about 250 employees here, and I don't know them all by name, but I've been here forever, so I know a lot of them. So, I wouldn't say I've workedcertainly I've worked hard at the relationships with cabinet, but the others have come from the normal interactions of life... I had lunch today at a table with two custodians, [the] multicultural director, a faculty member, graphic arts person, our grants writer, and somebody's brother (I don't know whose brother), but, yeah,...I like to be out and about. The Undercover Boss television show would not work here!

Hamilton proudly mentioned that U.S. \& World Report would be naming Bedford as one of the best colleges to work for in their upcoming, but not yet published, edition. She also added that she did not take any credit for the institutional kudos.

\section{Off-Campus Presence}

Presidents spent considerable time during their interviews addressing external relationships and how they made themselves available to others. There was a sense of enthusiasm in their voices regarding meeting external constituents, but there was also a 
sense of urgency to identify and establish those relationships. For example, Sinclair said, "I'm new to [the state]. I'm new to the Midwest, so I had to establish relationships quickly and authentically in order to understand how to leverage the strengths of our institution with the needs of our business and community." The sense of readiness to build her base was supported by Hamilton who said, "I knew I quickly wanted to meet key people in [town]. I've lived [out of town] most of my adult life, and I didn't know the shakers and the movers here," and by connecting with them she could also learn more about the concerns of businesses and what role Bedford could play in their success and vice versa.

There were multiple examples from presidents about the processes they used to identify key individuals. Many presidents spoke at length about business leaders, perhaps because business leaders tended to be the major donors to these institutions. When Graham assumed the presidency, she embedded herself in various community organizations in the community, including the Rotary, which gave her access to key constituents. It is important to note that Graham was a single woman living in a rural community who assumed a presidency in the early 1980s. She spoke about her strategy to meet people in the community:

I went to church. I was active in the church. I was on the Chamber board. Eventually, before too long I was on the hospital board. You know, I was on the Rotary, because that's where the men in this town [worked]...the business men, the non-farmers. There's a lot of money in this town that's farm money, but the businessmen, the bankers, the lawyers and stuff were primarily Rotarians. So, I was the first woman ever in Rotary. The only reason I was admitted was because the president had always been a Rotarian. That was the winning argument.

Even if constituents do not donate, they may possess reputational capital that can lead to other connections. Kahn said of one business leader who was on her board, "He is 
not as vocal in some ways but is very effective and simply has national connections that I think through his network can help us spring board beyond the region. That's what I'm looking to do [fulfilling agenda]." In a similar remark, Eyre said, "I used the board a lot of times as a network. In fact, I told them over and over again is that the most important thing they could do for me was to be a network-introduce me to people, get me connected with people." Fletcher also used her contacts to expand her constituent base of business leaders:

Many of the donors to the institution that I engage [are from the] in corporate world, the CEOs and those kinds of things. I see them constantly through the [city's development board]. Those kinds of things. So, that's pretty regular. I usually have a couple of corporate guys in the city who are either donors or strategic in reputational kinds of currency that you want.

Two more presidents mentioned how community members helped introduce them to their networks. Hutchins had a similar remark about an influential board member she was going to meet after the interview. She said the trustee held a number of dinners in her home to introduce community members to Hutchins after she assumed the presidency:

She knows everybody [laughs]! Her family has been in the local community for several generations. Her mother was the president of the largest local bank. It's actually a regional bank. There are buildings named after her family at [the nationally recognized university next to Hilliard]. Having a member of that family on our board connects us to a lot of people and raises community awareness of us and all sorts of things.

Sinclair repeated a similar message of how individuals connected her to other constituents with possible capital for Harley State:

Those two individuals, in partnership with some key organizations in both areas, both hosted welcome receptions for me, and they invited all the leaders, business leaders, community leaders, political leaders. [One city's] reception was hosted at a [major foundation]. Place where great ideas happen. The [other] reception [was held] in [another city]. Again, business leaders, community leaders, political leaders was hosted at [a local museum], and so it was an opportunity to engage. 
Presidents also used their time to participate in business and corporate initiatives that integrated them and their institutions into the lives of business and corporations. Murphy said this of her participation in an economic development group:

It's a group of CEOs who are leaders either in business or in non-profits. Mainly, business though. So, there are various committees. I'm on the education committee and their future workforce committee. And so I chaired an initiative for them called The Future Benefit, which was to raise the college attainment rate in the area...I'm on a few boards, so that I get to meet and know people. You know the real thought leaders in the community. That takes a lot of my time.

These initiatives can be regional in nature, such as the one Hamilton served. She was one of several educators asked to represent higher education and was introduced to the "movers and shakers from the larger region in terms of the [county seat's] community schools, superintendent, and mayors of several of the towns." More importantly, through her participation, she was introduced to a CEO of a health care system who identified a prime real estate location for Bedford's fledgling pharmacy program. Hamilton said the location was perfect, but without this relationship she would not have known about the land.

The only president who commented about using her cabinet to increase an institution's presence in the larger community was Childs. She, herself, was on the Chamber of Commerce's economic development board, which was the largest business organization in the region of the state, as well as the board for the largest museum in the region.

The cultural part and the economic part ought to be on the agenda of the president, and I also get my vps involved in those things as well, so I can spread out a little bit. So, we've got people on the symphony, and we got people in the art museum. So, among us all we're players across the [city], and people see that....And those are monthly meetings. I go to them and work with the folks who on those. 
Although no other president mentioned their expectations of cabinet members to attend campus functions, Childs emphasized time management throughout her interview in relation to her numerous responsibilities and travel schedule. She was forthright in sharing that 60 to $70 \%$ of her time is allocated to "cultivating relationships that will advance the university." In fact, she said she sits down with her development office every April, so that advancement officers can plan her upcoming academic year before she opens her calendar to everybody else.

Most presidents agreed that establishing relationships with political leaders was also important to their institutions. Hamilton said she introduced herself to the state representatives in Bedford's district by inviting them to visit the campus, as they lived close to the institution. Her town had no mayor, but there was a town council president who worked at the university, so she said she saw him all the time on campus. Graham stated that her goal was to "have the kind of relationships we can just call someone up and talk to." At the local level, she was proactive in establishing relationships with each new mayor. She said, "When we get a new mayor, I visit with him, talk about how we're going to work together or not [chuckles]."

In the most unique response offered about meeting a political leader, Eyre described the levels of contact she needed to make in order to meet the mayor of her city. Meeting the mayor was crucial for Eyre because "I knew almost immediately that I needed to know the mayor and I needed to kind of invest a little in the city, because the university carries the city's name and there are other universities in town," which competed with Bahn for attention and resources. She described a process of using a network of key contacts to establish her first meeting with the mayor: 
I knew one of his deputy mayors. I got to know her. I also knew [her] through our board. [She knew] the person that was head of [a major economic development group] and that's the movers and shakers in town. I got her to get me on that board, and she was a friend of [the mayor]. I went to her and said "Do you think we can set something up with [the mayor] - maybe a breakfast or something?"

She was successful in making an initial appointment with the mayor in his office. They had never met before, and her goal was to acquaint him with Bahn's mission. She explained to him, "I just wanted to tell you a little about where the university is and what it's done in relationship to the city, and I hope that can continue." This meeting led to future encounters between Eyre and the mayor, resulting in a partnership that benefited both the mayor and the institution:

Then I ended up being on a couple of boards with him. In particular, I got named, and this is another case of the university carrying the city's name led to this. An organization [named organization], which was an education reform organization. He started the organization, and he continued it after he left the mayor's position. I got appointed to that board, because the university helped play a pivotal role in getting them their not-for-profit status. That was a great connection to him. It led then to our being involved quite a bit for the university in the education reform movement in [the city]. It was definitely an in-road to an area that we might have not otherwise had.

When asked about the challenges she faced establishing the relationship, Eyre said, "Yes [laughs]. One is just getting his time and attention. You just can't be there all the time; you have to use your contacts wisely. Getting to know his staff and the people that kind of matter to him."

\section{Chapter Summary}

This chapter presented the different practices associated with identifying key constituents with whom presidents were motivated to engage and develop relationships. There were multiple constituent groups that provided a collection of assorted resources 
that presidents intentionally attempted to tap and retrieve for their institutions. While identifying stakeholders is a function of relationship building, it is more complicated than simply being able to convey which groups are important to them. Presidents shared that they attributed meaning to their interactions with stakeholders, giving a sense of why certain relationships were deemed critical to the success of the institution and why they directed their relationship building efforts towards those particular individuals and groups. For instance, a key stakeholder was one who helped give meaning to the institution or helped govern the institution or provided the president with opportunities to participate in campus events or donated much needed funds. Presidents also disclosed that identifying stakeholders was an intentional function, meaning that their attention and interactions to seek key stakeholders were motivated by their sense of purpose and mission, as well as their commitment to being deliberate, innovative, and credible in seeking out new bases of support. Their attention was simultaneously fixed on both oncampus and off-campus constituents, and they realized that identifying constituents involved both social and public dimensions. In other words, these participants understood that relationship building necessitated being both visible and interactive. Their time and attention was spent engaging and involving themselves with stakeholders through opportunities ranging from on-campus faculty meetings to nation-wide alumni events. In the next chapter, presidents reveal how they built and fostered relationships with key individuals and groups, attempting to move relationships closer to the securing of resources. 


\section{CHAPTER VII}

\section{HOW DID PRESIDENTS BUILD AND FOSTER RELATIONSHIPS WITH INSTRUMENTAL STAKEHOLDERS?}

It's always those constant negotiations with people. Constant. Constant. Constant. All day long. All you do as president is negotiate relationships of various kindsfaculty, staff, administrators, students, board, donors, the city, the public, the legislators in Washington and in [the state capital]. All day long. That's what you're doing.

—Kathleen Childs, Mathias University

\section{Building and Fostering Relationships with Instrumental Stakeholders}

How do women presidents build and foster relationships with individuals who possess resources that can achieve institutional objectives? This research question deals with about how the presidents in this study cultivated instrumental relationships. The act of identifying a key relation is followed by nurturing the relationship. For these presidents, cultivating a relationship meant nurturing the relationship to the point that the potential resources available through the relationship can be realized. Childs' practice of being focused on her relationships was representative of the degree of cultivation carried out by the other participants. Fletcher provided further evidence by stating presidents had to be "constantly attentive to where you need to be, so [it's] all about managing those relationships."

Four practices are associated with how presidents build and foster relationships with key constituents. One practice entailed staying involved and engaged with stakeholders who possessed potential resources. By continually maintaining contact with these 
stakeholders, the presidents demonstrated their continued commitment and attachment to key groups and individuals who can be helpful to the institution. Another practice was the use of surrogates. Due to the number of relations the presidents were responsible for making and sustaining, these interviewees described their dependence on others to help them with relationship building. A presidential practice also involved intentional efforts to reduce disturbances to existing relationships or to rebuild and reestablish dysfunctional ones. Finally, the presidents understood that relationships were reciprocal in nature and that they had a responsibility to those with whom they developed institutionally beneficial relationships. Presidents' vigils strengthened as those relationships matured. As many of these relationships with stakeholders became more personal, individuals began to associate the president as the institution. For example, Eyre recounted that individuals "think about the institution, the way they think about you. They make the judgment about where the university is based on those characteristics."

\section{Staying Involved and Engaged}

When presidents were asked about how they maintained relationships, the consensus amongst them involved touch points, which were described as either planned or spontaneous interactions, formal or informal exchanges that kept presidents engaged with their constituents. Contacts were critical for presidents as evidenced by them being able to quantify the time they spent with others or the number of functions they attended or hosted. In a typical response from participants, Sinclair shared the events and meetings on her calendar the day of her interview.

As an example, just today [I] was at one of our [city's] Economic Development Board meetings, then they had a groundbreaking for the technical college. I couldn't say "No" to that. I did shake hands with about 10 people, and those were 
important contacts and touch points. Then, I met with our faculty senate person. Then, I did a lunch with one of our partner institutions from India and advancing that partnership, and that was with faculty, the dean, and our guests from India. Now, I'm here with you. Then, after I finish with you, I'm going to get on a conference call with two of the chancellors and the president about an initiative with our private college counterparts. So, wonderful. Absolutely love it.

Seriously, and I got to see some students along the way.

These meetings were purposeful in nature, and even though she did not host all the events, Sinclair understood how the connections could help her move Harley State's agenda forward and how the institution could move the agendas of constituents forward.

Touch points, similar to Sinclair's, were driven by the intentionality demonstrated by presidents. This was evidenced in the external connections nurtured with members of the larger community. A president's purpose was to send signals to what her institution could do for others, as described by Kahn, who said, "We can't always be seen as the ones holding our hands out to the community. We've got to be willing to give. Willing to dig in and help where we can." In another example, Graham noted a quarterly breakfast she hosted on Post's campus for community leaders, which included bankers, lawyers, local and state representatives, and public school personnel. For these events, she always had a specific agenda item that was discussed as a "topic of common concern."

For instance, we have problems with infrastructure. The water pipes are 100 years old. It's a huge issue, and we got [name of dairy], which is the second largest co-op in the country, and we have to worry if we can pump good water to them, because the pipes are so fragile. We've talked about the impact of state funding on various entities in the community. We met when the mines closed... What would be the impact of the loss of 1,000 jobs on the community? We've had the public health department come in and talk about critical issues. When we're worrying about a flu pandemic, we had a meeting on that.

These meetings were intended to address the state of the community, but they were also a means Graham used to maintain relations with stakeholders. She admitted that if there 
was tension between business groups and Post she would "have all the bankers in or all the newspaper people in the county, and we'll have a just a little talk about [how] we work together." Sensing that she also needed to maintain a nexus between her institution and stakeholders, Drummond created a leadership institute that was coordinated between business leaders in the community and Westchester. Drummond visited businesses and industries in the community to solicit their support and ideas with the compelling argument that, "We're giving you something. We're giving you this opportunity for your employees to get leadership skills and training. It's an opportunity for you to join with the university." The institute's annual program brought 20 young professionals from local businesses together with 10 students into a cohort to learn and develop leadership abilities by following a curriculum designed by area business and university representatives. The program contained a civic responsibility component, so participants became more civic minded and became more likely to participate in school board meetings, city council meetings, and service organizations.

Nurturing links to create opportunities for potential exchanges also existed in the purposeful interactions presidents had with political leaders. It is important to note that the agendas of politicians were clearly known to the presidents, making relationships with them more straightforward. Childs provided an example of how she handled her relationships with political figures:

That's their job - is always to be thinking about what the outcomes [are] here... For instance, both of the congressional candidates in this newly formed congressional district - the Republican and the Democrat - have asked to come and see me. Do I say, "Yes?" Of course, I say, "Yes." Each one will come. Each one will lay out his stuff. I'll talk about what's important to me. He'll talk about what's important to him. They're both men. We'll have an understanding. Why do I do that? Because one of them is going to be elected, and I want to be able to 
work with that person. And I want to have good relations with the other guy as well.

Graham provided specific examples of how she perceived the needs of politicians in her district and state and how Post played an essential role in helping them fulfill their platforms:

[U.S. Senator] knows that we are important to the economy in this part of [the state], that we represent jobs, quality of life, that students from throughout his district are getting a good education at a reasonable price. He's taken a real strong stand with regard in controlling costs in higher education. And we are a really excellent example. He spoke at our commencement, so he's not ashamed to be connected to us. He's just been chewing higher education out in the past couple of years. I keep reminding him of that - our costs are low; our student debt is low; you know we're trying to help students you know they all work you know. He's knows that but just remind him. But we have him for commencement. We invite him to be on campus. We create opportunities for him to be to get good publicity, positive publicity in his district. The other U.S. senator is the same way and for the state politicians it's an even bigger deal.

She continued with the courses of action she undertook to keep Post and her students on her delegation's agendas:

You got to keep reminding them that it's about jobs. It's about students getting an education at a reasonable cost. One of the benefits to your district. You got to listen to what their platforms are and try to some of our more conservative politicians are pretty anti-education and you have to find a way to help them understand that this isn't an expensive, elite institution. You know, you send the students from their home town to call on them so that you know when they are asking for money, the young person asking for the money is a student they know. That's a pretty straightforward deal as long as you know what the political pressures on them are and what they're public stances have been.

Kahn also emphasized the need for her to stay politically neutral. She cultivated relationships with both Democrats and Republicans to keep the institution visible and open to revenue streams:

The legislature has been good to us in many ways. Our delegation, both D's and R's in our delegation, are fabulous supporters of our institution, so I don't have to battle. I mean fabulous support from the local delegation. 
Another critical constituent group with whom presidents cultivated relationships was the board of trustees. Relationship building with the board was also referred to by several presidents as "managing their boards." Hutchins remarked that $75 \%$ of her time was spent on board relations, which she admitted did not leave her much time to pay attention to the day-to-day business of the college, and Kahn mentioned throughout her interview that most of her time was also spent on board relations:

If I had to say where I invest a lot of time, it's with the board of trustees, and it's because I think of the changing temper of the times and how boards are being exhorted to more involved. So, I'm trying to provide the kind of information and transparent processes, so that they can see that things are doing well. We are doing well.

Examples of cultivating boards include one from Hamilton, who created an intranet for her board, making it easier for members to keep up to date on college activities. McKay made an effort to contact each of her board members every month. Depending on where board members resided, she used email for those outside the area or hosted lunches for those in the local community, explaining that:

It's my way of making sure they're engaged and making sure if there's something they're not happy about. It's an opportunity for me to hear it directly. Not have to wait for them to come to me. I'd rather know in advance [chuckles] then let something fester.

Graham also noted that discontented board members warranted her to take special action:

So, you need to be paying attention to what's going on with your board. And you got to really be paying attention to the ones who aren't happy. Who don't like what you're doing. Who disagrees with you with philosophically... They want to feel they're being listened to. Better be paying attention to them. Well, I'm going to be having lunch with one of my board members soon [chuckles]. I'm going to him, and we're going to have a conversation [quickly said]. For me, it's I'm old fashioned. I use the computer, and I talk on the telephone, but if I have important business to do I will be in your space. Making time to talk to you and listen to you about whatever it is that I know you're unhappy about. We'll talk about how together we can go forward and try talk about how we can go forward in a good 
way. [Pause]. If something's going wrong, I want to be face-to-face with you [taps table] in your space.

Managing boards also meant hosting board meetings on campus throughout the year, giving these presidents another opportunity to educate and integrate board members into the life of the institution, albeit meeting agendas were directed towards strategic and tactical issues. Several presidents mentioned that their boards met four times a year, and Kahn's board met the most with six annual meetings. Plus, boards included subcommittees that met throughout the year, and at Rosemont there were over 30 such committee meetings per year. Even though presidents did not have to be present at those meetings, they attended the meetings of committees with special foci, such as the executive committee or investment committee. Board meetings lasted for several days and included meetings with campus constituents, as well as an individual audience with the president to discuss personnel, legal, budget or other confidential matters. Childs, whose board totals 36 members of whom 30 have voting privileges, built in time for board members to confer amongst themselves in order to give them a sense of being part of a larger team:

Normally, I'll keep my vice presidents there till the very end when there's always time for just me [taps table] and those board members for anything that's on my mind. And then I instituted this, and they were stunned by it. I said, "And every time I will leave the room and you will have time just among yourselves." "Why would we need any time?" I said, "Don't have a clue, but you should always have that time." So, we will build it in, and I'll go out in the hall, and if it takes "you 5 minutes, and you call me back in, great. If it takes you 25 minutes. You should always have that time." Now, obviously, I need to be pretty secure in myself, because most presidents would get very nervous about that, but I figure they need the time, and it's worked very well. So, it also builds camaraderie among themselves, which I want to have happen. 


\section{Using Surrogates}

Participants were quick to admit that they used the help of others to nurture relationships. Hendrickson et al. (2013) remark that upon assuming office some presidents are left to build their own network of relationships, although several presidents in this study shared that they were introduced to key constituents by other instrumental stakeholders. However, participants in this study took the initiative to enlist surrogates and mobilize them to assist with tasks associated with the endless process of relationship building.

The obvious partners were the officers in advancement offices whose stated tasks included relationship building, as previously discussed in Chapters IV and V, but several presidents created special positions to assist them with this function. For instance, Childs mentioned that she assigned a dean to help her with the local workforce development group. If Childs was unable attend an event hosted by that important constituent, the dean went in her place and relayed, "Sister Kathleen sends her regards. Wishes you well. Wanted me to come to support this." Childs also created a full-time government relations position in the advancement area; this person was responsible for writing letters or making phone calls to legislators or visiting the state legislature four times a year. Donors represented another key group that helped presidents nurture connections. Although these individuals were already committed to the institution, their networks proved invaluable to presidents. In one example, Drummond said:

We just spent last year doing all the research for doing a capital campaign. We've probably got another year and a half of the silent phase before we announce it. Meeting these people, getting them involved so that in a year from now I can say, "You know you're from upstate New York and we have a concentration of alumni 
in New York, so would you host a regional gathering? Would you host people there that I could go out and meet with them?

Presidents also acknowledged that their organizational memberships helped with lobbying efforts. The National Association of Independent Colleges and Universities (NAICU) is the chief lobbying organization for private institutions, and it typically meets in February of each year. During its annual meeting, presidents said they went to Capitol Hill to meet with their respective federal representatives on educational issues affecting higher education; the visits were pre-arranged by the organization. The Council of Independent Colleges (CIC) hosts its annual meetings in January in locations where Hamilton said, “you're likely to have a lot of retired donors, so it's in Florida or Arizona. When I go to that president's meeting I usually have four dinners or visits with donors when I'm there." At the state level, Murphy admitted that she did not do as much lobbying as other presidents. When asked why not, she responded that "it's probably the nature of me. You know, it's just a time crunch for me. I should probably do more of that, but I don't." Lobbying for Sinclair was handled by her institution's system, which employed two full-time lobbyists. She credited them for helping her form instrumental relationships with state legislators:

So there are two lobbyists within the [state] system administration. Again some of those people I met helped me build relationships. This is a steep learning curve for me. I haven't done much of this work before. Learned a lot. And again intentionally building, cultivating sustaining, and nurturing relationships. They help me to know kind of when the timing is right. What not to mention. One of our visits when we [went] in, and she was prepping me to the minute. He was in one room and we were in the other, and she said "Don't forget to say this..." [lowers voice to a whisper]. We were going to go in June, but the person who helps in the capital said, "It's not a good time." So we're going to go in August, and she's going to go with us to introduce us around, so that they get to know him as well. Because he'll be the person who will help manage particularly some of the day-to-day things, particularly and making sure that the legislative staff knows 
who to contact on our end, because it's a new person. And we couldn't do it there was no interest in doing that in the spring, because of the recall election. And then post the recall, most everybody's kind of out and about in the summer, so that's the delay. You also have to think about timing, because you want to be able to use-invest your time.

\section{Minimizing Disruptions and Dysfunctions}

Presidents want to minimize the number of missed contacts (Trachtenberg et al., 2013), and presidents in this study were sensitive to their perceived lack of connections, which could lead to disrupted or dysfunctional relationships. In a typical response, Sinclair lamented:

I don't remember, maybe it was last fall I was struggling a bit-I didn't feel like I was having enough touches... with faculty. I went back in my calendar, and I said, "Okay this was a community engagement event. This was a development event. This was a faculty-type of event." I looked at it, and I said "I don't have enough intentionality around building this relationship with faculty or with students." I try to assess that, because it goes back to this building this base of support. Have to think that through. I can't take it for granted ever. Ever.

For Murphy, the lack of contact with her provincial leader created a disruption when the provincial leader of Columbia Hills moved to another state as a result of a consolidation move within the congregation. Instead of the provincial leader having a physical presence on the campus and being able to meet with the president every month to discuss operational items, Murphy admitted that their relationship was "now at a completely different level." She mentioned that:

Unless it's something specifically related to the sisters, I'll talk to her about it. Otherwise, we meet three or four times a year and it's more high level about what's going on. It's more challenging to have that kind of relationship.

Presidents agreed that relationships were fragile. At the time of the first 10 interviews, Theresa Sullivan, President of the University of Virginia, had just been reinstated to her position by the governor. Several presidents in this study mentioned her as an 
example of a president having strong relations with the institution's alumni, faculty, staff, and students, but a dysfunctional relationship with her board chair and some board members. In a strong example about the fragility of relationships, Fletcher recalled a relationship with a local bank in which its owners were also on Weldon's board of trustees:

I can think of one relationship that we've really damaged and there's not a lot you can do about it. It was our bank. This is a very small town with two privately held banks in it. U.S. Trust and Campbell Bank and Trust. And our library bears the name of Clinton, which is U.S. Trust and we had two members on the board-two members of the family - on the board when I arrived. And John who is the president of the U.S. Trust went off the board. He had come on with [the previous president]. So, my second year here his term was up, so I called him to renew, because very rarely do people not renew. And he said, "I'm not renewing. I'm moving on." It's like, "Okay." Then his cousin was also on the board when I called about her renewing, and said, "Juliana, [the president] guilted me always into staying on the board, and it's not really where my heart is." So, I said, "Fine. Claudia. Go." I mean I don't want you there if you're not passionate about it. I need a passionate board. So, but U.S. Trust has this incredible thing about loyalty. Now, no loyalty this way, but loyalty that way.

Then, Fletcher said there was an incident between the bank and Weldon that disrupted the relationship. The board of trustees decided that U.S. Trust would no longer hold the endowment and custodial accounts for Weldon:

So, when we got a $\$ 10$ million gift we had had our investments with them. They didn't hold our banking. Campbell Bank and Trust held our banking, but they held our endowment. Well, when we ended up with almost $\$ 15$ million and add 10 more to that. We had not really been excited about their performance anyway, and they [U.S. Trust] had been very nonresponsive to that whole issue... And then the custodial account. They didn't get the custodial account. Well, they're not large enough to be the custodial account, so they would have needed to farm it out. So, it almost doubles the fees. So, why do that? I mean if someone had come to me and said, "You know it's going to cost you an extra five thousand to have them and it doubles the fees, but is it worth keeping the relationship?" I might have gone to the Board and argued for it. That's neither here nor there.

As a result of discontinuing the accounts, Fletcher said the bank president was furious and told her, "That's it. We'll never give to you again." She shrugged and admitted 
"That's very typical in this town. You know you buy your car from one person, then other dealers stop giving to you. It's just hard in a small town." However, Fletcher conceded that she could have handled the incident differently by meeting with president and telling him:

I know we've had a long relationship with your family and etc., but we really need to move on. We've made our decision as a board, but the board [and] the Investment Committee made the decision that we are moving to a different manager - a more sophisticated manager — someone to deal with \$26 million.

Since that episode, Weldon floated a bond that was won by U.S. Trust. Remembering the earlier incident, Fletcher said she used this opportunity to repair the relationship with the president of the bank:

I went down, sat down with the president, and the guy who had done all the work on the loan and explained it to them personally and walked away. Well, I learned from the first one. If you're going to do something like that, you [should be able to] walk around and say, "I did it right." So, those are kind of really important things to be working on.

\section{Practicing Responsible Relationship Building}

When presidents were asked to identify two or three key relationships, several were unable or unwilling to name individual/s, because they considered all of their contacts as important. However, some participants did identify specific individuals, and their responses suggested how the relationships became more meaningful to them over time. These presidents revealed that some of their instrumental relationships developed to a level in which their interactions became more personal in nature. Eyre emphasized that her relationships contained a personal element to them. She said they "need to know you personally; they just can't know about your organization. They need to know you personally." In another example, Hamilton explained that she moved a relationship with a 
factory owner to the point where "he talked about his business woes and [I] got to know him in a really pleasant way." She cultivated her relationships with business owners by calling them to see how they were doing or inviting them to lunch. During these exchanges, Hamilton inquired about their businesses and the challenges they faced in running their businesses. With increased interactions similar to Eyre's and Hamilton's, the relationships developed to a point where they became coveted by both the president and constituents, as described by Kahn:

That's where you have these nurturing, nourishing relationships that you sit back and you listen to what they're talking about...I enjoy fundraising, because it really is about the relationship. Everyone focuses on the money raising part but really the relationship - you become in many ways friends with these individuals. You start to care about their lives, about what's happening with them in their lives, and they start to care about what's happening to you in your life.

Perhaps the strongest example was given by Graham, who spent considerable time speaking about a relationship she built with one of her alums and who later became a major donor. Twice a year, she visited with him and his wife in their home in a rural part of a southeastern state:

They have a lovely home, but it's simple. Not even a separate bedroom. You sleep behind - I mean this big fireplace in the living room — behind the fireplace there's a little sitting place, and I sleep on a sofa in there. And you sauna with them. You go out in the boat, and get crabs that you want for dinner. You sit around and talk about what they're reading and so forth, and cultivate that relationship.

At some point in the relationship, the alum suddenly died, and Graham needed to cultivate a relationship with his wife.

She doesn't have a connection to the college but wanted to do what he wanted done. It's a multi-million dollar estate. Now I visit her on a regular basis. We are still talking about books. Go and stay with her. One time that I went was right after he died and she finally gotten a new car, because you know they didn't spend money on anything they didn't have to. That's why he has $\$ 5$ or $\$ 10$ 
million. She said, "I want you to ride with me." We'll go visit - there were a bunch of art shows - people had opened up their galleries all up in the northern [part of the state], and she wanted try driving this car all by herself for the first time, but she wanted somebody with her, so I was to be her passenger and help her drive her car for the first time.

Graham went on to share details about how Post was involved in helping settle some of the alum's massive estate, which included a sizeable acreage of land that was worth millions of dollars.

We hired an attorney to assist with that, and we've had to manage that whole piece. She has her own representatives, but we have someone involved in that. He desperately wanted - they have land there - he was determined that it be preserved in its natural state in perpetuity, but he wanted to work a deal like he did in [names a Midwestern state], so the land got sold for market price, but we got all the money. For about 7 years we tried to do that deal. Well, since they sold the property in [the Midwest], places like [names a nonprofit conservation society], used to have money to buy land. Well, they don't any more. We worked for about 7 years with a variety of agencies... We dealt with all types of people trying to help him make his dream come true. In the end, we weren't able to do that. Since his death that land has been deeded to the Friends of Nature, so the cash that would have come from that land will not be ours. There's a sizeable estate that will be ours.

As she reflected more on this relationship, she shared intimate details about her practices to cultivate the relationships with the alum and his wife. She also made known the other factors involved with instrumental relationship building, and the complexities and responsibilities that she took into consideration as the relationship became more personal.

So, cultivating a major donor in my experience is a long process. It's a combination, you know, always involves these days pretty complicated legal issues. It often involves a fair amount of intimacy with the donor. You drive with her when she's learning to drive. You go to the doctor with them. You talk about strategizing. To strategize in such a way that you don't violate any kind of principles of what's right over a period that may last in my case some of these relationships are 20 years old. And you're managing these relationships through the deaths of their loved ones. Planning for their own deaths. You know dealing with helping them think through how they want to take care of their families after they die. How to help them make their dreams come true. It's a one in the same time intimate process and a very complex legal and financial process. 
But when you are dealing with individual donors and their estate planning over many years, it's a very complicated arrangement. And again [for] a lot of people probably, most presidencies don't last 20 years. So that's the other part of the deal. You know, they don't have 20-year relationships with people! That's a lot less complicated [chuckles]!

\section{Chapter Summary}

In this chapter, presidents expressed that nurturing relationships was more than just meeting, dining, speaking, or simply showing up to an event with constituents. The function of cultivating stakeholders, similar to their being identified, was multifaceted and necessitated continued intentionality on parts of the presidents. Presidents made known how they stay engaged and involved with stakeholders, how they used surrogates to help them nurture these vital relations, how they attempted to minimize disruptions or dysfunctions to relationships, and how they practiced responsible relationship building. These elements of cultivation required sustained visibility of the presidents, as well as their seemingly unceasing interactions with stakeholders. The presidents were aware that they needed to connect their institutions with external constituents through their interactions, creating mutual dependencies while serving the broader community. The same was true of internal constituents with whom the presidents relied upon to carry out the missions of their institutions. Presidents emphasized their continued investment of time, energy, and attention towards cultivating relationships in order to prevent them from becoming derailed. After identifying and cultivating instrumental relationships, presidents transitioned to acquiring resources, and the next chapter explores how presidents attempted to attain resources from stakeholders. 
CHAPTER VIII

\section{HOW DID PRESIDENTS SECURE RESOURCES FROM}

\section{INSTRUMENTAL STAKEHOLDERS?}

You really have to enjoy those relationships. It doesn't mean that you have to be real extroverted, but it means you have to enjoy meeting new people and hearing stories, following up when the excitement builds in a relationship or when the curiosity about what they're doing builds. I think it's right at the heart of it.

—Kathleen Hamilton, Bedford University

\section{Securing Resources from Instrumental Stakeholders}

How do women presidents capture embedded resources in their relationships to generate a return on that investment? The intent of the last research question was to link the practices presidents used to identify and cultivate relationships to the goal of retrieving institutional resources. On a macro-level, the practices of relationship building to secure resources (e.g., donations, grants, equipment, or good will) were dependent on the investments made by participants to identify and cultivate instrumental relations. On a micro-level, a president attempted to augment her networks and her leadership capacity to acquire additional resources. Hamilton's reflection, albeit a representative quote, provided an insight to the emotional and temporal investments that resource acquisition demanded and expected of presidents. As was the case with identifying and cultivating relationships, presidents revealed the multiple dimensions associated with retrieving resources. 
By asking participants "What has the institution gained from the relationship," four practices surfaced to suggest how presidents captured institutional resources. The first focused on the practices presidents followed to make the cases for constituents to give to their institutions. Presidents made deliberate efforts to project a positive image of their leadership, thereby building public confidence in the presidents themselves. In addition, presidents used storytelling to invoke images, stories, and institutional sagas to bring potential donors on board. The second practice centered on the status of the presidency and how presidents relied on the position's status to influence constituents to release valuable resources to their institutions. A third practice included presidents describing how they were constantly recognizing and seizing opportunities that could lead to outcomes. Finally, presidents shared that their most important function as president was relationship building, and they described the human dynamics involved with this practice.

\section{Making the Case}

The presidents in this study possessed a variety of attributes and skills, but participants also expressed a need to project and demonstrate their leadership capacity to stakeholders in order to show they could move the institution's strategic mission and plan forward. According to Murphy, constituents had "to feel comfortable with the president (or with whomever) [and] that you have the vision for the institution and that you have the capacity to implement that vision." Sinclair alluded to this when she mentioned that her system's president "shows his commitment to the good work that we are doing here on campus by being present." Good work, Sinclair surmised, brought the: 
Presence of [the] system's president on campus despite being two hours away from the [system's home office]. I know that he gets letters from some of our board members, because either he's told me or they've told me that they've sent them, and he responds to those.

Graham recalled that several significant gifts were made to Post after the institution started to emerge from its financial exigency status; one gift endowed a scholarship for students in the county who wanted to study at Post and the other was a half a million dollar gift. She said that the latter donor was publically quoted in the local newspaper as saying, "I've been holding on to this money waiting for things to turn around for Post, and I believe that's happened. Here's my gift." Once Post started to show signs of recovering, Graham suggested a state legislator began to show confidence in the institution by directing resources to it:

Sometimes part of this job is about living into what you want to be [laughs]. I mean I think we started to act like we were healthy long before we were. Okay? Because that inspires confidence. But we had a couple of people who made public statements that made it possible for us. And [state senator] saw that we got a lot of money... he began seeing that state money started to come our way. Once he thought we were stable, people began to see building going on, and we've done a lot of building in the last 20 years.

Regardless of the type and depth of relationships developed and cultivated, presidents were keenly aware that constituents were sensitive to the images the presidency projected. One image was shared by Fletcher who said, "They [donors] know why you're coming. You're not coming because you like them. You hate it when people look at you and go 'Where's my wallet?' Similarly, Kahn said that politicians "understand that I'm a college president and public college presidents always want more money [laughs]. It's in our DNA [laughs]!” Even though one image of the president may be one of who was constantly seeking money, the president, more importantly, 
projected an image of the university as described by Eyre:

You are certainly the face of the institution. Not to your alums necessarily, because they know it in a different way. Sometimes that's good. Sometimes that's bad, because some of them know it when it was much, much smaller, but to them it's personal and don't like the fact that you're getting bigger kinds of things. But to the business community, which I think is extremely important, business and government people, yeah you are the face of the institution.

She continued that the expectations of these constituents were based on the sustainability of the institution through the leadership capacity of the president:

They think about the institution the way they think about you. Are you competent? Then the institution is in good hands. Are you a visionary? Then the university's going to be visionary. Are you building buildings? Are you decisive? They make the judgment about where the university is based on those characteristics. That's how it is for presidents.

Similarly, Drummond mentioned how mindful she was in regard to how the health of the institution and of her relationships was communicated to others:

When you are having a financial problem, if you would go tell everybody, then the town would say, "Oh, Westchester University is going to close its doors. I'm not going to come." We've had that financial up and down. And, if I have a problem with one of my vice presidents, if I would go out and spout off about it, then people would begin to take sides.

Graham specifically mentioned how "public confidence" in her leadership that led to increased funding by donors and the routing of resources from legislators. She shared an intimate story about a conversation between her and a presidential colleague about the financial exigency history of Post. When she reached the part of Post's narrative where people sensed the college was flourishing, she told him, "You know, I never realized [this, but] you can tell people things are much better and going well. No one believes it like they do when you're suddenly building a building." That is when she said he laughed and said, "Why do you think I have scaffolding up all the time whether we're doing 
anything or not?!" The purpose of this quote is not to make the other presidents appear disingenuous but to emphasize the expectations of presidential capacity to move an institution forward. Thus, presidents in this study said that they kept the mission first and foremost, as described by Graham who shared, "You can't be having your own private hoo-ha about something. You are not a private citizen. You have to be very careful.” This comment was similar to one Hutchins' made about her position, “The world doesn't really care what Pat Hutchins wants or thinks. They care about what the president of Hilliard Colleges wants or thinks." Ultimately, the capacities of these presidents to lead were based on tangible outcomes, such as enrollment, tuition revenue, donations received, etc., but other results included demonstrating to constituents their leadership capacities reflected healthy and thriving institutions.

Another practice several presidents mentioned they used to compel constituents to connect to or to give or to give back to their institutions was storytelling. In his book on leadership, Gardner (1995) explains that stories are fundamental in leadership, as they create a sense of identity for a leader and followers. The stories are often told as journeys that leaders undertake in "pursuit of certain goals, and along the way and into the future, they can expect to encounter certain obstacles or resistance that must be overcome" ( $p$. 14). Murphy shared that "You do a lot of talking and telling [of] your story, and then that resonates with the people you're talking to." Consider McKay who spoke directly about story telling:

When you're a good storyteller, you know, you need to make sure that you're telling their stories in a way that's compelling as well. So, I think that is a big role. And that ties back into relationship building - to be a good storyteller you have to understand people and know what stories will inspire them. 
The stories presidents used were those that captured real experiences of individuals being affected by internal and external policies, and presidents used them to convey to stakeholders why those individuals should matter to the institution. Effective stories, according to Gardner (1995), are woven together with richness and attention to details, drawing the listener into the journey. In this study, presidents utilized stories to provide persuasive examples of why support or continued support was necessary, intertwining stories around a specific issue. McKay gave an example of a conversation she had with a major donor who questioned the financial assistance awarded to students:

My biggest donor who-I adore this man — but he's a very, very conservative Republican...He worked his way through college and became a billionaire. I mean he was a tenant farmer in Iowa, but I love this man and no one's got a bigger heart. [He says] "Well, they should be able to work their way through college. They shouldn't need all this aid." I used this example. This story helps a little bit. I said, "You know I went to a private college; it was $\$ 40$ a credit back then-in the day I went to college. And I worked at Sears Roebuck full-time out of high school. I made \$50 a week. So, in one week, I could pay for a credit and have money left over. What kid today could come out of high school and earn what one credit costs in a week? Impossible. At a private college you're talking $\$ 700$ to $\$ 800$ a credit. Couldn't be done. I said to him, “That's why they need still need aid. It's not that they're not working full-time. They can't earn what a credit costs."

McKay went on to explain the need for a collection of stories to help support a variety of circumstances that could be presented to any stakeholder:

Those are kinds of stories that you need at the tip of your fingers. You know to try to illustrate a point. "I agree with you kids don't always work as hard as they should, but some of them do," and it's still not possible [chuckles]. You can't do it. Making \$9 an hour is not going to cut. And, yes, college costs too much, and shame on us. You don't punish them, because we screwed up [chuckles]! But that's when you have to have stories for every occasion really. You have to pull one out of your hat and you have to also always how to be you know think fast on your feet. 
The presidents' stories in this study were collected by them over time, and accumulating them necessitated further engagement with their constituents. For instance, Drummond, who did not attend Westchester and who was in the third year of her presidency, said that she was still collecting stories. Her strategy was to ask alumni, "What was your most memorable experience at Westchester? What do you remember? What's your passion now? What can Westchester do better?" By asking about their interests, she was better able to align their interests with what Westchester was doing strategically. She actively listened and concentrated on what they were sharing to find out "what the hook is" for them to release resources. In a unique finding about storytelling, McKay said that there is a difference between being the story versus the storyteller:

[Previous president] was the story, and I'm the storyteller. She was bigger than life, and I think the down side to her presidency was that she was, and it wasn't her fault because she's just basically a humble person, but she's bigger than life. So, people knew her more than they knew the college. When I came in, I don't want people to know me as much as I want them to hear my stories about the schools, and that's a very different focus.

\section{Using Status of the Presidency}

The literature makes clear that the president is chief administrator (i.e., the first among equals); the major fundraiser of an institution; institutional representative at the local, regional, national, and international level; and the chief executive officer of a complex organization (Bornstein, 2009; Resnick Pierce, 2012; Trachtenberg et al., 2012). Returning to the theory of social capital, Lin (2001a) states that "the higher positions have more information about the locations of valued resources in the hierarchy-where specific types and amounts of resources are embedded" (p. 35). In this study, the status of the presidency opened doors for participants that would not have been available 
otherwise.

Eyre said being the president meant that she was the "external image and developer for an institution." Even though she was the only president who related her position as being a chief executive officer, she specifically used the reference when she spoke about positioning herself with business and corporate leaders in the city. She was also the only president who addressed how the position of the presidency was influential in relationship building. Eyre admitted that she slowly came to understand the influence of the position as result of her being one of few women leaders in the city:

Sometimes it's hard to recognize as the president that you carry status by virtue of your position. Women have a harder time recognizing that then men do. It never dawns on you that they might be proud to say "I'm a good friend of the president of the university." That's a hard one that it doesn't come easy to women.

By sustaining relationships with key stakeholders for a period of several years, if a project came along that Eyre felt a constituent might be interested in joining, she felt more comfortable saying to her or him, "I hope you can be a part of this." Over time, she began to ask herself, "You know, what would make this [project] worth for them?"

The feedback I've gotten is once they really like what's happening at the university; they like what we are doing for students; they like the connection we have with [with the city] and the fact that we take [the city] as an important part of our role and our agenda. Being a part of [a major sport event] and being one of the partners in there. Because we hosted and gave the [NFL team] a practice site, gave us incredible credibility with that group because that's a group of people who were putting together getting this thing done well, and we took something off their plate that they didn't have to build that was going to serve the [team] well. I looked at "Gee, it was great for the students"; they got to be a part of this, but it was also great for the university in terms of paying back to the community and being a part of the community. That's an important role for the president.

Before she retired from the presidency, Eyre revealed some of her advice to her successor about being president: 
I said in my letter to [the new president] just "remember to be the president" because sometimes it's hard to do that, because you think I'm just doing my job and it's just a job. It's a very important figure head to the institution. It's the position, not the person. You have to step into this position and accept that, and it took me a long time to realize that people actually wanted to know me. You know it was important for people to be able to say, "I was at the president's house for a dinner. We went to the concert at the Hahn Center with the president." That's the kind of thing that I just didn't get at first, and I think that's true of women [pause] going into presidencies [pause] for the first time.

Sometimes presidents were asked to intervene in relationships, so they could use

their influence to affect outcomes. Hamilton shared a story about a donor who was

presented with a one million dollar gift proposal, but the advancement officer was only

able to secure $\$ 50,000$. She was asked to help secure the additional resources:

Well, that's not how you kind of want it to go [chuckles], not that 50,000 isn't great [chuckles]. Then, today, our advancement v.p. came in and said, "You know, Katharine, you know them really well. I think it would be really good if you would go work with me now and show them the proposal again and talk with them and see if we can keep a door open for slightly bigger gift." So, I was already on the phone with them this morning.

McKay was also presented with a similar situation by a religious leader in her city, who asked her to serve in various capacities to help his high status position. Their relationship allowed both McKay and the cardinal to exchange resources generated through their positions:

So before when I first came it a cardinal who is now [on the east coast], [name of cardinal]. He and I hit it off and really became very good friends. And that's so important so. To give you an example, I'm now vice chair of the Association of Catholic Colleges. We wanted to get him to speak at something, and he said, "No" to everybody who asked him. So, they finally said, "Why don't you try?" [I did ask], and he said, "I'm doing it as a favor to you, Kiddo." And he came. Again, it goes back to that building capital. He would not have done if I had not done a lot of things for him too. He would ask me to take on this task force, "Would you do this?" and "Would you chair the seminary board?" So, you know, it's like one hand washes the other. So, when you need him for something, he came through. 


\section{Recognizing and Seizing Opportunities}

By virtue of their positions and responsibilities, participants were sensitive and aware that their relationships were intended to produce outcomes. Their stories were laced with successful examples, and several presidents provided strong examples of the practice of recognizing and seizing opportunities. According to Lin (2001a), instrumental actions are intended to result in a profit or additional resources to the principal. In this study, there were three strong examples of presidents who sensed deficiencies in their resources and developed relationships that led to opportunities for individuals or groups to provide resources to the institution.

In the first example, when she was asked to identify a key relationship, Hamilton responded with Margaret Brown, a vice president of a major charitable foundation in her state. This foundation provided a variety of institutions, including those in education, the opportunity to apply for significant grants to fund development projects. After Bedford approved a professional doctorate degree in pharmacy and hired a dean to oversee the program, Hamilton approached Brown about a potential proposal for funding it:

After [we hired a dean], we went to see her. She opened the door [for] a small proposal. ... She invited us to submit proposals for 2.5 million, 5 million, and 7.5 million....She then needed to tell us that we needed to get those proposals in by 2 weeks. And when [name of foundation] says that, you go, "Oh, sure. That won't be a problem [chuckles]."

While she worked on the proposal, Hamilton called Brown several times to ask questions about the proposal.

I just had the feeling they had more money even than what they had put out there. So, I said, "Could I send a bold proposal along?" She said, "Yeah, you can send a bold proposal." So, along with our three proposals I just attached two pages that I wrote and said, "Here's our bold proposal," and it was for $\$ 35$ million. It said, "This will allow us to do it the way we want to do it. It would allow us to get our 
building. It would allow us to hire the people when we need them. Not crimp along and just hire them at the last minute." And we got it -35 million.

The university did spend $\$ 15$ million of its own resources to construct the building, but without the $\$ 35$ million grant, it would have needed to borrow an additional $\$ 9$ million. Moreover, Bedford saved additional resources, because the parcel of land intended for the pharmacy school was identified by one of Hamilton's key stakeholders. The land was less expensive than other sites being explored by the college.

The backstory of Hamilton's relationship with Brown started shortly after she was named president. Bedford was part of another foundational grant that was being mismanaged by a Bedford administrator, and Brown was the foundation's account manager.

Well, when I became president just by fluke, I was the person in line to become the lead president for that [foundation] grant. The first thing I did-I became president in December - and by summer we had gotten rid of the director of the peace house in [the city]. He should never have been hired. Well, with that action on my part, my stock really went up with [the foundation]. It was like somebody finally had some guts to take some action here and stop the bleeding in terms of that. So, what was really a horrible grant with which to be affiliated in their eyes, I think my leadership in a transition time helped me build my credibility. So, I think Bedford came out unscathed.

In a different example, Drummond recognized that her actions could lead to outcomes for Westchester. Even though Westchester was located in the heart of the town, the campus' town and gown relationships suffered as a result of the pacifist college's stances against several wars. She did not realize the extent of Westchester's isolation from the community until her inauguration, when she invited the town's residents to join her celebration:

At my inauguration... we made pottery bowls. We had faculty, staff make pottery bowls. I engaged the fifth and sixth graders to make pottery bowls, and we sold them for $\$ 20$ each and then we gave all the money to the food pantry. And so the kids who made bowls were so proud of them, and they knew they were up for 
sale. But then they were sold at my inauguration, and that brought community people out to buy their kids' bowls. And I had so people say, "This is the first time I've been at Westchester." And I'm saying, "How many years of your life have you lived here?" Some people have lived their whole life here. Kids in elementary school have never been on Westchester's campus. And so if we don't have the parents buy-in, then going in to promote Westchester to elementary and secondary kids and getting them to think about coming to Westchester when it's right here in town. Or getting to come to a concert. Getting them to come to a lecture. The World Food Prize. We always have a world food prize laureate come in October. We have wonderful opportunities, but how do we get them involved?

A result of her efforts to become more inclusive with area residents resulted in an increased number of local high school students attending the university. She mentioned that 10 years ago only $1 \%$ of the senior class attended Westchester, today over $20 \%$ of seniors (of a class of 150) chose to study at the university. To attract local students, Westchester created a financial incentive, pledging that they would be charged the same rates as the community college in the area. Even though the students attended a college in their own backyards, Drummond said, "they will still make friends, you know, from California or Miami, or you know from someplace else," including students from five other countries.

In another strong example of recognizing and seizing opportunities, Sinclair told the story of the largest gift she received as president. She secured a $\$ 3.5$ donation to build an arts and humanities center serve to the region from Constance Johnson, the stepdaughter of Harley State's first employee, Emily Johnson. After Emily died, Sinclair engaged in a conversation with Constance about a gift to support an arts center.

I believe at that lunch, and I'm nervous as ever, I dropped the idea of naming. I never mentioned $\$ 3.5$ million. I just said the total project is $\$ 30$ million and would expect $10 \%$ of that amount. So, I never had to say what I asked for. So, there were some things with the estate, and I didn't really know if she had resources or not. I had a hunch but didn't have validation or verification of that. That was in summer of ' 10 . 
Sinclair and her team of administrators followed-up with Constance about 5 months later

to further along the conversation:

January of ' 11 we go to [the city] to meet with Constance. The dean of arts and humanities, the provost, and I, we spend the day with her; she's very involved with the [a museum at a university]. We went to lunch, and so during lunch my job was to pitch this a little more. [Constance said], "Well, you know I'm still working on some things." Okay. Okay. So, we get in the car, and we drop her off. The dean and the provost [said], "She's not going to do it. She's not going to do it." I said, "Listen. She didn't say no." That's all I said, "She did not say no." They said, "She didn't say yes." I said, "I know. These things take time they tell me [chuckles]."

Sinclair beamed when she described the excitement over hearing Constance's decision

that would have long lasting effects on Harley State and its community:

So, the end of January...I love telling this story - It was Friday night and I was sitting at my desk, and we were having the Martin Luther King Celebration on campus. I get a call from our dean. Constance couldn't reach me, so she called him before she was going to Florida for a few weeks in the winter. She said, "I'm going to do it...It has to be named in honor of Emily." I mean I get chills thinking about it.

After she recounted the story, Sinclair pointed out how her relationship with Constance

was the foundation behind the gift:

So, how did that come to be?...We were able to negotiate the gift. We have all the signed agreements. She is paying on her pledge - that's the best news of all. It's a 5 -year commitment. You know, so all kinds of pieces there. We did a naming ceremony with her and her family in October. And then had the full unveiling... The students named it "The Emily." She [Constance] loves it, so it's great. How did that come to be? It's truly about relationships, and it was not only about honoring Emily's relationship with the university, but it was also about trying to reconnect and establish a relationship with Constance and the university. And so she serves on the advisory board for the [center]; it started out with theatre; she loves theatre. So, she came to a couple of shows during this time we were cultivating the relationship. Still comes.

Despite securing the gift, Sinclair pointed out that she still continued to seek exchanges and touch points with Constance: 
She's here most Tuesday nights doing some stuff in [a nearby city], because she got relationships [there] with friends. The other piece is I connected her with the Adventures in Life Long Learning, which is primarily [made up of] retirees organized here. They do classes. They do seminars. They do trips. Well, Constance loves to talk about British history. She loves to talk about Chicago architecture, whatever. And so the two passions match. They needed somebody to talk, she was able to help. So that's how I believe we were successful in doing this. I talked to Constance about 2 weeks ago, and she was headed to Iowa. Then, when she gets back she's going to come, and we're going have coffee or tea or dinner or whatever works out. But it's about_-it's truly about relationships.

\section{Appreciating Human Dynamics}

All presidents considered relationship building as one of the most critical and important responsibilities of their positions. Their capacities to reach people who possessed diverse interests with whom they wanted to influence and convince to connect and stay connected to the institution was presumably based on their skills to build relationships that led to resources. Admittedly, skill sets are important to be successful in that venture, but participants also brought to the surface a leadership mantra that emphasized the "human dynamics" of their positions; an embraced mantra fueling their desires to create instrumental, albeit authentic, relationships that benefitted their institutions. As described in the previous chapter, presidents also remained sensitive to the personal and fragile states of relationships as those connections further evolved.

Daniel Goleman (1995) argues that there are fundamental human aptitudes that direct peoples' attention and interactions, including "self-control, zeal, and persistence, and the ability to motivate oneself' (p. xii). Other emotional competencies he considers essential are being self-aware, listening to others, being collaborative and empathetic towards others, and effectively managing relationships. Goldman (2001) refers to these aptitudes as part of an individual's emotional intelligence, which he considers as the 
"abilities to recognize and regulate emotions in ourselves and in others" (p. 14). In this study, the level of a president's emotional intelligence in linking individuals with her institution may have determined how successful they were in recovering resources. For Hutchins, she made reference that emotional intelligence was the essential attribute an individual brought to a presidency:

Learning the tasks of a job is relatively easy. The hard part is always the people. Not only is it the hard part, it's also the fun part. It's the rewarding part, but your people skills are more important than your IQ, than anything I think. Relationships will either make you or break you. You have to do your work. You have to do your work, but people can either help you or hinder you in getting your work done, which is a lot dependent on people and the relationships you've built with them. To me, it's at the heart of it all.

Similarly, Murphy implied that not understanding the role of emotional intelligence in leadership was detrimental to leaders. She said how a president related to people was the key to her success. The following described her approach to connecting with internal constituents.

How you motivate people, how you reward people, [and] how you listen to people? Those are all key elements in leading an institution, so people want to be there with you. They want to join you in the journey. They feel they're important, and the journey is important...You have the support, because no one does this alone. Everybody who is successful has a great team that's helping them.

Murphy emphasized that not only did she need to embrace and embody the mission of Columbus Hills, but she also needed others to support its mission in order to strengthen her message to other constituents. Her invitation to join the journey reflected her inclusionary nature, as well as her dependency on others.

Thus, emotional intelligence became one of a president's most useful tools. In this illustrative example, Kahn explained how the "rapid change" in technology affected her relationship with faculty. Here she spoke to the fears she sensed in faculty: 
I mean for faculty, the fear that this is going to replace them...I mean they went into their professions because they love their fields, and that's what animates them. And how will this change it? Will it routinize it? Will it automate it? Will it take away the heart and the soul of what they're doing? I happen to think that there is a way of integrating technology that won't [be disruptive], and I think the evidence is out there.

She acknowledged the role and the responsibilities her position and other administrators played in alleviating faculty fears and seeking remedies:

But it is up to us to provide opportunities for learning for faculty to help them see that. And that's usually through other faculty learning it and taking it back to faculty. So, it doesn't come through lectures...Administrators lecturing faculty does not work and lecturing students doesn't always work either. So, I just think you know finding ways of getting to that through different paths; it's not going to be through one path.

As she continued with her story, Kahn said she reached out to one of State's major donors who owned multiple companies, one of which one focused on cloud technology:

So, I just sat down with him and said, "I'm a student. Help me to understand the terminology and what I should be thinking about." Again, taking on that role of the exchange and saying, "Help me to understand this" gives me valuable information and perspective and gives them [faculty] a feeling that someone is actually hearing me and listening and I'm going to have an impact on the direction of this university.

Universities are expected to utilize technology, and Kahn was sensitive that technology had the power to alter relationships. Thus, she admitted to the multiple layers that technical systems and applications had on the operations of the institution, and that they ultimately affected the people using them. She created a new cabinet position, director of computing services, so that she could make not only informed decisions about technology but how technology could affect her relations with constituents:

So, I need somebody at the table to say you know, "Don't frame it like that. Here's what's possible. Here's where the leading edge is." And so that's what I'm looking for is that sense, but I mean I feel challenged on multiple levels in terms of how to move us forward in terms of technology, in terms of the ways in 
which it can change my relationships with the faculty, ways in which it changes relationships with alumni, ways in which it can enhance some of those relationships with alumni.

Being an optimist, Kahn also expressed concern about how technology could make her relationships dysfunctional:

I'm a glass is half full kind of person; I'm an annoying positive thinker. [laughs]. I keep thinking of ways in which it can help, but I'm very aware of the fear of how it can disrupt fundamental relationships and concepts of what I'm doing as a professional. I think the business perspective and then technology have been two things I'm spending a lot time thinking and are affecting the kinds of relationships I'm reaching out to learn from.

There was also the need for presidents to maintain meaningful connections with external constituents in order to give individuals the sense that their dreams and visions were valued by the institution. This was considered essential in order to receive a "gift." Regardless of an individual's background, Graham said she approached relationships with "integrity" and "respect" and kept the focus on the institution, not herself:

I think in my opinion it's never about you. It's always about the institution. We all let ourselves get in the way sometimes. None of us are perfect. It has to be about the institution and about integrity and respect whether it's a farmer or an iron maker whose made millions but has no education or somebody with multiple degrees from the most prestigious institution in the country. You got to meet them where they are and where you share a dream or a vision. People want to be communicated with; they want to hear from you.

McKay moved Graham's comment forward with her opinion of how to discern and learn what mattered to constituents:

I think [this is what] people forget about sometimes with wealthy people. They're used [to] people wanting their money, but what's most precious to them are their ideas. You have to show interest in their ideas. You have to show interest in their ideas even when they're whacky. Often implausible and ridiculous...And rightly so, because you just don't want to be used for your money. That takes patience and hard, hard work. 
For her, the hard work and patience was not only a realization that constituents were not all the same but that relationships had to be developed in a meaningful and genuine manner. Since stakeholders had different backgrounds and experiences, presidents developed relationships to learn what constituents supported or did not support, meaning that relations had to evolve in order for presidents to elicit this type of information. This was reflective of Hamilton who said she attempted to "work in all the things you know" about a person to move that relationship forward by appreciating what they appreciated and conveying that to them.

As a result, some relationships developed to a point they became personal for both the constituent and the president. Relationships were made at the professional level, but presidents spoke to the need for some constituents, mostly donors, to know them personally, so that they could interact in more meaningful ways with them. It is important to note that several presidents specifically mentioned boundaries existed between them and constituents. For instance, Childs and Callaghan made it very clear that they did not socialize on a personal level with constituents, explaining the need to keep their personal lives separate from their university positions. Others explained that personal relationships were a means of connecting with constituents for professional purposes and outcomes. Eyre repeatedly called her key constituents "friends," and she described how she and her husband went out with other couples to create a "sense in which there was a comfortableness that we can work together. That wasn't so officious." In another example, Hamilton developed a relationship with a wealthy couple who donated to Bedford. She recently gave the husband a tour of the new pharmacy facility and said she was going to meet him and his wife in their home the week following her interview. Her 
relationship with the couple developed to the point where their connections became more personal in nature.

Do you remember the Norman Rockwell painting of little Ruby going to school in the segregated South? Well, they own that, and I've known them for a long time, but that painting had always been out on loan to museums. I had just heard in the grapevine that they had it back [chuckles]. So, when I called [the wife] and asked if I could see them to talk about Bedford [chuckles], trying to say it without her saying, "No, we don't have it," and I said, "I hear that you have Ruby back [laughs]. I still haven't seen that!"

The opportunity to know constituents on a deeper level brought outcomes that would not

have necessarily happened otherwise, as Kahn described:

Yeah, it may be a little more maintenance but there's more give and take, there's more exchange, there's more texture to that relationship. Yes, I go out and visit I'm heading out next week to the east coast and visit with friends of the university. One person's been a long-term friend of the university. The other person's brand new. You know you get leeway once the relationship has been established. They even feel comfortable enough to tell you, "I didn't like what you did." "Oh really? Excuse me!" [laughs] That leeway starts to exist in a relationship where you give and take...

To this end, Kahn hosted dinners in her home that provided her opportunities to interact

with people on a more personal level:

Never underestimate-I never underestimate the power of a social evening. Fixing some food. You know at the University home we've got great food service staff, but I don't like people hovering. I like people in the kitchen. I like folks bringing their own wine [tapping table]. I like mixing it up. That's part of what also getting to know people more on a social level. It's all those pieces. Yes, conferring business one to one. It's also getting to know each other as people. Putting the business part away and just talking. You're able to speak more, freely, you just get to know each other better.

Kahn continued her story by sharing how a conflict arose between her and a key

stakeholder. This example showed how the functional aspect of relationship building had been replaced with more personal one: 
We had one donor-she and her husband great friends of the university. There are places on this campus named after them. She moved her husband when he became very ill to the retirement community here in back of the university. He became so incapacitated he was in the nursing facility. Well, she got so bent out of shape with me, because I didn't come sit with her and her husband. And yet her closest relationship was with the previous president, and I had been told, "These are his donors. You leave them alone." So, I thought okay. So, I couldn't share that with her that I had been told to stay away. So, I just began building a friendship with her. We now have lunch at least once a month, and we e-mail. I mean she's in her 90s and you know she came in and said, "I was upset with you." I said, "I'm sorry you were upset with me. I didn't understand that you wanted me to be there. So, I'm sorry." She was fine.

Presidents shared that not all relationships are personal; instead, some have quid pro quo exchanges. Relationships with politicians are one example of this type of reciprocity, and Graham gave a description of her relationships with this stakeholder group:

You know what they need. I mean they need publicity; they need exposure. They need to be convinced that whatever you want will ultimately be in the best interest of their district or they're electability in the future or whatever. It's a pretty clear exchange. Now, we've been blessed that the leadership in [this state], [names of US senators] are people of principle who believe in what we are doing. So, it's not a nasty, it's not a dirty kind of exchange. You know he knows that we are important to the economy in this part of [the state], that we represent jobs, that you know quality of life, that students from throughout his district are getting a good education at a reasonable price. He's taken a real strong stand with regard in controlling costs in higher education. And we are a really excellent example.

Childs concurred that the exchanges she made with politicians were easy for her to distinguish from other relationships. She told her legislators that she would be supportive of their efforts when they introduced legislation that she felt she could support them on.

When there are bills you need to support on, that you think I can support you know me, let me know, and I'll be glad to write letters on behalf." So, I'll work for them, but they got to work for me. Everybody knows that. It's very clear. There are no hidden agendas here. Unh. Unh. If there are, you're stupid. Really.

This quid pro quo arrangement was also apparent with vendors with whom the institution negotiated contracts for services, such as electricity, or products, such as the pouring rights for certain brands of soda served in dining centers. 
Presidents said their framework in considering relationships was grounded in how they ascribed meaning to their interactions with constituents and the principles that guided their interactions and attention with them. The strategies that they utilized and applied to reach the outcome stage were on the surface utilitarian. Although this project did not focus on leadership approaches, there appeared to be a sense of authenticity in how they described their approaches to outcomes. They were acutely attentive of their behaviors and the perceptions of others (Lyman, Strachan, \& Lazaridou, 2012). In this example, Sinclair said that when she moved from the South to the Midwest she had to "establish relationships quickly and authentically in order to understand how to leverage the strengths of our institution with the needs of our business and community." She realized that her authenticity may be challenged when she asks herself, "Are you really present or are you just going through the motions?" This question drove her to reflect that on some days "I have to stop and say, 'Okay, be present. Be present and what does that mean [to be present]?'” For her, the quality of relationships or touch points was central to her approach to relations. Graham also was sensitive to the human qualities that madeup and grounded her relationships:

Well, being a college president is all about relationship building in my opinion [said very slyly], and [pause] human beings want to be respected, and they want to deal with someone who's honest. They want honesty consistency, fairness. They want to be respected, and you have to meet them where they are and really respect them. Because one of my colleagues said one time that we are one of the most blessed human beings because we get to live in so many different cultures and share peoples' lives in such intimate ways. It's a rare individual who gets to have those kinds of opportunities.

What drove the request for resources was the quality of the relationship that a president built with constituents, as described by Kahn: 
Some folks go at everything as if they got to lead with what they want. And what people want is to develop a connection first to get to know you first...but, you know, I have to understand the ways in which I need to convey what they've already helped to build as well as what we're doing not to just ask for money. So it's got to be the feeling that we're hearing them, as well as them hearing us.

It would not be correct to presume that all presidents cannot be authentic and strategic about outcomes at the same time. When asked if she thought about outcomes as she evolved relationships, McKay said:

So, I'm thinking about their money right then and there, but I am as I'm leading up to it. Cause you're trying to think about what will help... What strategy is it going to take to get them to cross that line and give me the money? It's a puzzle often, because it's not the same for everybody. But you have to know the person well. Some people, for example, want no attention, and they despise any attempt that you're going to give them credit. And they're lovely people to be with because it's not about them. And for other people it is about naming. They want their names on things, and they have the right to do it. But you have to think about so what's going to really appeal to them? And it's a lot of work. And you have to get to know other people who know them who can tell you things too [laughs]! It's not just them. It's like "Okay what are all the other places they've given money to? What do they seem to like? What is it that made them give to this but not that, so you don't make that mistake?" It's a lot of more work than what people. [There is a] strategy behind [it]. People think if you're just good with you people you go, "Hey, by the way could you please give me money?" But it's so more complicated than that, but more interesting too... And oh my gosh, the multiple levels that go into it.

Yet, several presidents understood how they could be perceived as manipulative or dishonest by pushing the boundaries of a relationship to find its depth. On several occasions Hamilton iterated that her reasons to form relationships were not done in a "conniving" or "disingenuous" way but rather to find the "common humanity" between her and the other person. Kahn gave a similar comment, "Yeah, I am deliberate, and yet deliberate doesn't mean insincere. It means I'm constantly aware that I represent an institution. I'm constantly aware that how I represent the institution has an impact on how people think about that institution." Unlike McKay, who said that she consciously 
thought about outcomes, Callaghan said she probably did not think about outcomes

enough. Her framework to achieve outcomes was more ambivalent than McKay's, partly because she did not want to appear to be manipulative, making others think she was establishing relationships for the sole purpose of getting "something" from them. The distinction between personal and quid pro quo relationships changed that framework, as noted with the following the example when Callaghan showed she was strategic and deliberate with legislators:

On the other hand, I know if there is a matter going on in Congress right now, and so-so is a key player in that process, then I need to develop a relationship with that person. Now, it doesn't mean that I'm necessarily going to achieve my outcome. You know what I'm saying? But it would be foolish to think well "They'll just do this for us because they're nice people." They have to understand our issues. They have to understand that what we're engaged and what we're willing to do in this process. We have been successful in the past, not at a huge level, but we've received some earmarks in the $\$ 100$ thousand, $\$ 200$ thousand range, so we're not a huge player but that was strictly done with personal calls to staff members and to people in Washington and telling the story of Eastman [she taps her pencil on the desk] University and why it would be a good investment on their part to provide funding for this particular piece of equipment in the science lab. You know what I'm saying?

Her responses of "You know what I'm saying?" suggested that she wanted to be clear regarding the probability of an outcome, as well as the story that she would need to manifest to increase the probability of success. She also recognized that she may not be successful in her attempt to secure an outcome. The recognition that every attempt may not be successful prompted presidents to embrace risks in their efforts to secure resources without creating undue stress that every attempt must result in a resource. Drummond shared advice that she received from a mentor who told her:

"Sarah, you're never going get $100 \%$ of the people to do $100 \%$ of what you plan $100 \%$ of the time [laughs]. It ain't going to happen!" So, he said, "You know just don't try for it." In fact his idea was that if you can start something small and if 
you start some little things out here [draws diagram], you know, and you can just start some things. He said, "Then if they grow, there is some gravity, and that gravity pulls them into and they become part of the formal structure."...He said, "You start something and when you start small things you don't know if they're going to work or not, like the [leadership institute] or the speaker's bureau or the parent's organization... They're not all going to be homeruns, but if you can work on one or two of them into that formal structure, then the better off you are."

Authenticity's value was woven into all relationships, as Hamilton summed up her approach to fundraising:

I think it's at the heart of fundraising, but I also think it's at the heart [of] working with faculty, students. They can tell. I mean they have good radar... What do you call them? [Pause]. Crap detectors. They know when it's not legitimate or it's not authentic.

\section{Chapter Summary}

The function of obtaining embedded resources also contained multiple dimensions that relied on the intentionality, abilities, and desires of these presidents to form instrumental relationships that were earlier identified and cultivated as having meaning for their institutions. After making the initial investments, presidents now needed to make the case to constituents, use the prominence of their positions, recognize and seize opportunities, and to appreciate and value human connections to secure resources. While they were motivated to form relationships to capture resources for their institutions, they were equally conscious of their capacities to lead their institutions. Thus, if presidents asked others to invest in their institutions, they were sensitive to the sustainability, viability, and health of their institutions. Through the interviews of presidents, the position of the presidency possessed its own capital—status. Each president formed and developed connections as result of being in a high status position, a position that allowed access to other high status positions (e.g., chief executive officers and affluent 
individuals) and with others in non-high status positions. Regardless of the level or type of position that an individual held, presidents were keenly aware of their reliance on forming connections intentionally, but authentically, with a variety of constituents who possessed a diversity of resources to offer the institution. Despite their best intentions and efforts, the release of resources did not always occur, leaving presidents to re-engage with constituents until the resources could possibly be gained. This action took place as presidents continued their attempts to identify new relationships, as well as cultivate existing relations. 


\section{CHAPTER IX \\ FORGING A NEW PERSPECTIVE FOR RESEARCH ON \\ WOMEN PRESIDENTS AND INSTRUMENTAL \\ RELATIONSHIP BUILDING}

With interviews concluded and analyses completed, the final chapter summarizes what was learned and considers new research paths that may be explored regarding academic presidents and relationship building. Twelve presidents with unique personal backgrounds and experiences from 12 institutions of higher learning made one common decision, which was to participate in a study that focused on how women presidents identified and cultivated relationships with constituents with whom they could retrieve resources for their institutions. Even though the literature focusing on women presidents (Bornstein, 2003; Darden, 2006; Eddy, 2009; Kuh \& Natalicio, 2004; Madsen, 2008; Mangels, 2009; Turner, 2007; Valdata, 2006; Woodlee, 1992) acknowledges the importance of relationships to women in academic presidencies, and although presidential biographies and testimonies (Flawn, 1990, Gardner, 2005; Lee, 2005; Jones, 2005) suggest that relationships are critical for presidents regardless of gender, none explain the mechanisms involved with relationship building, specifically for instrumental outcomes. The purpose of this study was to explore the practices that were strategically developed and practiced by participants to identify and build relationships that would further institutional missions. Women presidents were specifically targeted as a result of the 
literature suggesting that they tend to form internal relationships with constituent groups to "foster a sense of cohesiveness and oneness" (Eddy, 2009, p. 20), instead of specific outcomes, and "may be seen as inept in developing relationships of importance to the institution, because many women are averse to the external requirements of the presidency” (Bornstein, 2009, p. 210).

The stories shared by participants in this study captured their approaches to identify and cultivate relationships, as they pertained to retrieving instrumental outcomes. All of these practices were being performed at the same time; while the presidents were identifying new relationships, they were cultivating existing ones. The methods were highly functional, making relationship building practically appear routine. However, when presidents described the methods they used to form instrumental relations, they revealed processes that were quite complex. The presidents also confirmed that instrumental relationship building with stakeholders contained an outcome dimension, meaning that the presidents were purposeful in establishing and evolving relationships to achieve resources for their respective campuses.

By breaking down relationship building into three components, these presidents put into action their plans to capture resources for their institutions. First, even though identifying stakeholders is a function of relationship building, the practice, itself, was more complicated than presidents simply listing important constituents. The presidents attributed meaning to their interactions with stakeholders. They described how they were driven to connect with stakeholders, and they conveyed how they created a presence both on and off campus with constituents. Second, presidents provided evidence that fostering relationships was more than just meeting, entertaining, and showing up to an event with 
constituents. Cultivating relationships meant participants continued to engage and stay involved with stakeholders. They used surrogates to help them nurture relations, and they attempted to minimize disruptions or dysfunctions that could harm relationships. Participants remained mindful that a high degree of responsibility on their part was required to sustain these relations. Finally, after making the initial investments in their relations, presidents utilized a variety of practices to secure resources for their institutions; they did not simply ask constituents to release their resources. Instead, they made the case to constituents, used the prominence of their positions, recognized and seized opportunities, and relied on their abilities to make human connections. These practices demanded the presidents to engage and re-engage with constituents regardless of whether a resource was obtained or not.

Lin's (2001a) theory of social capital provided a useful and appropriate framework to consider the resource acquisition strategies that this study's participants utilized. His concept of social capital emphasizes how social connections and networks are essential elements of creating or enhancing outcomes at the micro level. Obtaining resources is critical for institutions and their presidents who are ultimately responsible for strengthening, improving, and transforming their institutions. As learned from these participants, establishing relationships with diverse constituents, who often possess disparate needs and expectations, was challenging, flustering, and time consuming; yet, they also found it personally and professionally rewarding.

Because there is no past research on how women presidents form instrumental relationships, the stories shared by this study's participants and considered through the lens of social capital captured the multiple dimensions of the practices used with this type 
of relationship building. By using a qualitative research design, the narratives of participants uncovered the intentional, as well as the temporal and emotional facets associated with relationship building and the academic presidency. Coffey and Atkinson (1996) point out that qualitative research has value in "uncovering the complex causal relationships at play within a given social milieux" (p. 143), and for these presidents, their social environments could, indeed, be described as complex, because they formed relationships for a variety of different purposes, using diverse strategies and practices to manage and move those relations.

\section{Key Findings}

The theoretical framework guided this study's three research questions, which were designed to explore how women presidents purposefully identified and built relationships for resource purposes. They also gave direction in discussing themes that emerged from the stories and narratives of the participants. The research questions and their key findings are below.

\section{Research Question 1: How Do Women Presidents Identify Social Relations that have Embedded Resources?}

The findings in this section relate to how participants identified key internal and external constituents who possessed resources that were valuable to their respective institutions. Three practices emerged, reflecting the deliberate actions and behaviors undertaken by presidents.

- Presidents indicated that they ascribed meaning to their interactions with constituents. This practice allowed them to link key relationships to their presidential functions and responsibilities, allowing them to identify 
constituents who could assist with fundraising, strategic planning, administrative leadership, external relations, as well as fulfill their campus' visions.

- Participants also shared that they were purposeful with the time and energy they dedicated to identifying key stakeholders. Their attention and interactions were guided by being passionate and mission-oriented, entrepreneurial, strategic, perceptive, and credible.

- Presidents suggested that they could not isolate themselves from their constituents. They needed to intentionally insert themselves into their campus' communities, as well as the communities that surrounded their respective institutions, in order to identify stakeholders with whom they needed to build their bases of support.

\section{Research Question 2: How Do Women Presidents Build and Foster Relationships with Individuals Who Possess \\ Resources that Can Achieve Institutional Objectives?}

The findings for this question uncovered the multiple dimensions associated with building and fostering key relationships. Similar to the practices related to identifying constituents with valuable resources, presidents suggested that this stage of relationship building was not a passive one. They continued to dedicate their attention towards nurturing relationships in order to eventually acquire potential resources.

- Participants revealed that they continued to stay involved and engaged with key stakeholders. They attempted to create touch points, which gave them opportunities to sustain nexuses between their institutions and constituents. 
- As a result of the number of relationships that required nurturing, presidents utilized surrogates who worked with constituents, met with stakeholders in the presidents' absences, or lobbied on behalf of their institutions.

- Because relationships could become dysfunctional or disrupted, presidents did not take them for granted. Participants suggested they needed to be attentive to their relationships and purposeful in their communications with constituents to avoid derailing critical relationships.

- Some relationships became more meaningful over time for constituents and presidents. Even though presidents may have formed and sustained relationships for instrumental purposes, long-term involvement with constituents who advanced the institution could lead to deeper and more personal connections and interactions.

\section{Research Question 3: How Do Women Presidents Capture}

\section{Embedded Resources in their Relationships to}

\section{Generate a Return on that Investment?}

Findings for this question suggest that participants used a variety of practices that they hoped would lead to institutional resources. Their responses indicated that this component of relationship building continued to be an active and on-going process.

- Presidents needed to make a case to constituents about releasing resources to their institutions. By projecting positive images of their leadership capacities, they built public confidence in themselves, knowing that stakeholders preferred to release resources to thriving institutions. Participants also shared how 
essential it was for them to collect and share stories about their campuses in order to compel constituents to release their resources to their institutions.

- The status of the presidency linked participants to constituents in high status positions or in positions with high public visibility, which, generally, symbolized an availability of or access to resources. Presidents mentioned that they used their positions to influence or to affect outcomes that could eventually lead to resources.

- Several presidents provided examples of how they recognized and seized opportunities to retrieve resources. They recognized the potential for gain by identifying a deficiency (e.g., funding or student enrollment), then creating an opportunity that could lead to the shortfall being diminished or eliminated.

- All presidents suggested that relationship building was the most important function of their positions. Participants understood that their abilities to acquire resources from their relationships were grounded in appreciating the human dynamics of those relationships and the emotional intelligence they possessed to sustain them.

\section{Purposeful and Instrumental: Contradicting Conventional Wisdom}

I think that internal, external [relationships] makes relationship building all the more important and all the more wearing, because that's what you're thinking. That's what I'm thinking about every day. I get up and think, "I got to contact this one and this one. I haven't contacted that donor or that donor..."

- Gloria Kahn, University of the State

Kahn captured an essential function of the academic presidency—relationship building with external and internal constituents. She also shed a new perspective on relationship building as practiced by these women presidents for the purpose of resource 
acquisition. These participants were knowledgeable about their stakeholders and acutely aware of the needs and expectations of those constituents. They were also strategic and deliberate with the methods they used to connect with and cultivate individuals who could make significant contributions to their institutions. With their stories now shared with a larger audience, these presidential experiences can now be put into the context of the current literature on women presidents. The first section focuses on the attitudes of women presidents in this study as they relate to relationship building and the next section centers on the purpose of relationship building as it relates to institutional outcomes.

\section{Attitude Towards Relationship Building}

In her book chapter about women presidents and their efforts to build legitimacy, Bornstein (2009) noted that a lack of empirical studies on women in academic leadership, specifically the academic presidency, may lead to statements and anecdotes about the way women lead, or not lead, leaving the impression that women are not capable of even being candidates for such positions. One such perception is that presidential search committees may perceive women candidates for the presidency as "inept in developing relationships of importance to the institution, because many women are averse to the external requirements of the presidency" (p. 210). The effect of this opinion on presidential search committees or women interested in committing to a presidency is unknown. Martin (2010) and Ibarra, Ely, and Kolb (2013) suggest that there is a perception women have not been socialized to successfully compete in male dominated professional worlds, thus they must be coached the skills that their male counterparts acquire as a result of their sex. The anecdote that Bornstein makes note of is yet another pronouncement of how gender traits have been essentialized as result of culturally 
embedded beliefs that women's characteristics and leadership skills are weaker and less preferred than those possessed by their male counterparts (Bornstein, 2009; Eddy, 2009; Lipman-Blumen, 1996; Niddifer, 2001; Valian, 1999).

Findings from this current study suggest that these participants were neither incompetent at nor opposed to forming relationships for the necessity of developing and cultivating relationships with internal and external stakeholders (Bornstein, 2009). Asking participants to share their individual and unique pathways to the presidency was one means of learning what experiences, proficiencies, and challenges contributed to their success (Madsen, 2008), and the stories of these presidents reflected how their life experiences shaped and prepared them for the level of relationship building that occurred at the presidential level, even if they had no intention of seeking the position. Childs' probably shared the most self-assured response regarding her preparedness for the level of relationship building required of the presidency:

It was not a learning curve for me. We [she and her sibling] were expected from the time we were tiny children to mingle among these adults and be comfortable. I mean I could have talked to the president of the United States when I was 12 years old, because that's the way we were raised. So, from the time I was 10, I was giving speeches. So, I did not have a learning curve.

She admitted that her specific challenge was not building relationships; instead, she had to "learn all the people" with whom she would need to build relationships with as president. It is important to note that the expected learning curve of identifying key constituents is a different challenge than not being able to form instrumental relations or being opposed to that function and responsibility. Another president who reflected on her previous experience in relationship building relative to the presidency was Murphy, who had been a schoolteacher for two decades. 
...My years of being a teacher really served me well because teaching is all about relationships with children. You can't be a good teacher unless you have strong relationships with your students. So, in that sense, I think I was really well prepared, but I also think that it is something that I'm good at, so it's one of the gifts that I bring to the presidency.

Kahn was very deliberate with her professional pathway to the presidency. She knew that relationship building was a critical function of the position, thus she prepared for that role by requesting to be involved in fund raising activities as a dean and provost. Relationship building was also on Fletcher's radar as she made her way to the presidency. Her experience as an untenured department chair at a state university made her realize that she needed to build relationships with each individual tenured faculty member, because being their chair meant nothing to them.

I couldn't use positional power very well, because they had power of rank. They were full professors. They had experience. They had been vice presidents. They had tenure. They had all of that. If I'd relied on positional power, I would have been dead. It was about the ability to conceptually get them to buy into a concept; found out where we could come together; and to influence them that way. Purely by the ability to talk with them and meet with them and get them to meet with each other and recognizing when one was a lost cause [chuckles].

Others, like Eyre and Callaghan, mentioned how they developed and honed their relationship building skills while in their previous positions. They both recounted their experiences with community and business leaders through their memberships on Chamber of Commerce and United Way boards. Their learning curves were dependent on how they employed and navigated their relationship building skills in their new environments; Eyre needed to understand how a larger business community operated in a bigger metropolitan area, and Callaghan needed to learn how to apply her relationship building skills from her corporate and volunteer activities to higher education. Yet neither disclosed an opposition or hesitation to apply their relationship building experiences to an 
academic presidency. This is supported by Madsen (2008), who found in her study on the experiences of women presidents that participants' initial discomforts in tackling new responsibilities were replaced with self-assurance and the development of new skill sets.

For Sinclair and Graham, their presidencies created learning curves for them.

Sinclair stated,

It's [relationship building is] not a choice, you know. The choice was entering the search to be the [president] at Harley State University...I had to realize that the relationships that I had with previous institutions may have been more internal, and I had to shift my thinking....mind shift to more external and how do you balance that?

Yet, she learned how to partner with multiple constituents in her student affairs positions and this "big picture view of the institution" was what she brought to her presidency and relationship building. Despite not having the external relationship experiences, Sinclair recognized the significance of those relationships, as well as how internal and external relations demanded a president's attention and effort. As for Graham, who was simply appointed and not vetted for her presidential position when her predecessor suddenly resigned, she said that she inherited a "mess" and admitted she did not know how to cultivate relationships:

I certainly wasn't [prepared]. I was not, but I never intended to be president. You know, I wasn't doing the things that people do when what they want to be is the president. You know, I never did that. [Pause]. I don't recommend my path [chuckles].

However, when Graham's responses about identifying and cultivating relationships were revealed in this study, she disclosed how intentional she actually was in developing relationships as Post emerged from financial exigency and throughout her career as president. 


\section{A Purpose of Relationship Building: Institutional Resources}

Once presidents assumed their positions, instrumental relationship building was demonstrated through their praxis. Although Kahn was joking when she shared a comment about the DNA of a public institution president being comprised of the ability to ask for money, the professional coding of a president may indeed have to include a set of instructions that compel them to understand the need and the necessity of the position to form and sustain instrumental relations with a diversity of constituent groups. The narratives of these presidents provided explicit examples of the forces that demanded them to move from the core of their institutions to its outer margins. Within each practice associated with relationship building, presidents described the intentionality that was required to move relations forward to the ultimate goal of resource reallocation. Even when a resource was secured, the presidents did not suspend the relationship; instead, they looped back to cultivate and foster the relationship. If the resource was not secured, they looped back to cultivate and foster the relationship, repeating their efforts to secure a resource. The repetitive looping occurred as presidents sought new relationships to build and nurture. Hence, the practices of relationship building transpired simultaneously, as presidents attentively managed diverse relationships at different levels with individuals who possessed divergent needs and resources. The narratives of the participants also provided additional evidence demonstrating that participants did not expect to be successful in retrieving resources with every attempt at relationship building but understood an outcome would be realized only when the opportunity was right for the person relinquishing the resource. 
These findings extend those found in Eddy's (2009) study. Using a gender-related theoretical framework as a lens, she considered if community college women presidents led in gendered ways that differed from the leadership styles of their male counterparts. One theme that emerged from her study focused on the leadership perspectives of the women presidents relative to relationship building; men tended to view internal relationship building as a means to affect their agendas, whereas women regarded relationship building as a means to build community within their campuses. She found that men were not as personally invested in relationships and appeared to be more detached from their relationships than women presidents in the study. Though not part of her study, what if the women presidents in her study considered community as a strategic outcome? What if her participants could elaborate on the potential resources that could be accessed and acquired as a result of their efforts to create relationships? Would they consider themselves intentional, deliberate, and strategic in their relationship building attempts?

In part, these 12 presidents answered those questions as evidenced by their own stories. Using social capital as a lens, it is evident that their efforts to identify and cultivate instrumental relations led to access to legislators; advocacy on behalf of legislators; institutional acceptance of the mission; cooperation and goodwill between the institution and community, business leaders, and alumni; donations; effective governance by the board; effective governance by central administration; effective governance by the chair of the board; engaged board and faculty members; effective institutional practices; high morale and confidence in the institution; positive publicity for the campus; greater reputational currency for the institution; new facilities; more admission applications; opportunities for students; and new ideas. In making her case about the connection 
between instrumental relationship building and resources, Fletcher said:

I spent a lot of time in that first year making sure I had relationships with people here, that I understood the campus here...I believe has served me exceedingly well...You want to talk about resources? If you're constantly dealing with fighting and bickering internally and you got people saying bad things externally...challenges resources. The ability to get people to move in a direction by coercion doesn't happen as far as I'm concerned in higher ed.

Further, presidents recognized that constituents provided resources to those institutions that were healthy and thriving. Eyre commented that "the day-to-day work of the presidency depends on the institution operating well," which was why she considered her relationship building essential to Bayer's success. A prospering campus to these presidents meant significant economic multiplier effects on their local communities through employee payrolls and student spending, as well as the fiscal infusion of what new capital projects meant for businesses. Colleges and universities hosted cultural, athletic, leadership programs, and special speaker events that connected stakeholders to the life and mission of those institutions. New major programs and capital projects were approved and funded by foundations or legislatures or donors or a combination of those groups to meet the needs of constituents and the larger society. These presidents recognized that they were not solely responsible for the good fortunes coming to their institutions, but, as presidents, they were an essential part of its success. With this statement, Hamilton acknowledged her role in improving community relations: “I don’t need to take credit for that at all, but I think I've worked harder at that and been more of a help with that than people probably will ever know." 


\section{Creating New Research Paths}

Institutions of higher learning matter, as does the leadership that guides and furthers their roles and missions regionally, nationally and globally. Although the presence of women in academic presidencies has increased, they still make up only slightly more than a quarter of presidents (ACE, 2012). As a result, similar to women leaders in other professions, presidents of colleges and universities continue to be subjected to scrutiny and preconceptions about their ways of leading, including their abilities and capabilities to lead these important institutions. Thus, further research about women educational leaders may lead to new interpretations of the academic presidency and relationship building, as well as the socialization of women into the role. Potential ideas arising from this study are considered within the context of the research questions of this study.

Research on instrumental relationships using a post-modern leadership framework could provide the opportunity to explore new insights on how women presidents consider collective practices relative to relationship building. Social capital, as conceptualized by Lin (2001a), allowed this study to consider women presidents at the individual level, however, presidents in this study said they relied on others to do the "work" of the institution. Because leadership is a collective action, Wheatley (2006) stresses the holistic nature of leadership and considers leadership as a relational endeavor. Traditional leadership theories focus on defining leadership, how leadership is done, and who are the leaders. But emerging leadership theories center on the process of leadership (Lyman, Ashby, \& Tripses, 2005; Rost, 1993). These emerging leadership theories are based on non-coercive relationships between leaders and followers with the expectation that those 
roles are interchangeable by the actors (Rost, 1993). Using this perspective, the president may sometimes become the follower rather than being the leader, and new leadership assumptions provide new insights on strategic relationship-building for academic presidents. Ruth Simmons, who is now a former president of Brown University and who introduced this study, said these questions are essential in solving systemic problems, "What motivates us? What challenges us? What moves us?" (Simmons, 2009). Simmons' series of questions regarding human connections is compatible with Wheatley's conceptualization of leadership:

We must understand the behavior of networks in the densely connected world. We must understand human motivation and our astonishing capacity to selforganize when we care about something. We must understand that we lose capacity and in fact create more chaos when we insist on hierarchy, roles, and command and control leadership. (p. 186)

The application of a leadership theory, such as Wheatley's, to a phenomenological study would include the voices of constituents, as well as the president's. Potential themes emerging from such a study could include perceptions of relationship building, consideration of networks created by group members to learn and strategize from each other, and the impact of actions intended to achieve institutional goals. This may help institutional leaders redefine or conceptualize leadership as a synergistic phenomenon involving both leaders and followers that does not simply focus on hierarchical approaches to problem solving.

Further research on the women presidents from underrepresented groups would enhance our understanding of women's leadership in higher education. From 2006 to 2011, the percentage of African-American women presidents increased from $32 \%$ to $34 \%$, and the number of Hispanic women presidents increased from $34.8 \%$ to $38.7 \%$. 
Despite these modest increases, the total percentage of minority presidents decreased from $13.5 \%$ in 2006 to $12.6 \%$ in 2011. Presidents from underrepresented groups were predominately represented at public master's and bachelor's institutions.

According Freeman, Bourque, and Shelton (2001), social class, race, and ethnicity have significant implications on the opportunities afforded to different groups of women, and Turner and Kappes (2009) argue that sexist and racist attitudes persist to restrict educational prospects for women of color, while institutional policies may impede and inhibit women faculty from rising through the academic ranks or seeking administrative positions. Examining the pathways of three women of color who were the "first" of their gender, race, and ethnicity to become a president of a public, baccalaureate institution, Turner (2007) unveiled their emphasis on communicating and interacting with others relative to their institutional missions. These researchers argue that the experiences of women of color may lead to different leadership approaches and methods, and Mertz (2009) suggests that women of color need to be "studied on their own, in their unique and particular voices, and their experiences disaggregated for us to truly 'see' what they experience in the academy" (p. ix.).

Future studies could apply the theoretical framework and research design from the current study to learn more about the intentionality and strategies relative to relationship building that women of color may use to secure resources. Participant narratives may lead to some common themes, but the expectation would be that new patterns of relationship building would emerge, thereby, increasing our knowledge of relationship building, securing resources, and women of color in the presidency. 


\section{Concluding Thoughts}

Actually being involved in this [economic development group], which is this 10 county area, has helped me understand more fully what I had said more glibly before which is that old cliche "a rising tide floats all boats" to the extent that the educational institutions can flourish, to the extent that the businesses can flourish, to the extent that municipal governments can get their acts together it's going to benefit all of us. I mean um so if there's any way we can cooperate or at least not stand in each other's ways, the likelier we will all improve.

-Kathleen Hamilton, Bedford University

"A rising tide floats all boats" is an aphorism that is apropos in describing the purpose of instrumental relationship building for these 12 presidents. Hamilton's quote was representative of the practices and philosophies of presidents in this study. While resources are given to the institutions, the benefits of those resources are redistributed to others both on and off campus. This study revealed the strategic and purposeful intentions of presidents, who were keenly aware of the environment affecting higher education, as well as their regions, states, and local communities, and how they identified and cultivated relationships with multiple constituents for institutional resources. Their stories captured an appreciation and respect for their institutions, missions, and, particularly of, stakeholders. Instrumental relationship building was undertaken by the president as a vigilant act--it took patience, perseverance, enthusiasm, and the hope that constituents would see the value of sharing resources with an institution that possessed much meaning for them personally and professionally.

Whether institutions are led by a woman or a man, they are resource dependent, and the current economic, political, and social climates demand that higher education play significant and varied roles in meeting expectations of states and the federal government, business and commerce, and individuals who seek advanced educations. 
The aforementioned cliché could also serve as a signal to constituents that the community of an institution must recognize the dearth of resources to fulfill these obligations. With fewer earmarks, decreased federal and state funding, and possibly shrinking or slower growing endowments, institutional-wide entrepreneurialism will be necessary to help institutions compete for finite resources from finite sources (Clark, 2004). Clark states that the "pace of change dictated a more flexible and adaptable posture" by institutions working towards their own sustainability. He contends that "entrepreneurialism works when it is significantly collegial" and that "new forms of academic-administrative relations have to be worked out" (p. 173). Kahn mentioned several times throughout her narrative that the "pace of change" was moving quickly in higher education, and it forced her to consider how relationship building with faculty and other constituents would be affected by it. Institutional responses towards sustainability will vary based on missions and on capacities to seek resources, and one strategy presidents may have to pursue includes integrating new groups, individuals, and ideas into institutional practices directed towards instrumental relationship building. 


\section{REFERENCES}

Adler, P., \& Kwon, S. (2002). Social capital: Prospects for a new concept. Academy of Management Review, 27(1), 17-40.

Alexander, K. (1976). The value of an education. In D. W. Breneman, L. L. Leslie, \& R. E. Anderson (Eds.), ASHE reader in finance in higher education, pp. 85-111.

Allan, E. (2011). Women's status in higher education: Equity matters. ASHE Higher Education Report, 37(1). San Francisco, CA: Jossey-Bass.

American Association of University Professors. (2006). Statement on government of colleges and universities. Retrieved on September 1, 2009, from the AAUP website: http://aaup.org.

American Council on Education. (2005). On assuming a college or university presidency: Lessons from the field. Washington, DC: Author.

American Council on Education. (2007). The American college president: 20th anniversary (2007 ed.). Washington, DC: Author.

American Council on Education. (2012). The American college president: 2012. Washington, DC: Author.

Association of Governing Boards of University and Colleges. (2006). The report of the $A G B$ Taskforce on the state of the presidency in American higher education: The leadership imperative. Retrieved November 1, 2010, from the AGB website: http://agb.org.

Astin, H., \& Leland, C. (1991). Women of influence, women of vision: A crossgenerational study of leaders and social change. San Francisco, CA: JosseyBass Publishers.

Bass, B., \& Stogdill, R. (1990). Bass \& Stodgill's handbook of leadership: Theory, research, and managerial applications. New York: The Free Press.

Baxter Magolda, M. (1994). Gender and making meaning of experience. In J. Fried (Ed.), Different voices: Gender and perspective in student affairs administration (pp. 12-29). Washington, DC: National Association of Student Personnel Administration. 
Bee, R. E. (2001). The preparation of the Christian college president and fund raising effectiveness (Doctoral dissertation). Retrieved from ProQuest. (Publication No: 3003463).

Bensimon, E., Neumann, A., \& Birnbaum, R. (1989). Making sense of administrative leadership: The " $L$ " word in higher education. ASHE-ERIC Higher Education Report No. 1. Washington, DC: School of Education and Human Development, The George Washington University.

Bila, T. A. (2003). Involving faculty members in institutional fundraising. In M. T. Miller \& J. Caplow (Eds.), Policy and university faculty governance (pp. 137-152). Greenwich, CT: Information Age Publishing.

Birnbaum, R. (1988). How colleges work: The cybernetics of academic organization and leadership. San Francisco, CA: Jossey-Bass.

Birnbaum, R. (1992). How academic leadership works: Understanding success and failure in the college presidency. San Francisco, CA: Jossey-Bass.

Birnbaum, R. (2004). The end of shared governance: Looking ahead or looking back. In W. Tierney \& V. Lechuga (Eds.), Restructuring shared governance in higher education (pp. 5-22). San Francisco, CA: Jossey-Bass.

Birnbaum, R. \& Eckel, P. D. (2005). The dilemma of presidential leadership. In P. Altbach, R. Berhdahl, \& P. Gumport (Eds.), American higher education in the twenty-first century: Social, political, and economic challenges $\left(2^{\text {nd }} \mathrm{ed}.\right)$ (pp. 340-365). Baltimore, MD: The Johns Hopkins Press.

Blau, P. M. (1994). The organization of academic work ( $2^{\text {nd }}$ ed.). New Brunswick, NJ: Transaction Publishers.

Bogdan, R. \& Biklen, S. (2003). Qualitative research for education: An introduction to theories and methods ( $4^{\text {th }}$ ed.). Boson: Allyn and Bacon:

Bolman, L. \& Deal, T. (2003). Reframing organizations: Artistry, choice, and leadership $\left(3^{\text {rd }}\right.$ ed.). San Francisco, CA: Jossey Bass.

Borland, K. W. (2003). The relationship between faculty and academic administration in governance functions. In M. T. Miller \& J. Caplow (Eds.), Policy and university faculty governance (pp. 137-152). Greenwich, CT: Information Age Publishing.

Bornstein, R. (2003). Legitimacy in the academic presidency: From entrance to exit. Westport, CT: Praeger Publishers. 
Bornstein, R. (2009). Women and the quest for presidential legitimacy. In D. R. Dean, S. J. Bracken, \& J. K. Allen (Eds.), Women in academic leadership: Professional strategies, personal choices (pp.208-237). Sterling, VA: Stylus Publishing.

Bryman, A. (1999). The debate about quantitative and qualitative research. In A. Bryman \& R. Burgess (Eds.), Qualitative research: Volume I (pp. 35-69). Thousand Oaks, CA: Sage Publications.

Brubacher, J. S. \& Rudy, W. (1976). Higher education in transition ( $3^{\text {rd }}$ ed.). New York, NY: Harper \& Row Publishers.

Burgan, M. (2004). Why governance? Why now? In W. Tierney (Ed.), Conceptions of academic governance: Negotiating the perfect storm. Baltimore, MD: Johns Hopkins Press.

Burns, A. (2007). From the school of hard knocks. National Journal, 39(32), 33-34.

Burns, J. M. (1978). Leadership. New York, NY: Harper \& Row Publishers.

Burt, R. S. (2001). Structural holes versus network closure as social capital. In N. Lin, K. Cook, \& R. Burt (Eds.), Social capital: Theory and research (pp. 31-56). New York, NY: Walter de Gruyter, Inc.

Campbell, D. (2003). Leadership and academic culture in the senate presidency: An interpretive view. American Behavioral Scientist, 46(7), 946-959.

Carnegie Classification of Institutions of Higher Education. Retrieved September 10, 2011, from http://classifications.carnegiefoundation.org/.

Center for the Study of Education Policy, National Association of State Student Grant Aid Programs, \& State Higher Education Executive Officers. (October, 2006). Recession, retrenchment, and recovery: Vol. 1. State higher education funding \& student financial aid.

Chliwniak, L. (1997). Higher education leadership: Analyzing the gender gap. ASHE-Eric Higher Education Report, 25(4). Washington DC: The George Washington University Graduate School of Education and Human Development.

Christman, L. (2003). Characteristics of effective liberal arts college presidents (Doctoral dissertation). Retrieved from ProQuest. Publication No: 3079021.

Clark, B. (2004). Sustaining change in universities: Continuities in case studies and concepts. New York, NY: Open University Press.

Coffey, A. \& Atkinson, P. (1996). Making sense of qualitative data: Complementary research strategies. Thousand Oaks, CA: Sage Publications. 
Cohen, A. (1998). The shaping of American higher education: Emergence and growth of the contemporary system. San Francisco, CA: Jossey-Bass Publishers.

Cohen, M. D. \& March, J. G. (1986). Leadership and ambiguity: The American college president $\left(2^{\text {nd }}\right.$ ed.). Boston, MA: Harvard Business School Press.

Cole, J. R. (2009). The great American university: Its rise to preeminence, its indispensable national role, and why it must be protected. New York, NY: Public Affairs.

Coleman, J. S. (1990). Foundations of social theory. Cambridge, MA: Belknapp Press of Harvard University Press.

Collis, D. (2004). The paradox of scope: A challenge to the governance of higher education. In W. Tierney (Ed.), Competing conceptions of academic governance: Negotiating the perfect storm. Baltimore, MD: Johns Hopkins Press.

Cowley, W. H. (1980). Presidents, professors, and trustees: The evolution of American academic government. San Francisco, CA: Jossey-Bass Publishers.

Creswell, J. (2007). Qualitative inquiry and research design: Choosing among five approaches $\left(2^{\text {nd }}\right.$ ed.). Thousand Oaks, CA: Sage Publications.

Darden, M. (2006). Women presidents in American four-year colleges and universities: An analysis of reported changeable attributes contributing to their success (Doctoral dissertation). Retrieved from ProQuest. (Publication No. 3216360).

Dean, D., Bracken, S. J., \& Allen, J. S. (2009). Women in academic leadership: Professional strategies, personal choices. Sterling, VA: Stylus Publishing.

Denzin, N. \& Lincoln, Y. (2008). The landscape of qualitative research. Los Angeles, CA: SAGE Publications.

Duderstadt, J. (2000). A university for the 21st century. Ann Arbor, MI: The University of Michigan Press.

Duderstadt, J. (2004). Governing the twenty-first century university: A view from the bridge. In W. Tierney (Ed.), Competing conceptions of academic governance: Negotiating the perfect storm. Baltimore, MD: Johns Hopkins Press.

Duryea, E. D. (2000a). Evolution of university organization. In M. Brown II (Ed.), Organization \& governance in higher education ( $5^{\text {th }}$ ed.). Boston, MA: Pearson Custom Publishing. (Reprinted from The University as an Organization, 1973).

Duryea, E. D. (2000b). The academic corporation: A history of college and university governing boards. New York, NY: Falmer Press. 
Eddy, P. L. (2009). Leading gracefully: Gendered leadership at community colleges. In D. R. Dean, S. J. Bracken, \& J. K. Allen (Eds.), Women in academic leadership: Professional Strategies, personal choices (pp.8-30). Sterling, VA: Stylus Publishing.

Ehrenberg, R. G. (2002). Tuition rising: Why college costs so much. Cambridge, MA: Harvard University Press.

England, K. V. L. (2006). Interviewing elites: Cautionary tales about researching women managers in Canada's banking industry. In P. Moss (Ed.), Feminist geography in practice: Research and methods (pp. 200-213). Malden, MA: Blackwell Publishers.

Fisher, J. L. \& Koch, J. V. (1996). Presidential leadership: Making a difference. Phoenix, AZ: Oryx Press.

Fisher, J. L., Tack, M. W., \& Wheeler, K. J. (1988). The effective college president. New York, NY: Macmillan Publishing Company.

Flawn, P. (1990). A primer for university presidents: Managing the modern university. Austin, TX: University of Texas Press.

Freeman, S., Bourque, S., \& Shelton, C. (2001). Women on power: Leadership redefined. Boston, MA: Northeastern University Press.

Fujita, E. (1994). A good college president: A constituent view. Journal of Personnel Evaluation in Education, 8(1), 75-91.

Gilligan, C. (1993). In a different voice: Psychological theory and women's development. Cambridge, MA: Harvard University Press.

Gardner, D. P. (2005). Earning my degree: Memoirs of an American university president. Berkeley, CA: University of California Press.

Gardner, H. (1995). Leading minds: An anatomy of leadership. New York, NY: Basic Books.

Glesne, C. (2006). Becoming qualitative researchers: An introduction. Boston, MA: Pearson/Allyn \& Bacon.

Goleman, D. (1995). Emotional intelligence. New York, NY: Bantam Books.

Goleman, D. (2001). Emotional intelligence: Issues in paradigm building. In C. Cherniss \& D. Goleman (Eds.), The emotionally intelligent workplace: How to select for, measure, and improve emotional intelligence in individuals, groups, and organizations (pp. 13-26). San Francisco, CA: Jossey-Bass. 
Granovetter, M. (1974). Getting a job ( $2^{\text {nd }}$ ed.). Cambridge, MA: Harvard University Press.

Halpern, D. (2005). Social capital. Malden: Polity Press.

Hearn, J. C. \& Bunton, S. A. (May, 2001). Economic and social returns of baccalaureate, graduate, and professional degrees (Policy Brief 01-01). University of Minnesota.

Hendrickson, R. M., Lane, J. E., Harris, J. T., \& Dorman, R. H. (2013). Academic leadership and governance of higher education: A guide for trustees, leaders, and aspiring leaders of two-year and four-year institutions. Sterling, VA: Stylus Publishing.

Hesse-Bieber, S. N., \& Leavy, P. (2006). The practice of qualitative research. Thousand Oaks, CA: Sage Publications.

Hesberg, T. M. (1999). God, country, Notre Dame. Notre Dame, IN: University of Notre Dame Press.

Hirschorn, L. \& May, L. (2000). The campaign approach to change: Targeting the University's scarce resources. Change, 32, 30-37.

Hodel, R., Laffey, M., \& Lingenfelter, P. (2006). Recession, retrenchment, and recovery: State higher education funding \& student financial aid. Boulder, CO: State Higher Education Executive Officers. (ERIC Document Reproduction Service No. ED502180).

Ibarra, H., Ely, R., \& Kolb, D. (2013). Women rising: The unseen barriers. Harvard Business Review, 91(9), 60-67.

Indianapolis Business Journal. UIndy capitalizing on Super Bowl attention. Retrieved August 30, 2014, from http://www.ibj.com.

Institute of Higher Education Policy. (February, 2005). The investment payoff: A 50state analysis of the public and private benefits of higher education.

Johnsen, J. R. (2006). Leadership in context: A case study of presidential effectiveness in a state university system (Doctoral dissertation). Retrieved from ProQuest. (Publication No. 3209995).

Judge, D. (2001). Leadership behaviors and attitudes of effective presidents of small private colleges (Doctoral dissertation). Retrieved from ProQuest. (Publication No. 3030151). 
Kezar, A. (2004). What is more important to effective governance: Relationships, trust, and leadership or structures and formal processes? In W. Tierney \& V. Lechuga (Eds.), Restructuring shared governance in higher education (pp. 35-46). San Francisco, CA: Jossey-Bass.

Kezar, A., Carducci, R., \& Contreras-McGavin, M. (2006). Rethinking the "L" word in higher education: The revolution of research on leadership. ASHE Higher Education Report, 31(6). San Francisco, CA: Jossey-Bass.

Kezar, A. \& Eckel, P. (2008). Understanding leadership strategies for addressing the politics of diversity. The Journal of Higher Education, 79(4), 406-441.

Kirp, D. L. (2003). Shakespeare, Einstein, and the bottom line: The marketing of higher education. Cambridge, MA: Harvard University Press.

Kirschling, J. M. (2004). Building social capital: Leading and leveraging constituencies outside the college. Journal of Nursing Education, 43(11), 517-519.

Kotler, P. \& Murphy, P. E. (1981). Strategic planning for higher education. The Journal of Higher Education, 52(5), 470-489.

Kouzes, J. M. \& Posner, B. Z. (1993). Credibility: How leaders gain and lose it, why people demand it. San Francisco, CA: Jossey-Bass.

Kouzes, J. M. \& Posner, B. Z. (2007). The leadership challenge ( $4^{\text {th }}$ ed.). San Francisco, CA: Jossey-Bass.

Krishnaveni, G. \& Ehrich, L. C. (2010). Transition into high school: A phenomenological study. In G. Dall'Alba (Ed.). Exploring education through phenomenology: Diverse approaches (pp.66-84). Malden, MA: Wiley-Blackwell.

Kuh, G. \& Natalicio, D. S. (2004). Forging a new direction: Connecting leadership contexts and competencies. Journal of Leadership and Organization Studies, $9(2), 18-28$.

Lazega, E. \& Pattison, P. (2001). Social capital as social mechanisms and collective assets: The example of status auctions among colleagues. In N. Lin, K. Cook, \& R. Burt, (Eds.). Social capital: Theory and research (pp. 185-208). New York, NY: Walter de Gruyter, Inc.

Leverage. (n.d). In Dictionary.com. Retrieved August 20, 2014, from http://dictionary.reference.com/browse/leverage.

Lin, N. (2001a). Social capital: A theory of social structure and action. Cambridge, UK: Cambridge University Press. 
Lin, N. (2001b). Building a network theory of social capital. In N. Lin, K. Cook, \& R.S. Burt (Eds.). Social capital: Theory and research (pp. 3-30). New York, NY: Walter de Gruyter, Inc.

Lipman-Blumen, J. (2000). Connective leadership: Managing in a changing world. New York, NY: Oxford University Press.

Lyman, L., Ashby, D., \& Tripses, J. (2005). Leaders who dare: Pushing the boundaries. Lanham, MD: Rowman \& Littlefield.

Lyman, L., Strachan, J., \& Lazaridou, A. (2012). Shaping social justice leadership: Insights of women educators worldwide. Lanham, MD: Rowman \& Littlefield.

Lucas, C. J. (2006). American higher education: A history. New York, NY: Palgrave Macmillan.

Madsen, S. R. (2008). On becoming a woman leader: Learning from the experiences of university presidents. San Francisco, CA: Jossey-Bass Publishers.

Mangels, S. (2008). Does balance matter? The relationship between work-life balance and success for women college presidents (Doctoral dissertation). Retrieved from ProQuest. (Publication No. 3316751).

McAdory, A. R. (2004). Transactional and transformational leadership: Differences between representative and peer-nominated effective presidents and as a function of institutional type and presidential gender (Doctoral dissertation). Retrieved from ProQuest. (Publication No: 3122332).

McGoey, S. (2007). A comparison of institutional stakeholders' perceptions of presidential effectiveness. International Journal of Educational Management, 21(2), 86-104.

McMillen, W. (2010). From campus to capitol: The role of government relations in higher education. Baltimore, MD: Johns Hopkins University Press.

Mertz, N. (2009). Breaking into the all-male club: Female professors of educational administration. Albany, NY: State University of New York Press.

Michael, S. O., Schwartz, M., \& Balraj, L. (2001). Indicators of presidential effectiveness: A study of trustees of higher education institutions. International Journal of Educational Management, 15(7), 332-346.

Miles, M. \& Huberman, A. (1994). Qualitative data analysis: An expanded sourcebook $\left(2^{\text {nd }}\right.$ ed.). Thousand Oaks, CA: Sage Publications. 
Minor, J. (2001). Making sense of leadership: Leadership attributes and practices of successful university presidents (Doctoral Dissertation). Retrieved from ProQuest. (Publication No. 3020847).

Nahapiet, J. \& Ghoshal, S. (1998). Social capital, intellectual capital, and the organizational advantage. Academy of Management Review, 23(2), 242-266.

Nelson, S. (2007). Leaders in the labyrinth: College presidents and the battleground of creeds and convictions. Westport, CT: Praeger Publishers.

Nelson, S. (2009). Leaders in the crossroads: Success and failure in the college presidency. New York, NY: Rowman \& Littlefield Education.

Niddifer, J. (2001). New leadership for a new century: Women's contribution to leadership in higher education. In J. Niddifer \& C. T. Bashaw (Eds.), Women administrators in higher education: Historical and contemporary perspectives. Albany, NY: State University of New York Press.

Odendahl, T. \& Shaw, A. (2001). Interviewing elites. In J. F. Gubrium \& J. A. Holstein (Eds.), Handbook of interview research: Context and method (pp. 299-316). Thousand Oaks, CA: Sage Publishing.

Olscamp, P. J. (2003). Moral leadership: Ethics and the college presidency. Lanham, MD: Rowman \& Littlefield.

Patton, M. (1990). Qualitative evaluation and research methods (2 $2^{\text {nd }}$ ed.). Newbury Park, CA: Sage Publications.

Patton, M. (2002). Qualitative evaluation and research methods $\left(3^{\text {rd }}\right.$ ed.). Thousand Oaks,CA: Sage Publications.

Paulsen, M. (2001). The economics of human capital and investment in higher education. In M. Paulsen \& J. Smart (Eds.). The finance of higher education: Theory, research, policy, and practice. New York, NY: Agathon Press.

Ramo, K. J. (1997). Reforming shared governance: Do the arguments hold up? Academe, 83(5), 38-43.

Relationship, (n.d.). In Merriam-Webster.com. Retrieved August 20, 2014, from http://www.merriam-webster.com/dictionary/relationship.

Resnick Pierce, S. (2012). On being presidential: A guide for college and university leaders. San Francisco, CA: Jossey-Bass.

Rosia, L. (2006). The successful college president: Strategies for leading in a complex environment (Doctoral dissertation). Retrieved from ProQuest. (Publication No. 19204). 
Rost, J. (1991). Leadership for the twenty-first century. New York, NY: Praeger Publishers.

Rowley, D. J., Lujan, H. D., \& Dolence, M. G. (1997). Strategic change in colleges and universities: Planning to survive and prosper. San Francisco, CA: Jossey-Bass.

Rowley, D. J., Lujan, H. D., \& Dolence, M. G. (1998). Strategic choices for the academy: How demand for lifelong learning will recreate higher education. The JosseyBass higher and adult education series. San Francisco, CA: Jossey-Bass.

Seale, C., Gobo, G., Gubrium, J. F., \& Silverman, D. (2007). Qualitative research practice. London: Sage Publications, Inc.

Seidman, I. (2006). Interviewing as qualitative research: A guide for researchers in education and the social sciences ( ${ }^{\text {rd }}$ ed.). New York: Teachers College Press.

Shapiro, H. T. (1998). University presidents-Then and now. In W. Bowen \& H. T. Shapiro (Eds.), Universities and their leadership (pp. 65-100). Princeton, NJ: Princeton University Press.

Shenton, A. K. (2004). Strategies for ensuring trustworthiness in qualitative research projects. Education for Information, 22, 63-75.

Silverman, D. \& Marvasti, A. (2008). Doing qualitative research: A comprehensive guide. Thousand Oaks, CA: Sage Publications, Inc.

Simmons, R. (2009). Remarks made at inauguration of Jim Yong Kim. Retrieved September 30, 2009, from http://dartmouth.edu.

Simmons, R. (2009). Remarks made during Reflections on Leadership for Social Change panel. Retrieved August 30, 2014, from htt://youtube.com.

Slaughter, S. \& Rhoades, G. (2004). Academic capitalism and the new economy: Markets, state, and higher education. Baltimore, MD: The John Hopkins University Press.

Stakeholder. (n.d). In Merriam-Webster online. Retrieved February 19, 2012, from http://www.merriam-webster.com/dictionary/stakeholder.

Tarule, J., Applegate, J. H., Earley, P. M., \& Blackwell, P. J. (2009). Narrating gendered leadership. In D. R. Dean, S. J. Bracken, \& J. K. Allen (Eds.), Women in academic leadership: Professional strategies, personal choice (pp. 31-49). Sterling, VA: Stylus Publishing.

Thomas, A. (2008). Preserving and strengthening together: Collective strategies of U.S. women's college presidents. History of Education Quarterly, 48(4), 565-589. 
Trachtenberg, J., Kauvar, G., \& Bogue, E. G. (2013). Presidencies derailed: Why university leaders fail and how to prevent it. Baltimore, MD: Johns Hopkins University Press.

Trow, M. (2010). Twentieth-century higher education: Elite to mass to universal. Baltimore, MD: Johns Hopkins University Press.

Turner, C. (2007). Pathways to the presidency: Biographical sketches of women of color firsts. Harvard Educational Review, 77(1), 1-38.

Turner, C. \& Kappes, J. (2009). Preparing women of color for leadership. In D. R. Dean, S. J. Bracken, \& J. K. Allen (Eds.), Women in academic leadership: Professional strategies, personal choice (pp. 149-180). Sterling, VA: Stylus Publishing.

Valdata, P. (2006). Lonely at the top? Diverse Issues in Higher Education, 23(20), 28-33.

Valian, V. (1999). Why so slow? The advancement of women. Cambridge, MA: MIT Press.

Veysey, L. (1965). The emergence of the American university. Chicago, IL: University of Chicago Press.

Wheatley, M. (2006). Leadership and the new science: Discovering order in a chaotic world ( ${ }^{\text {rd }}$ ed.). San Francisco, CA: Berrett-Koehler Publishers.

Wolverton, M., Bower, B., \& Hyle, A.E. (2009) Women at the top: What women university and college presidents say about effective leadership. Sterling, VA: Stylus Publishing.

Womack, J. D. (2009). College and university presidents of the Council for Christian colleges and universities: A comparative study of presidential effectiveness. (Doctoral dissertation). Retrieved from ProQuest. (Publication No. 3376153).

Woodlee, B. W. (1992). Factors relating to retention of women as presidents in higher education leadership. (Unpublished doctoral dissertation). Vanderbilt University, Tennessee.

Zacharakis, J., \& Flora, J. (2005). Riverside: A case study of social capital and cultural reproduction and their relationship to leadership development. Adult Education Quarterly, 55(4), 288-307.

Zumeta, W. (2004). State higher education financing: Demand imperatives meet structural, cyclical, and political constraints. In E. P. St. John \& M. Parson (Eds.), Public funding of higher education: Changing contexts and new rationales (pp. 79-107). Baltimore, MD: The John Hopkins University Press. 
APPENDIX A

INVITATION AND FORMS FOR PRESIDENTS 
Date

NAME

TITLE

ADDRESS

CITY, STATE, ZIP

Dear:

As part of my doctoral studies in the Educational Administration and Foundations program at Illinois State University, I am conducting a qualitative dissertation on how women academic presidents strategically identify, build, and foster relationships with stakeholders whom they recognize as possessing resources that may work towards meeting institutional outcomes. A summary of my study's purpose and procedures is enclosed. I am writing to request your participation in the study.

Should you decide to participate, I would like to interview you at a place and time of your choosing. The interview will last at least two hours and will focus on your general thoughts and opinions concerning the strategies you use to develop and sustain relationships and how you use those towards meeting institutional objectives.

Your insights will make a valuable contribution, helping to add to the literature of women in academic presidencies. By taking your experiences into account, a better understanding of the complexity between leadership and relationships is likely. In addition, although the study will yield few direct benefits to you personally, I hope you will find that the opportunity to reflect on your leadership experience is useful.

Thank you for your consideration of this request. Please feel free to contact me with any questions (my contact information is provided below). You can also contact my dissertation advisor, Dr. Jim Palmer (jcpalmer@ilstu.edu), and the Research Ethics \& Compliance Office at Illinois State University (309.438.2529).

A response form with a postage-paid envelope is enclosed. If it is easier, please feel free to respond via e-mail at $\quad$ or you may fax the form to me at

Sincerely,

Susan A. Woollen

Department of Criminal Justice Sciences, Illinois State University

Campus Box 5250

Normal IL 61790-5250

Phone:

Email: 


\section{Study of Women Academic Presidents (insert enclosed in invitation letter)}

Purpose of the study

Study procedures

Recruitment of study participants

Risks

Steps that will be taken to minimize risks

Benefits
The purpose of this qualitative study is to explore the practices strategically developed and used by women presidents of four-year public and private colleges and universities to identify, build, and foster relationships with institutional stakeholders whom they recognize as possessing resources that may work towards institutional outcomes.

The study will involve interviews with women academic presidents. The interview will be conducted at a time and place that is convenient for the participant. It is expected that the interview will last at least two hours. Each participant will be asked for permission to audiotape the interview, so that the researcher will have an accurate record of the participants' comments.

Participants will be selected using membership directories of the American Association of State Colleges and Universities, the Association of American Universities, and the National Association of Independent Colleges and Universities. They will be selected from 4-year public and private institutions in Illinois, Indiana, Iowa, and Wisconsin. An invitation to participate will be mailed to presidents, explaining the study and requesting that they contact Ms. Woollen should they want to participate.

There is always a concern that a confidentiality break could affect participants' reputations. Each participant has the right to expect that her comments will remain confidential. All participants will be assured of this confidentiality and steps will be taken to eliminate identifying personal information from the transcripts and to physically secure the tapes and transcripts themselves. Publications summarizing the results will examine general themes that emerge in the interviews. Participants, institutions, and any other individual(s) named during the interviews will be given pseudonyms.

As noted above, personal identifying information will not be included in transcripts or in published summaries of the study results. Audiotapes and paper transcripts will be secured in a locked cabinet in Ms. Woollen's office at Illinois State University. Electronic copies of the transcripts will be secured in password-protected computers in Ms. Woollen's office (Schroeder Hall 446) and at her home (2009 Foxwood Run, Normal IL).

This study will fill the gap in extant research on women presidents and how they strategically build and foster relationships that may lead to institutional outcomes. In addition, the participants, themselves, may benefit personally through the opportunity to reflect on what they have experienced with relationship building. 
Study of Women Academic Presidents

Response Form

(enclosed in letter to presidents)

Name of President:

Yes, I will participate. Here is the name and contact information of the person you should contact to schedule the interview:

I may participate, but I have questions. Please contact me at the following email address or telephone number:

No, thank you, I opt not to participate.

Please return this completed form to Susan Woollen in the enclosed postage-paid envelope. If it is easier, you may send your response to Ms. Woollen at 
APPENDIX B

CONSENT LETTER 
Letter of Consent

As part of my dissertation, I am conducting an exploratory research study to explore how women university presidents identify, build, and foster relationships in their leadership practices, and I would like for you to participate in the project. The time commitment is a minimum of two hours. If you agree to participate, you will be asked to participate in a one-on-one interview that will be conducted by me. During the interview, I will pose questions about the career path that led you to the presidency and about the relationships you have built with stakeholders inside and outside of the university to achieve your goals as president.

Your participation in this study should of course be voluntary. If you choose not to participate or to withdraw from the study at any time, there will be no penalty of any kind. You may also decline to answer any question. Interviews with be taped so that I will have an accurate record of your comments. After the interview, you will receive a copy of the transcript from your interview. You will be given the opportunity to amend, edit, or clarify what you shared. You will be provided an executive summary of the final study. If requested, a full copy of the dissertation will be sent to you.

Your participation poses risks involving the confidentiality of what you say during the interviews. These risks will be minimized in the following ways. First, the results of the research study will be published, but your name, institutional affiliation, geographic location, or other identifying information will not be used. Pseudonyms will be employed to mask the names of institutions and interviewees. Second, although I will prepare transcripts of the interviews for analysis, identifying information will not be included in these transcripts. Third, steps will be taken to secure interview tapes and transcripts. Paper transcripts and notes will be kept under lock and key either in my office in Schroeder Hall 446 at Illinois State University. Electronic files of recordings, transcripts, and notes will be kept on password protected computers located either in my office or at my home (—). After transcription, the only individuals who will have access to the transcripts will be Dr. James Palmer, my dissertation advisor at Illinois State University, and me. I will be the only person with access to the recordings to electronic copies of transcripts. Three years after the completion of the study, the original data will be destroyed. Paper documents will be shredded and electronic transcripts will be erased.

The possible benefit of your participation is to assist administrators in higher education and researchers gain an understanding of how relationships are developed and sustained in order to effectively address and achieve institutional needs and goals.

I consent to participate in the above study.

Signature of participant Date 
Should you have any questions concerning the research study, please contact me at

, or Dr. James Palmer at 309/438-2041 or jcpalmer@ilstu.edu. In addition, if you have any questions about your rights as a participant in this research, or if you feel you have been placed at risk, you can contact the Research Ethics \& Compliance Office at Illinois State University at 309/438-2529.

Thank you for considering this request to participate in the study. If you agree to participate, please sign, date, and return the attached consent form by mail (see address below), fax (

), or email

Susan Woollen

Department of Criminal Justice Sciences

Illinois State University

Campus Box 5250

Normal IL 61790-5250 
APPENDIX C

INTERVIEW PROTOCOL 


\section{INTERVIEW PROTOCOL}

\section{Introduction}

1. Introduce myself. Thank participant for agreeing to be a part of the study.

2. As you know, I am conducting a study concerning how women academic presidents strategically identify, build, and foster relationships with institutional stakeholders whom they recognize as possessing resources that may work towards institutional outcomes. Today's interview may last approximately 2 hours.

3. If the president did not return the consent form prior to the interview, I will present the interview and audiotape consent form. Would you mind signing the consent to participate? I would also like to tape record our conversation in order to help me listen more carefully about what you are saying, rather than trying to write down all your responses. Do I also have your permission to tape record our interview?

4. If the president did return the consent form prior to the interview, I will read the letter to the president and secure informed consent. After reading the letter, I will ask if "May we proceed with the interview?"

5. The format of today's interview will focus on your general thoughts and opinions concerning how you identify, build, and foster relationships with stakeholders whom you recognize as possessing resources that may work towards institutional goals.

6. Finally, I assure you that everything you share with me will be held in the strictest confidence. The results will be summarized and presented using a pseudonym, so that you, your institution, and any named individual(s) cannot be identified. Do you have any questions? Let's begin.

\section{Interview Questions}

1. Tell me about the journey that led you to the presidency of University/College?

2. Thinking back on your experiences as president of University/College, what relationships have you had to build with people within the university to achieve your goals as president? Outside the university?

3. What are the two or three most important relationships you have had to make as president?

4. For each relationship mentioned, the following will be asked:

a. Tell me about that relationship. How did it emerge?

b. What challenges, if any, did you face in forming that relationship?

c. What contributed to the success of the relationship?

d. What have you (or the university/college generally) gained from the relationship?

e. How do you maintain that relationship?

5. Given your experiences, what have you learned about being president?

6. Is there anything else you would like to say about relationship building that was not covered in these questions? 